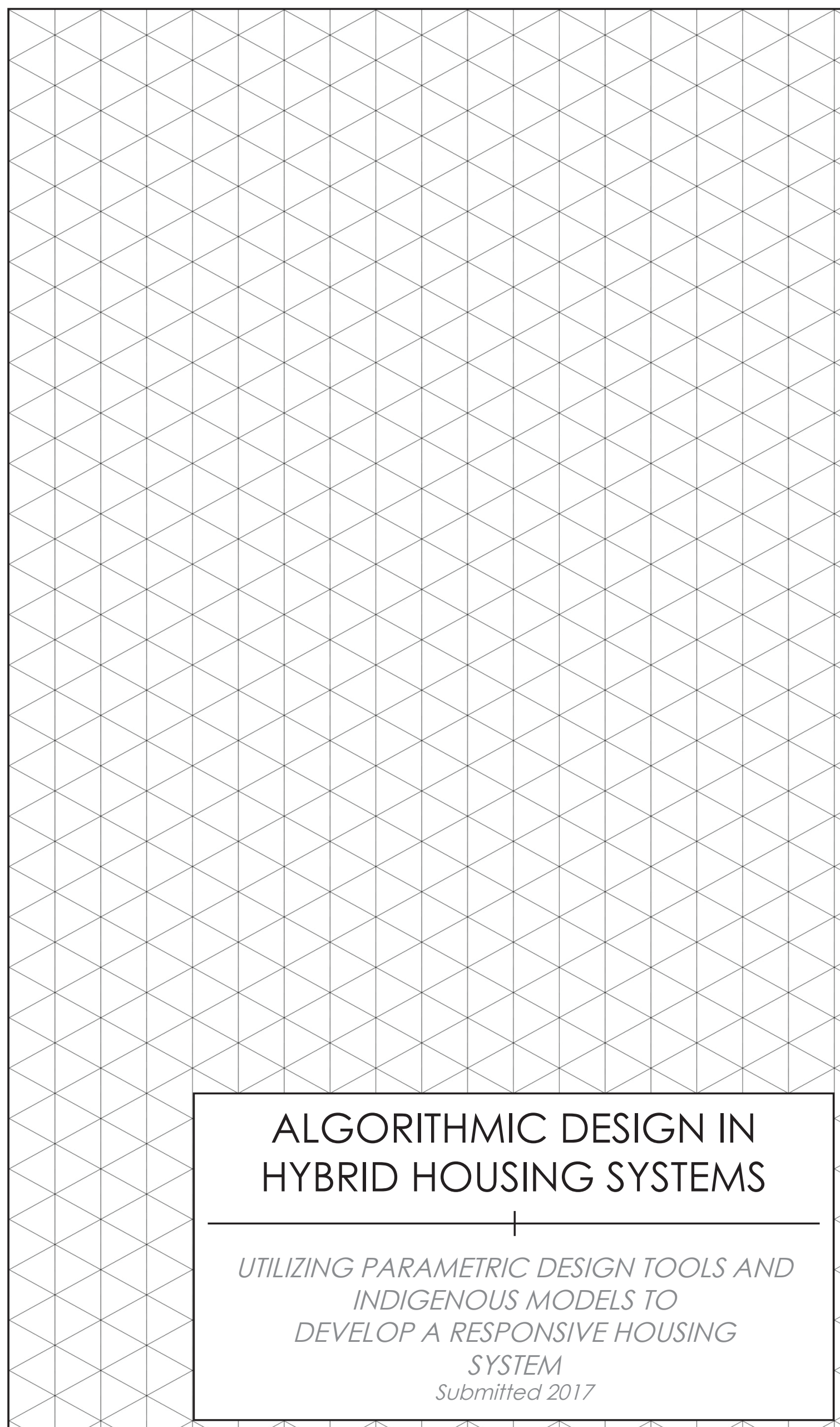




\section{Algorithmic Design in Hybrid Housing Systems}

UTILIZING PARAMETRIC DESIGN TOOLS AND INDIGENOUS MODELS TO DEVELOP A RESPONSIVE HOUSING SYSTEM

\section{by Robert Paulin}

\section{Submitted 2017}

A 120 point thesis submitted to the School of Architecture, Victoria University of Wellington, in partial fulfilment of the requirements for the degree of Masters of Architecture (Prof.)

Victoria University of Wellington 


\section{Abstract}

Algorithmic Design in Hybrid Housing

This thesis utilises digital tools to explore notions of flexibility and resilience in the New Zealand suburban house typology. Through aligning with culturally specific paradigms found in traditional Māori Papakāinga settlements, the research questions current western models of community and connectedness through digital simulations. The methodology brings together social, cultural and climactic forces as key influences to internal domestic programme and overall form.

The design process is informed by occupancy requirements associated with family types and projected domestic behaviour. This is mapped to cumulative weather data in relation to location and context. Buildable form is therefore a reflection of site specific conditions and planning in relation to various social configurations influenced by culture and community. A key aspect of this research is the creation of a residential model for multi-generational living. Long term adaptability of this residential model is established through planning for future organic expansion \& contraction within the development through the careful consideration of modular building platforms that can deal with varying degrees of social diversity.

This design research is largely influenced by pre-Socratic theorists and architects working on translating social, geographical and cultural information into data that can inform computational design and simulations. This form of design interpretation through mathematics has arguably stemmed from the birth of calculus in the 17 th century, whereby a formula is used to clarify equations with a multitude of variables often represented by Letters and symbols. Utilizing this knowledge in computer aided design (CAD) allows a designer to produce an equation that represents the process from data to design. Aligning design to the mathematical systems allows the work to represent a quantified, systematic depiction of information as opposed to the romanticized view of the 'Genius Architect'. The workflow and theory behind this research solidifies the role of algorithmic design in architecture and testing the plausibility of these theories in a housing system. While being largely based on the theories of multi-agent systems and algorithmic design, this system also outlines a modular building technology that embellishes design diversity and flexibility.
The architecture proposed utilizes parametric design tools and the concept of housing types in a state of flux, whereby the singular entity of the home is considered as part of a much wider collection of housing situations which is forever changing. By adopting the ecological approach seen in nature we allow the space for intergenerational, bicultural living arrangements that have the flexibility to respond to changes without diminishing the flow of social domains. 


\section{Acknowledgement}

This thesis would not have been possible without the support and encouragement from the Victoria University academic staff, friends, family and colleagues.

I'd like to thank my supervisor, Derek Kawiti for his ongoing advice and passion throughout my endeavours. Without your broad knowledge in Māori architecture and the field of parametricism I

$$
\text { would have been lost. }
$$

Secondly I'd like to thank Lilli for supporting me throughout the Master's program and dealing with varying mood swings through assignments. Also thanks to Noah, Dylan, Tama and Shayna for invaluable advice throughout this research.

Finally I'd like to thank my parents Meg and Kevin, you have made sure I've had every opportunity possible in life and none of this wouldn't have been possible without the inspiration you have given me. 


\section{Contents}

Abstract

Acknowledgements ..VIII...

Contents .VIII...

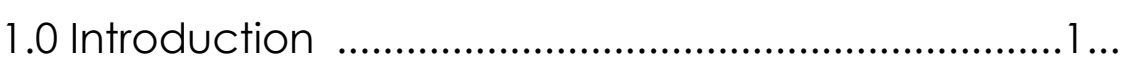

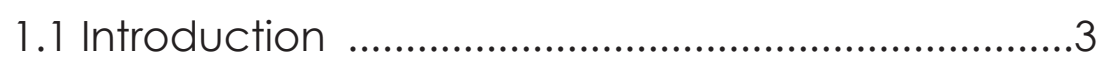

1.2 Methodology .........................................................

2.0 Background $9 \ldots$

2.1 New Zealand housing .............................................11

2.2 Papakainga \& Social Agencies ............................15

2.3 Metabolism \& Resilience .......................................19

2.4 Digital Workflow

2.5 Container Architecture …........................................26

3.0 Social Systems $31 \ldots$

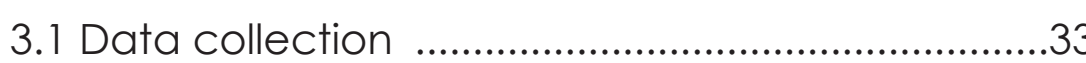

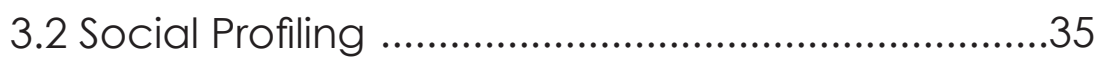

3.3 Geography Mapping .............................................41

3.3 Systems of Organization .........................................45

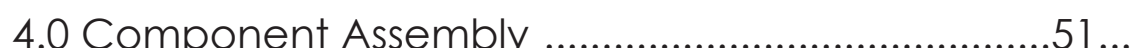

4.1 Construction Rationale ..........................................53

4.2 Grid Framing System .............................................54

4.3 Module Setup …………........................................ 59

4.4 surface treatment ...................................................66

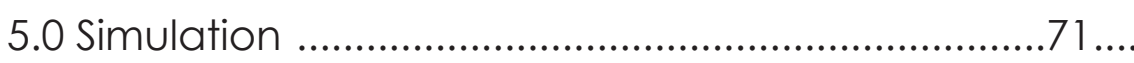

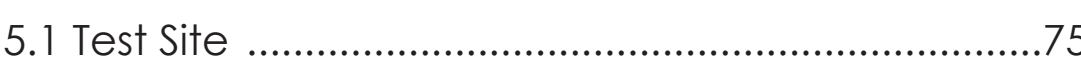

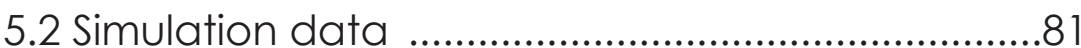

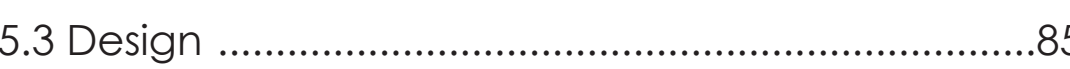

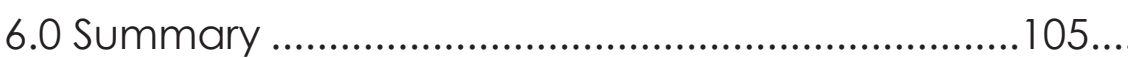

6.1 Critical Reflection ...............................................106

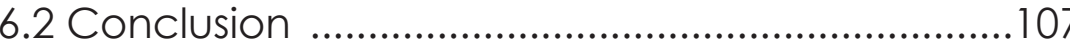

Works Cited ...............................................................108...

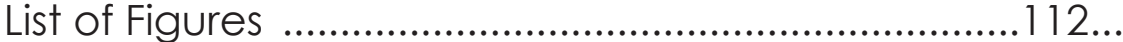




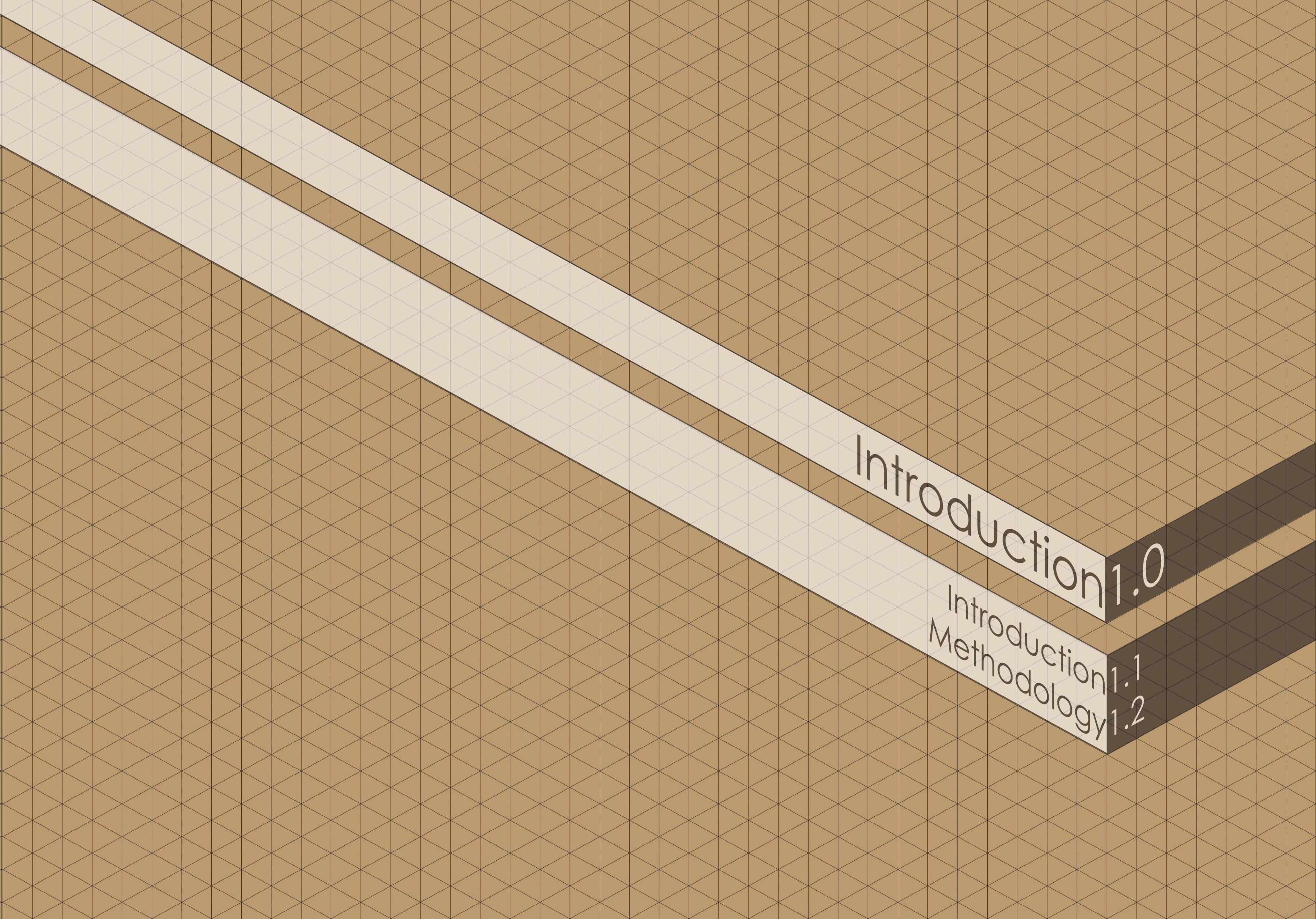




\section{Introduction}

Algorithmic Design in Adaptable Housing

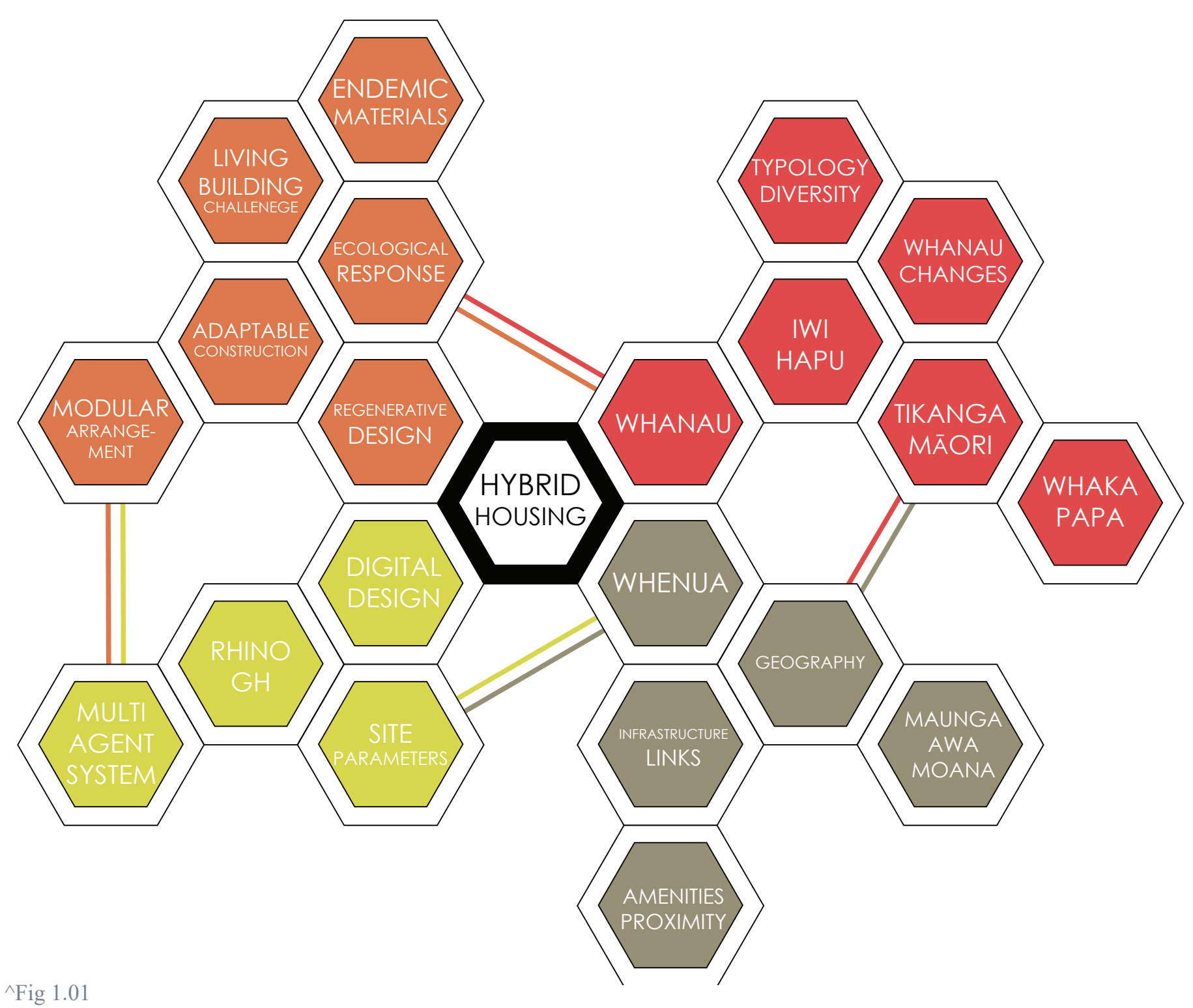

Input entitie
Present architectural discourse concerning 'affordable' housing seeks to address the issue of planning and implementation through a 'one size fits all' ideology. This approach has caused a lack in the diversity seen across housing developments in New Zealand. This research seeks to test the implications of parametric design tools in the development of adaptable housing systems. Digital design tools can allow for a more responsive system through simulated site conditions and social arrangement information.

The question being presented is; how can the use of parametric design tools be used to create a more responsive affordable housing system? Whereby this system adopts notions of communal shared living and family support structures present in traditional Māori settlements. The building system endeavours to find alternative building techniques to that are currently overlooked for the use of affordable housing. Furthermore this thesis uses 'upcycled' shipping containers as the bases for modulation while introducing a framing system that encourages the reintegration of native green spaces.

Section 2.0 explores the current discourse of New Zealand social housing, the Metabolist movement in Japan, digital simulation systems and papakāinga housing as a basis for the methodology throughout the thesis. These concepts are overlapped with the opportunity to implement shipping container housing as a way of compressing privatized space and introducing an alternative to current affordable housing construction.

Development of the system is described through Section 3.0, beginning with the adaptation to site and implementation of social, climactic and cultural data. Testing of social arrangements and defining nodal points is discussed as a way of building a logic throughout the system. 
Continuing from the previous section, Section 4.0 explores the actuation of the modules, framing system and surface treatment about the system through renders and diagrams. Finally the system is tested on a theoretical site in Wellington, New Zealand to investigate the implementation of such a system on a challenging site. The system is set to work within the bounds of single dwelling to medium density housing, but the setup could easily stem to large scale arrangement simulations and a multitude of challenging sites.

How can the use of parametric design tools be used to create a more responsive affordable housing system?

Digital design applications are carried out using the grasshopper visual programming language (a plugin to McNeel's Rhinoceros), whereby the architectural outcomes stem from the functions set throughout the systems development phase. Following the testing and development phase is the implication of social demographic data and geographical landscaping information. 


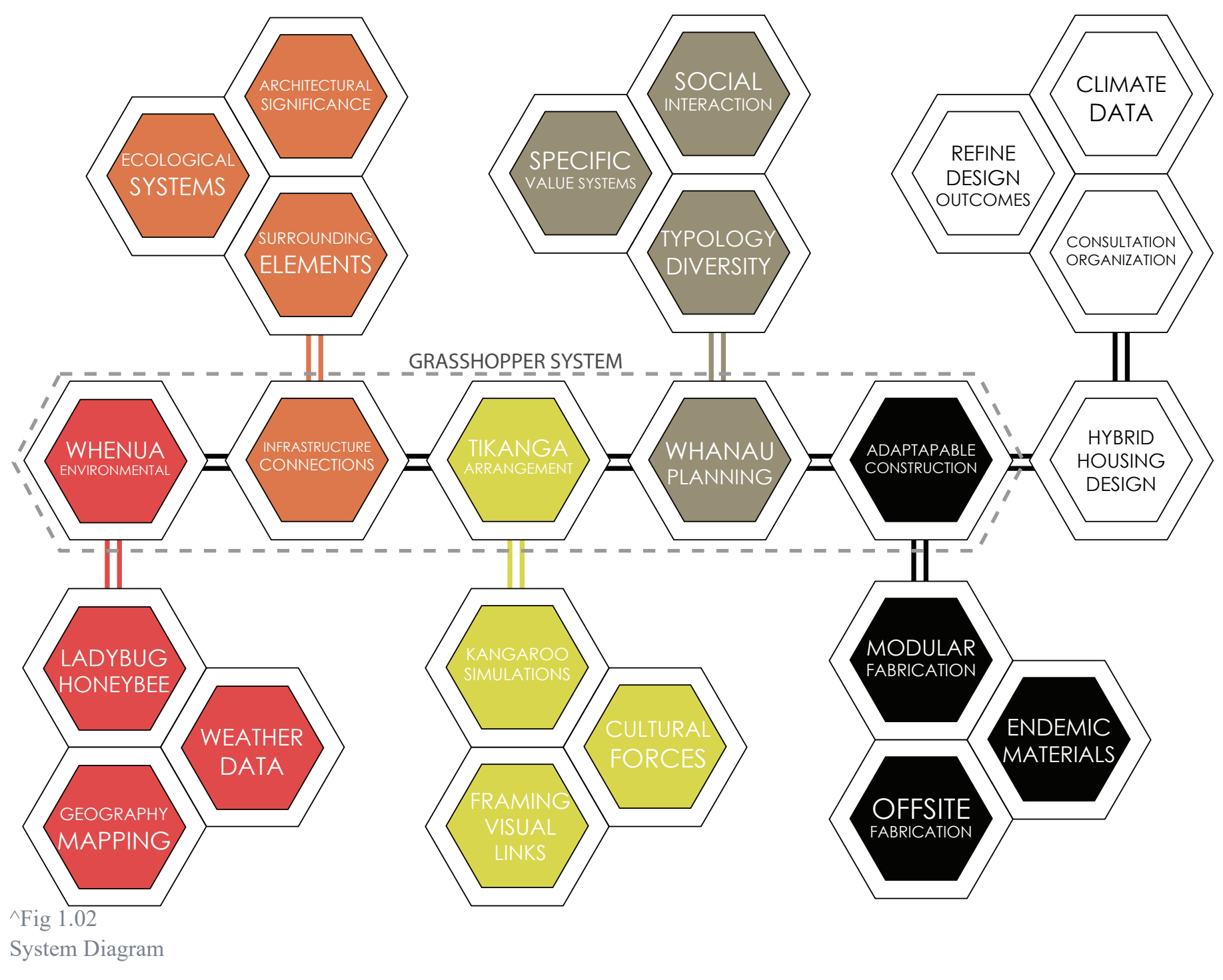

\section{Methodology}

Algorithmic Design in Adaptable Housing

Design-led research is an experimental journey in testing alternative design tools in a hybrid housing system. Focus throughout the research varies between development of a parametric design system and grounding in affordable housing models. The process relies on a feedback loop of testing and development through the visual scripting tool 'Grasshopper' and 'Rhinoceros 3d'.

To differentiate from current affordable housing trends this system adopts a communal housing model present in traditional Māori communities. Overlaying this concept is a form of 'hybrid metabolism' that is derived from the post-world war two movement in Japan that sought to implement a harmony between technology and the environment. The testing model for this system utilizes modular housing formed from recycled shipping containers as a way of integrating 'up-cycling' and modular design into the system.

Overall the research follows a methodology of digital design integration and systems development exemplified by digital architects such as Greg Lynn and Patrik Schumacher. Through this process we are able to integrate physical, social and cultural data into the system and challenge the current design discourse around community arrangements and construction techniques. 


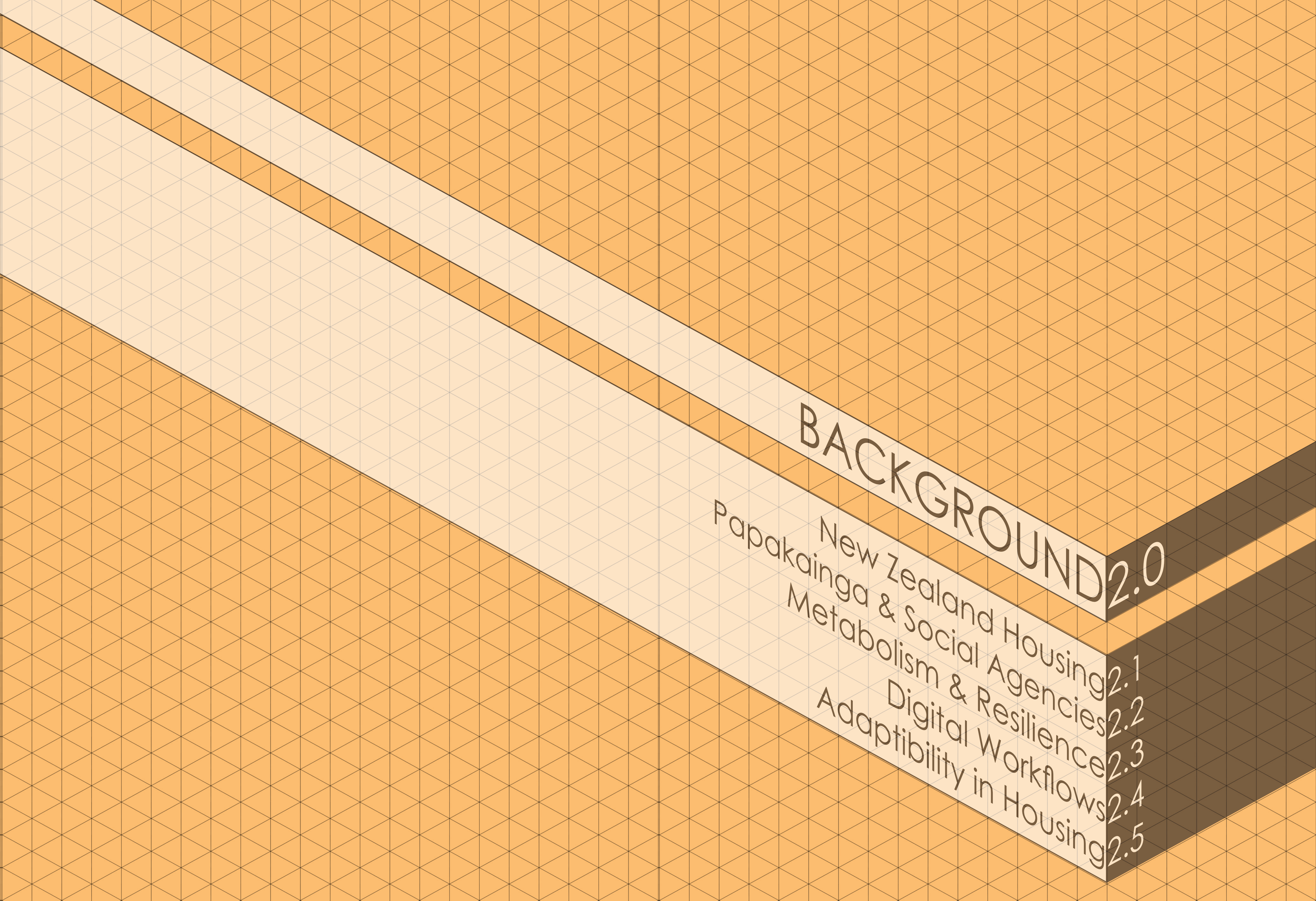


Trends, Issues, Possibilities

The current state of housing in New Zealand shows a misalignment with the social, climactic and physical needs of the inhabitants. There has been an issue with affordability and access to quality housing since the first inception of the 'state home' in 1905, whereby the New Zealand government attempted to amend extortionate rents and expanding slums throughout the country. But it wasn't until 1935, when the labour government initiated the first surge in the construction of affordable state housing (NZ History, 2014, p. 3). There was a period of resurgence in the 1950's, whereby the government introduced incentives for state home renters could work towards buying their homes. With 5\% deposits and 3\% mortgage rates it was eagerly encouraged. Throughout the period from 1937 to 1980 , the design of NZ state homes stayed relatively similar throughout. With very few being built after this time. The design of pre-world war 2 state houses represented an attempt to produce high quality housing that provided tenants with ample space and safe, affordable housing. What resulted was a housing style that neither reflected the local climate or the cultural and social values of tenants (NZ History, 2014, p. 5).

Climactically, New Zealand is a country with varying geographical conditions and the housing throughout should reflect this range of differences. Instead through the National Building code (NZS3606), we see a standardised 'countrywide' approach to site even though conditions in Kaitaia contrast to sites and climates in Bluff (aside from wind/snow loading) use of materials and an inflexible design system across the social housing spectrum to site and an inflexible design system across the social housing spectrum (Johnson, 2007, p. 11).

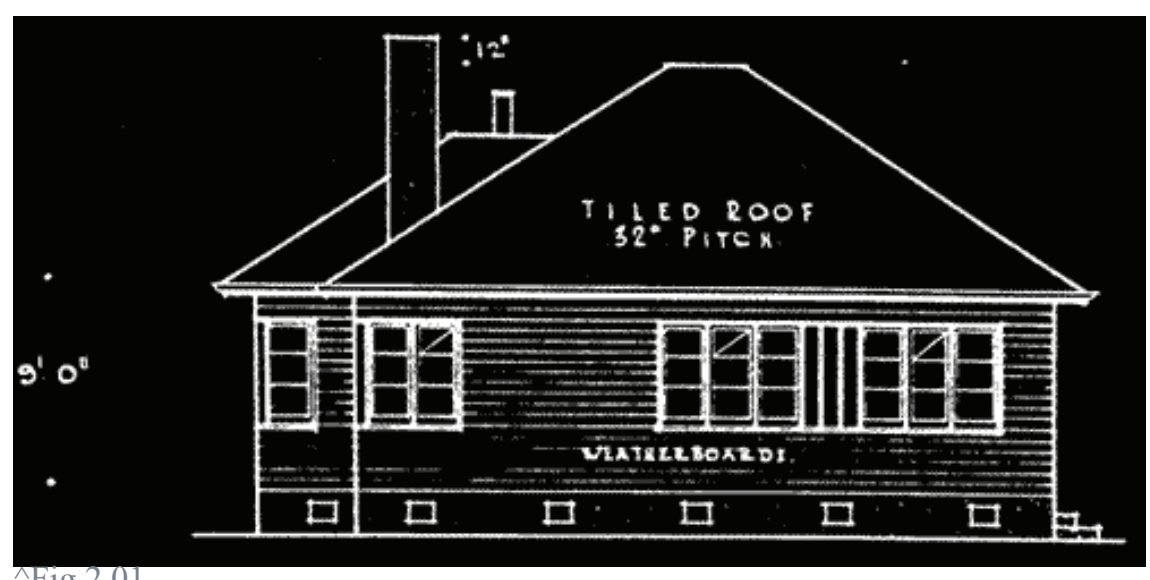

Early state housing design (NZ History, 2014. p. 7) 


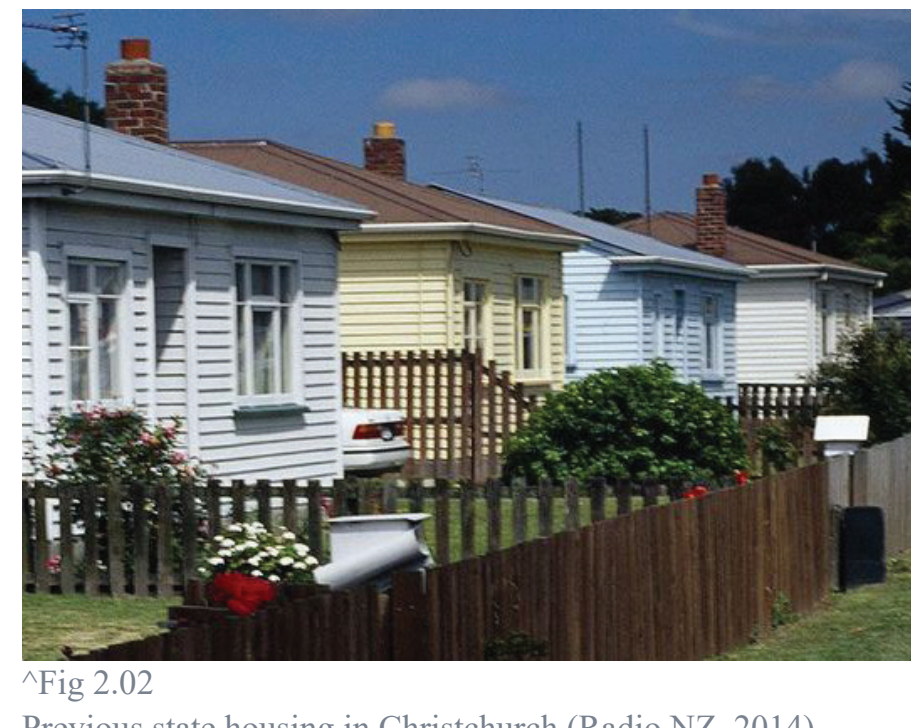

Previous state housing in Christchurch (Radio NZ, 2014)

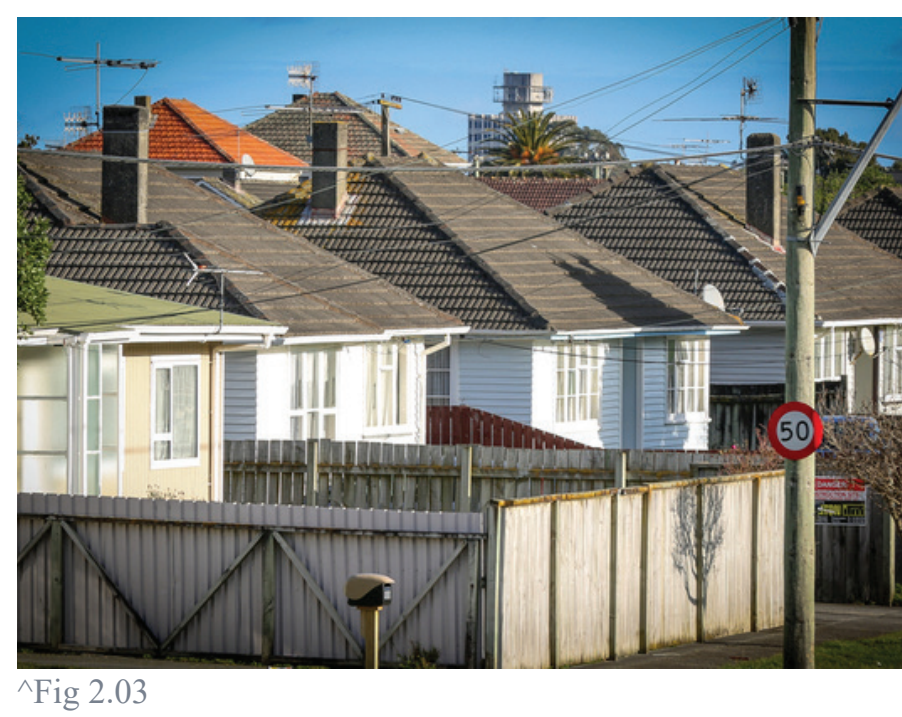

Previous state housing in Whangarei (Radio NZ, 2016)

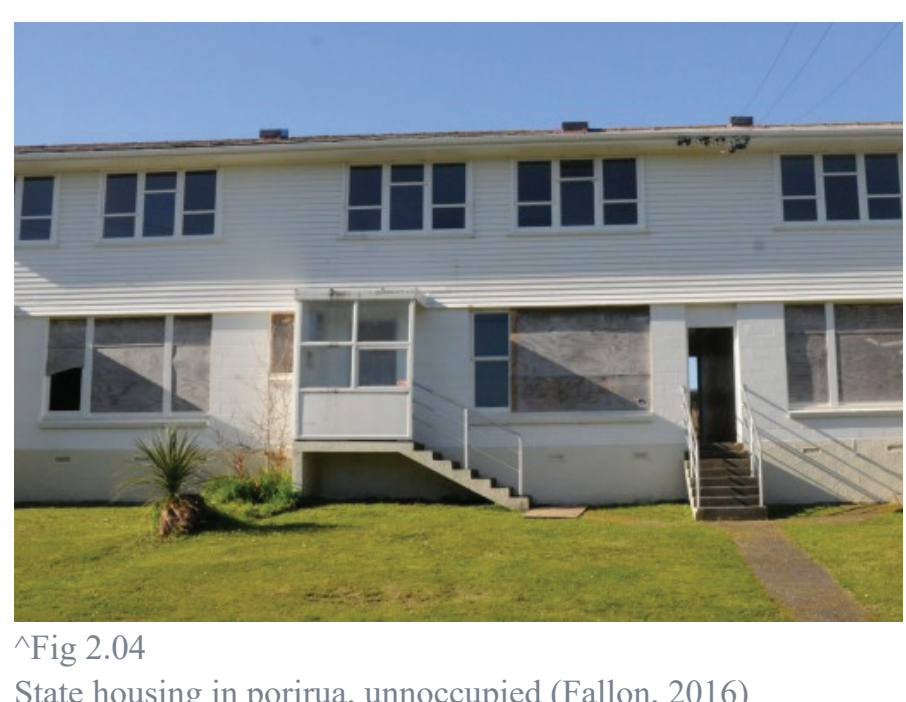

State housing in porirua, unnoccupied (Fallon, 2016)
During the period between the 1950's and 60's the NZ government attempted to reduce the price of state housing by building double storey units with cheaper materials, contributing to poor housing longevity. Some Social housing built in this period still stand today, refer to 6 . These developments have become desolate and abandoned due to the quality of housing, lack of landscaping, and overall misalignment to community interaction (Martin, 2016)

Through all the flaws seen in state housing, perhaps the greatest pitfall is its master planning on large areas of government subdivided land. Master planning shortfalls included no design or coordination of landscaping with interconnectedness, contributing to low levels of safety for the families. And state tenants. The implications of mediocre design and planning of social housing can be argued to have had affected Maori and pacific island peoples the most. Larger average family sizes and lower average income meant they were burdened by the access to adequate housing (Ministry of health, 2015). Furthermore, the new state housing reform seeks to introduce housing developments that deal with a diverse mix of families that are migrating from a communal, rural setting into urban centres and this needs to be addressed (Housing New Zealand, 2015, p. 11). With quality master planning and a more flexible housing system we would see a more resilient form of housing that responds to social, cultural and geographical conditions.

Over recent years the social housing discourse has shifted to increasing 'affordable' housing to match rapid urban development in major cities, with an obsolescent, tired, exhausted social housing no longer relevant and in disarray. The major focus of this reform was to target and provide low cost housing in areas closer to large urban centres as opposed to the suburban social housing of the 40 's- 80 . These new developments focus on maximizing affordability and usage of space while still arguably neglecting issues of cultural and social misalignment in their design aspects.
This thesis proposes an alternative to affordable housing that implements a systematic approach to housing that responds to local cultural models of community and sociality while taking into account specific geographical conditions. 
4

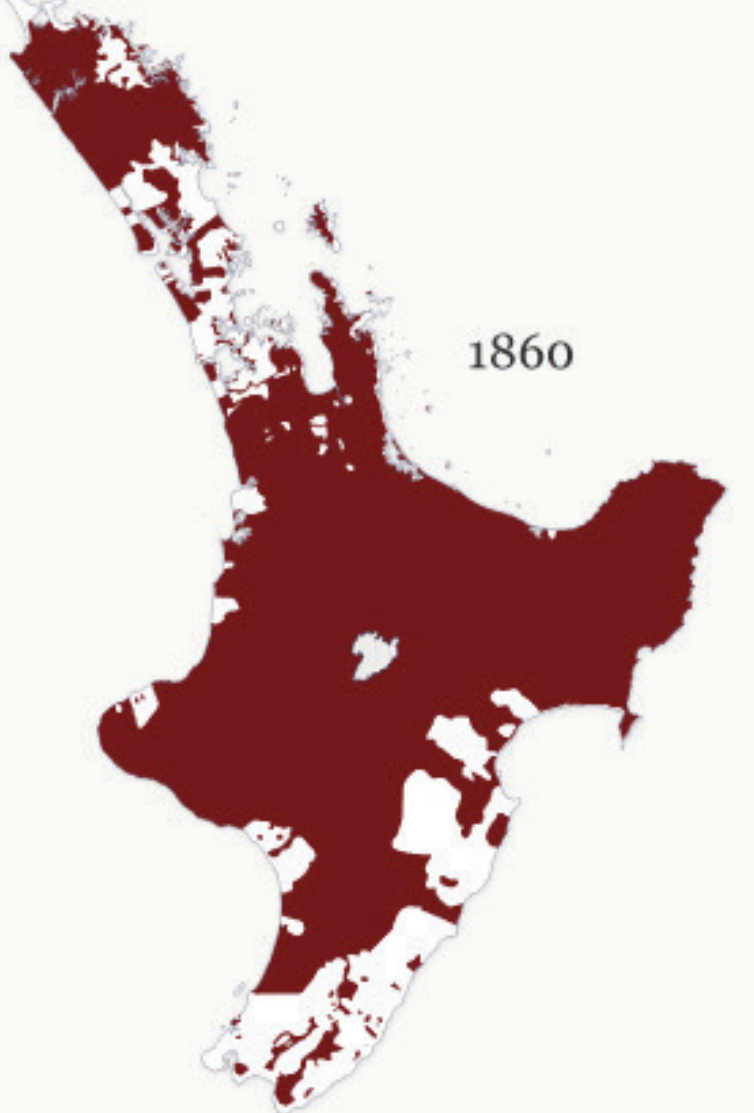

6

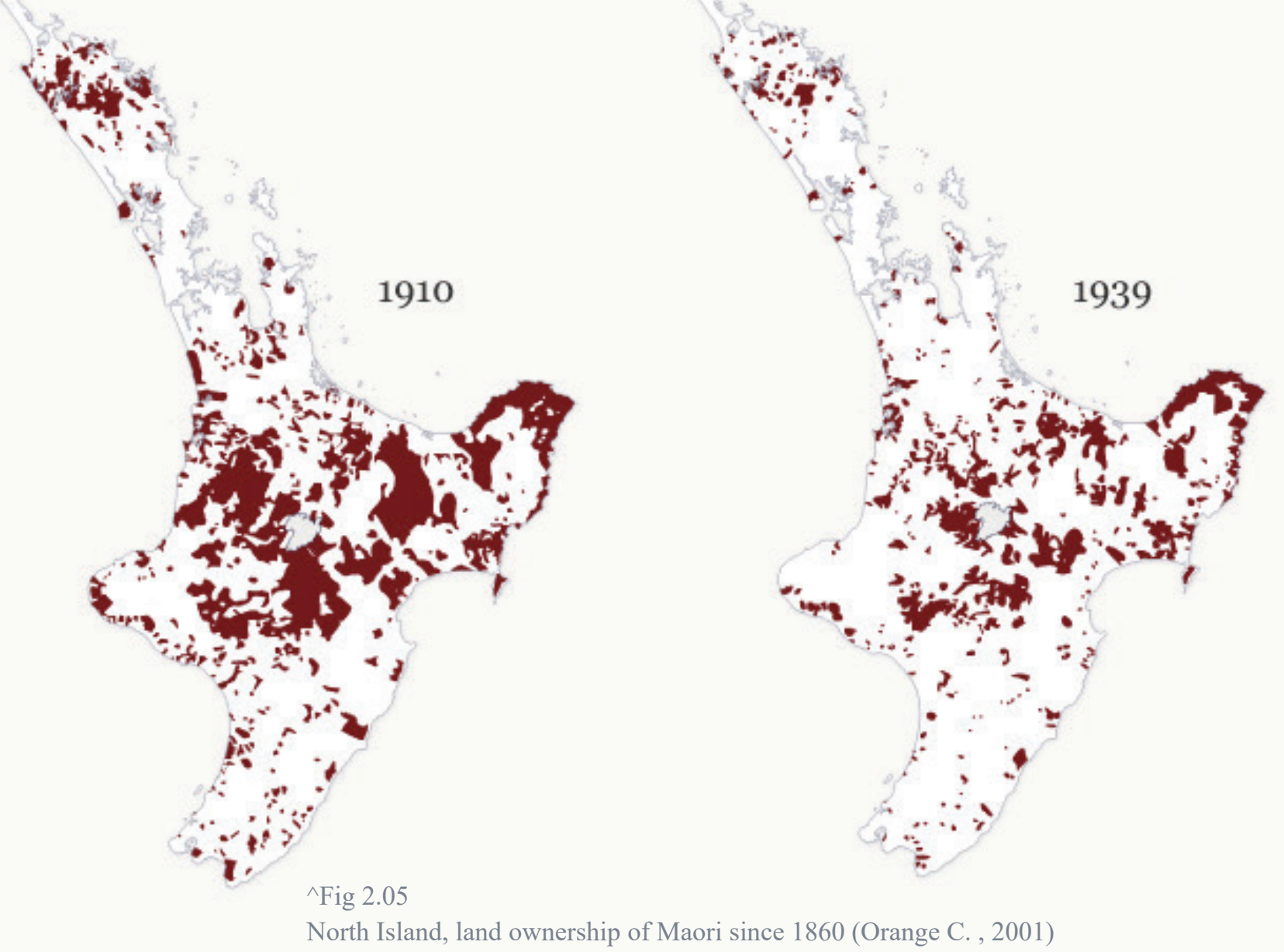

Papakainga \& Social Agencies

Maori settlements \& Organizational systems

Prior to British colonization, New Zealand was primarily occupied by Māori tribal groupings found within largely coastal settlements ranging the length of the country (Wilson, 2005). With the arrival of European settlers and industry in the late 18th century much of the land under tribal ownership was acquired through either private sale or through agents acting on behalf of the crown (New Zealand Company), resulting in what is known as illegal and unlawful acquisitions and the subsequent western development of this land (Orange C. , 1987, p. 18)

Still relevant today the treaty defines legal rights and obligations of both the crown and tāngata whenua and is our founding document concerning Māori and pākehā relations. As British influence on the country spread, so did new technologies, constructional and building methods, commerce and European typologies including the most prevalent domestic typology of the colonial villa style (Ryan, 2010, p. 2).

By 1911 the Māori land base had declined to only $11 \%$ of total New Zealand landmass and the late 90 's saw only $5.5 \%$ of the landmass in New Zealand being owned by Māori (Kingi, 1997). Further iindustrialization during the post-war era leading into the 1950s saw a migration to cities, for work and livelihoods resulting in $86 \%$ of all Māori living in urban areas before the turn of the century (Te Puni Kōkiri, 2001). The loss of connectivity to traditional papakāinga on traditional landholdings, te reo Māori through the schooling system and overall cultural identity had irreversible effects on Māori communities. The assimilation to western culture has meant a large portion of Māori feeling disconnected from their ancestral lands while living at odds within the new urban context (Meredith, 2000, p. 7). Furthermore the socio-economic climate for Māori shows a large disparity between Māori and Pākehā. Ministry of Health statistics illustrate this inequality, with Māori over represented in unemployment (2.6 times that of Pākehā), imprisonment and 18.8\% of all Māori are experiencing overcrowding in their homes (Ministry of health, 2015). 
Even with the incorporation of western lifestyles and loss of tribal land, Māori still maintain a strong connection to the core values that underpin the Māori world view. Listed below are three of the most influential characteristics present in modern Māori culture.

The described Māori values are predominan attributes perpetuated by Iwi, with many fulfilling the fundamental aspects through the development of their land and traditional kinship (whakapapa) relationships (Fig 2.09). A key priority for Iwi over the past 20 years has been to provide housing opportunities for iwi members on tribal lands in light of both older and younger generations moving back to the land.

Traditional Maori settlement from 1880's (Lambert, 2015)

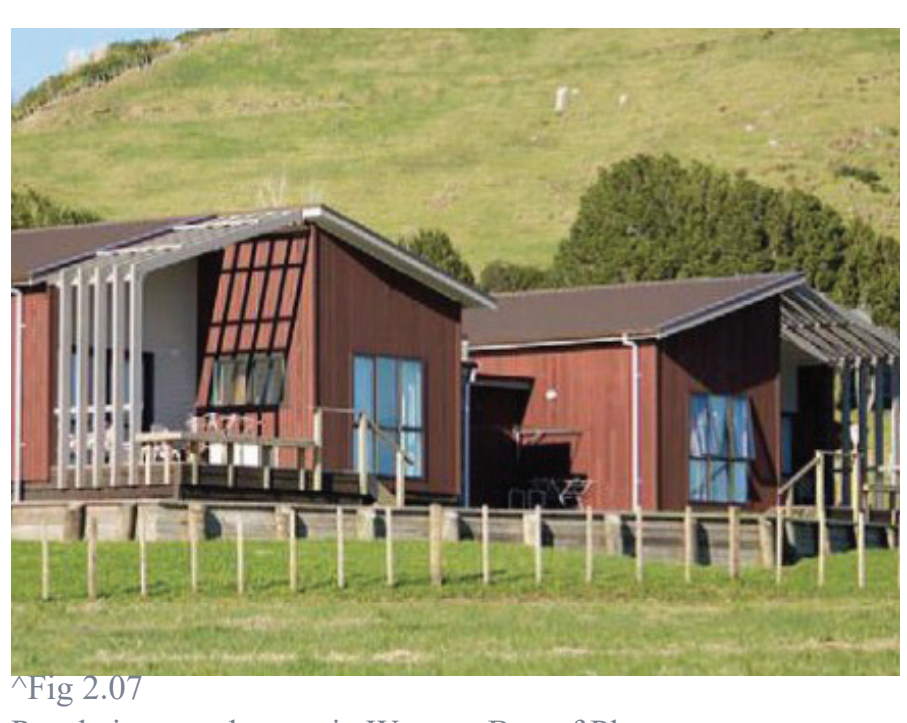

Papakainga settlement in Western Bay of Plenty (MahiTahi, 2015)

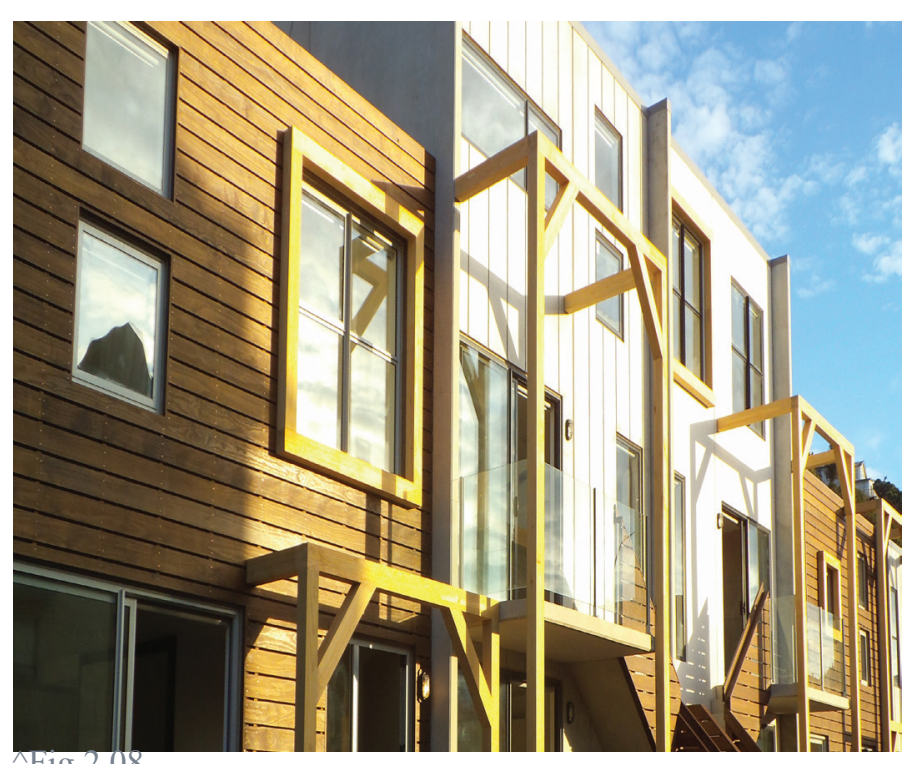

\begin{tabular}{|c|c|c|}
\hline \begin{tabular}{|l|l} 
Principle \\
\end{tabular} & Description & Purpose \\
\hline Kotahitanga & $\begin{array}{l}\text { Collective cooperative } \\
\text { and effective } \\
\text { partnerships and } \\
\text { collaboration with } \\
\text { community }\end{array}$ & \begin{tabular}{|l} 
To encourage community \\
unity \\
and identity
\end{tabular} \\
\hline Wairuatanga & \begin{tabular}{|l|}
$\begin{array}{l}\text { Emotional connection } \\
\text { with the environment } \\
\text { that links people }\end{array}$ \\
\end{tabular} & $\begin{array}{l}\text { To maintain and preserve } \\
\text { the } \\
\text { essence of Ngăti } \\
\text { Whătuatanga }\end{array}$ \\
\hline \begin{tabular}{|l|} 
Manaakitanga \\
\end{tabular} & \begin{tabular}{|l|} 
Acceptance and \\
hospitality given to \\
visitors, and protection \\
and security of \\
community
\end{tabular} & $\begin{array}{l}\text { To embrace and welcome } \\
\text { all } \\
\text { peoples especially visitors } \\
\text { and } \\
\text { to provide a safe and } \\
\text { secure } \\
\text { community environment }\end{array}$ \\
\hline Whanaungatanga & $\begin{array}{l}\text { Participation and } \\
\text { membership in the } \\
\text { community and social } \\
\text { setting }\end{array}$ & $\begin{array}{l}\text { To encourage community } \\
\text { participation and pride } \\
\text { through } \\
\text { building and emphasising } \\
\text { community identity and } \\
\text { Ngatai } \\
\text { Whätuatanga }\end{array}$ \\
\hline Kaitiakitanga & \begin{tabular}{|l|} 
Protection of \\
significant landscape \\
features important to \\
the local community
\end{tabular} & $\begin{array}{l}\text { To support the protection } \\
\text { of } \\
\text { important environmental } \\
\text { and } \\
\text { cultural features through } \\
\text { community ownership and } \\
\text { collective responsibility }\end{array}$ \\
\hline Rangatira & $\begin{array}{l}\text { Community can take a } \\
\text { lead and responsibility } \\
\text { for creating and } \\
\text { determining their own } \\
\text { future }\end{array}$ & \begin{tabular}{|l} 
To promote self- \\
determination \\
and independence, where \\
Ngâti Whătua governs, \\
controls and manages their \\
own destiny
\end{tabular} \\
\hline
\end{tabular}

Te Aro Pa in Evans Bay, Wellington.

(Dwell housing trust, 2016)
Fig 2.09

Papakāinga design principles (Rolleston, 2009)
Māori housing developments on joint ownership land is often referred to as Papakāinga. 'Papakāinga' refers to 'papa' or Papatuanuku as the ancestral earth mother and 'kainga' as the village communal living environment (Hoskins, 2012, p. 1). Papakāinga were essentially communal entities based upon common tribal descent and strong ties to its particular land based setting, food sources through hunting and harvesting for local subsistence (Brown, 1996).

As the introduction of the western home and the institutionalisation of the suburban setting. What this transition meant in a lot of situations was a replacement of one (traditional) lifestyle with another (western) model of lifestyle. This meant a reduction in Tikanga Māori in housing developments, whereby aspects such as safety, sociability, expandability and cultural diversity were replaced with suburban homogenised social housing developments (New Zealand Controller and Auditor-General, 2011).

Over the last 25 years we have seen Maori participate more and more in the New Zealand economy as a result of Post treaty of Waitangi Settlements (Haywards, 2014, p. 13). As Iwi gain more economic independence from the state we see a shift towards Māori demanding more control over design decisions and the qualitative aspects of housing that are potentially overlooked through western house design and priorities. With many providing culturally resilien housing aspirations with future generations in mind.

Since the settlement of claims resided over the pas two decades we have seen Iwi develop housing and infrastructure on Māori owned land. Due to the multiownership titles and the difficulty of securing loans on Māori land, the development of papakāinga has been difficult. Most developments have been low density and primarily in a rural setting, with little testing in urban areas even with most Māori living in an urban setting (Te Puni Kōkiri, 2001). Māori housing developments throughout New Zealand mostly reflect the style of social housing estates, whereby the encouragement of social dynamics are side-lined for cost efficient housing. Papakāinga housing presents an exciting opportunity to bring communal infrastructure and support systems to housing that isn't prevalent in New Zealand housing developments.
A major hurdle in developing papakāinga is gaining areement from all land owners, which can be upward of 100 members (WDC, 2015). One solutions to egating the issue with securing loans and agreement housing is to provide moveable housing that provides insurance on the house only (excluding the land, primarily owned by many people). Providing daptable housing on papakāinga developments would allow for a flexible system that reflects the changeable intergenerational families in modern Māori homes. This thesis aims to investigate the possibility of affordable, flexible housing that reflects cultural and social needs of an intergenerational family typology in a medium density setting. 


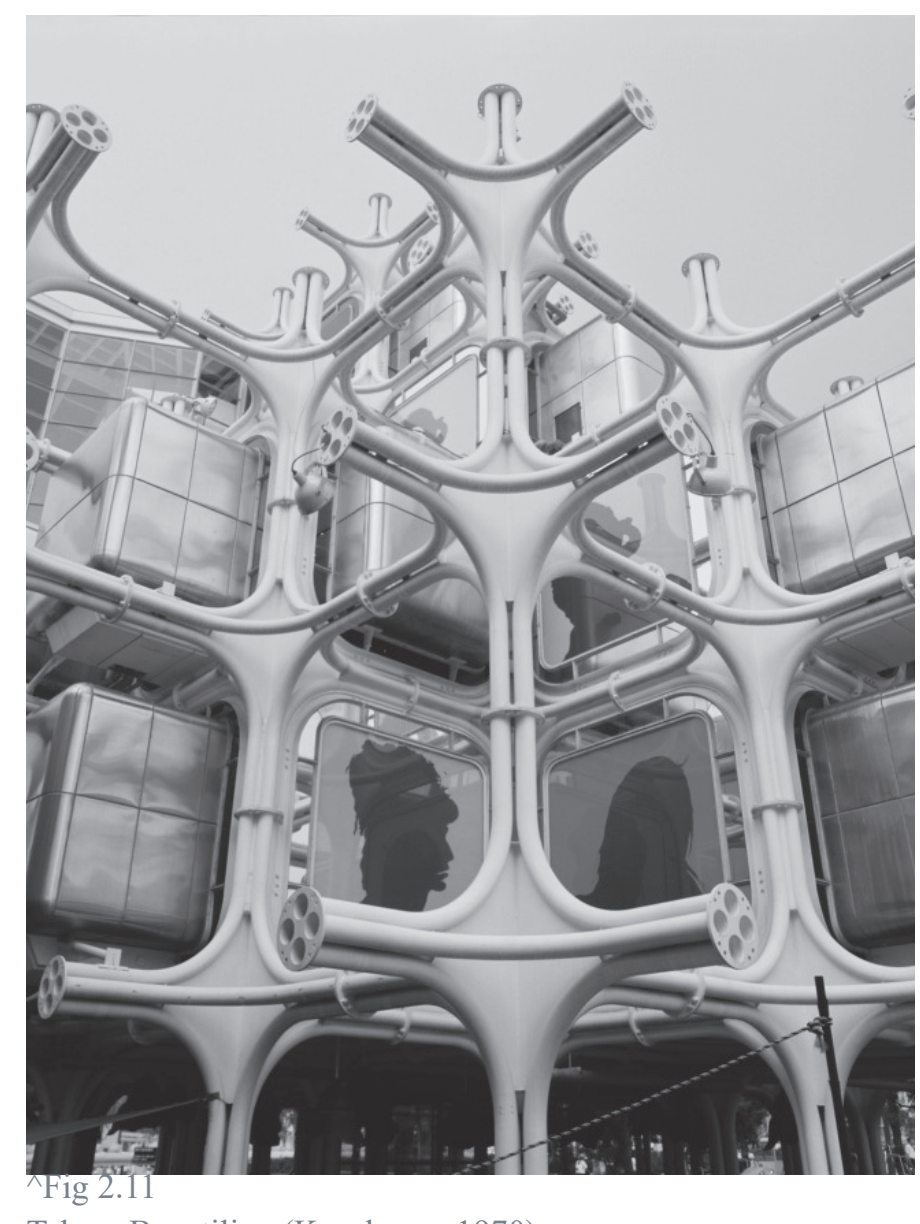

Takara Beautilion (Kurokawa, 1970)

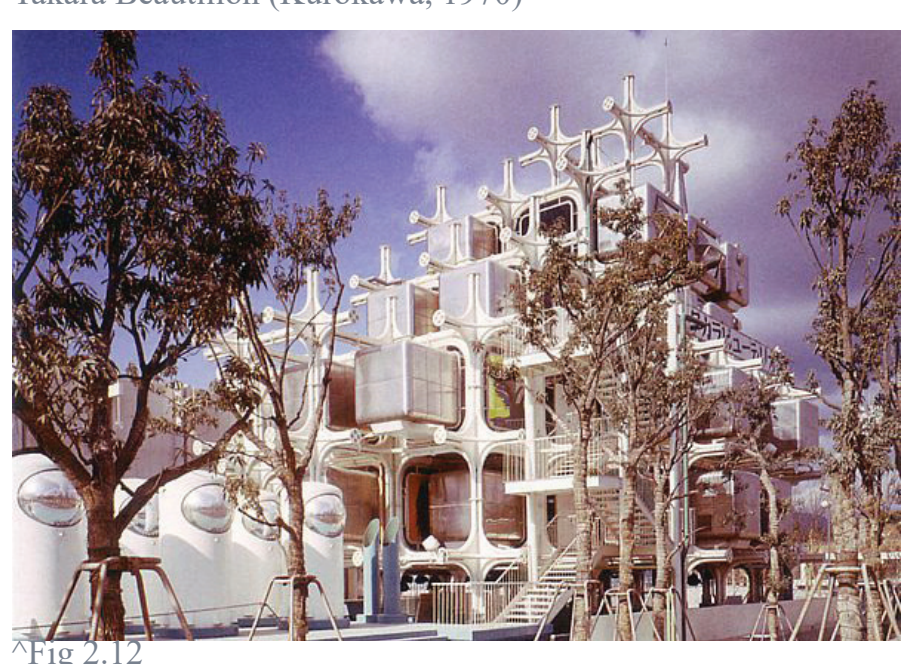

Takara Beautilion (Raubenweiss, 2005)

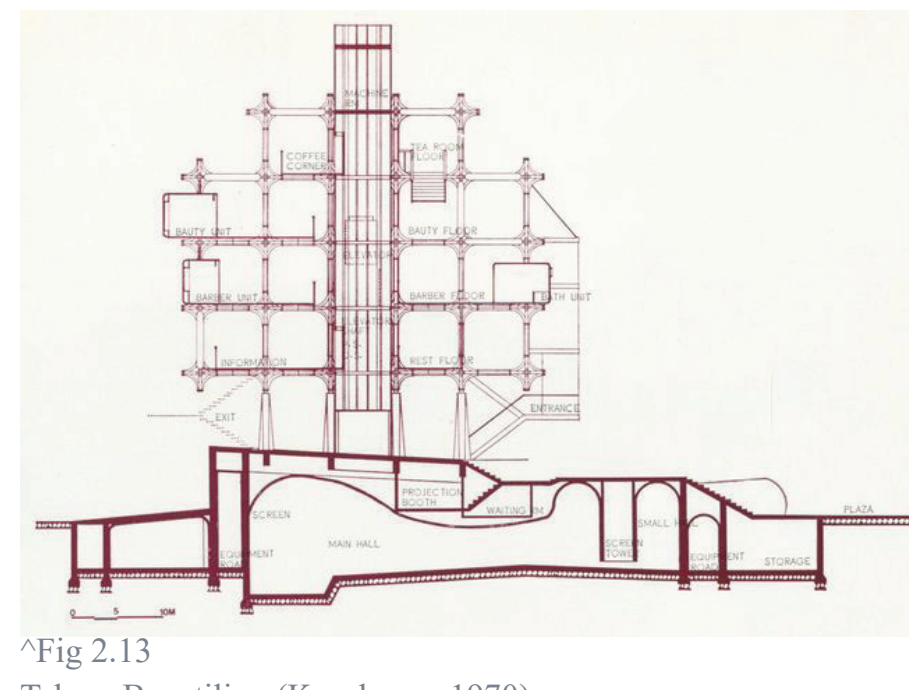

20 Takara Beautilion (Kurokawa, 1970)
The movement consisted of a small group of Japanese architects that conceived architecture within a "Circle of transmigration", whereby buildings continue to change over time and remain in a state of flux (Yamazaki, 2010). At the forefront of this movement was Kenzo Tange, who choreographed the 'Osaka Expo 70' alongside Kisho Kurokawa, Noboru Kawazoe and Arata Isozaki. The works produced for the expo stemmed from the Tokyo Olympic buildings that inspired Japanese architects and the fundamentals of metabolism. The architect that displayed metabolism in its most pure form was Kisho Kurokawa. While adhering to the predominant theories, Kurokawa took the concepts of adaptability and flexibility to new heights with his exhibition 'Expo 70 Takara Beautilion'.

Suita, Osaka, Japan

Construction: 1968 - 1970

Site Area: $1,000 \mathrm{~m}^{2}$

Building Area: $298 \mathrm{~m}^{2}$

Total Floor Area: 1,237.6m²

Structure: Steel Structure

Basement Stories +4 Stories

(Kurokawa, 2015)

The Takara Beautilion was an exhibition piece that characterized a tree structure that could extend in six directions. The building was four storeys tall and housing installation art pieces, the purpose of the project was to exemplify the metabolism theories of growth and expansion. The Takara Beautilion works on a structural grid that stretches out withstanding its own weight and the modular pods which slot into them. The pods were prefabricated and the framing and installation only took 6 days, exemplifying the promising future metabolism presented.

Kurokawa studied under Kenzo Tange for many years and was possibly the member of the Metabolists that exemplified the movement with the most rigor. His first large Metabolist project was the 'Nakagin Capsule Tower', that rises in the middle of Tokyo city.
The building is credited as being the first example of habitable capsule architecture and is a monument to Japanese architecture of the 60 's and 70's. This building resembled the promising future of 'living architecture' and buildings that were constantly changing. The tower had 140 capsules, each attached to the concrete cores by four high tension joints. The concept was to have a residential building that would expand and change over time depending on the social, political and environmental climate (Schalk, 2014)

Ginza, Tokyo , Japan

Design / Construction:1970-1972

Building Area: $429.51 \mathrm{~m}^{2}$

Total Floor Area: $3,091.23 \mathrm{~m}^{2}$

Steel and Reinforced Concrete

1 Basement Floor +11 and 13 Floors

(Kurokawa, 2015)

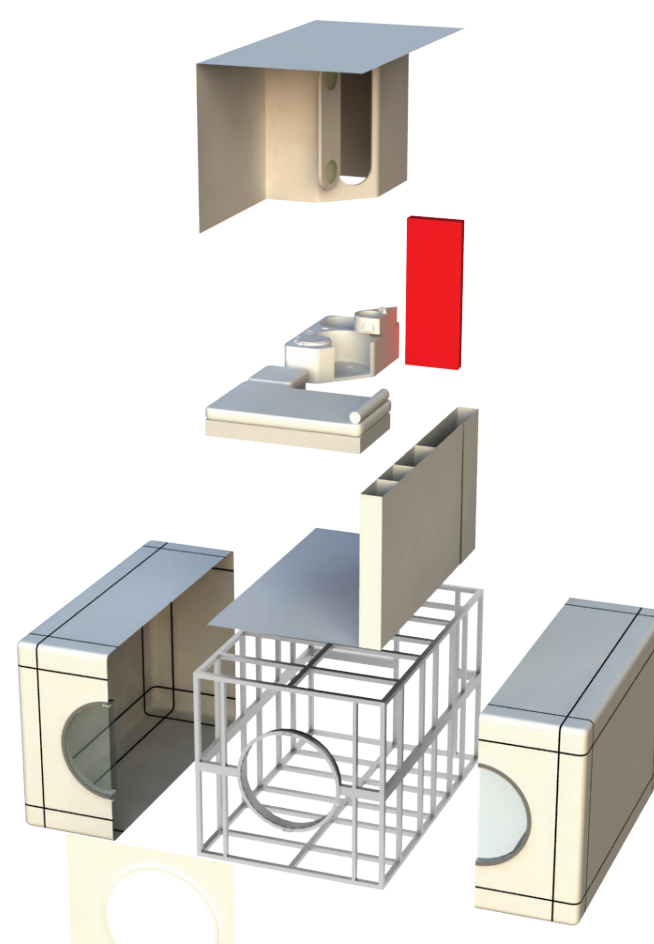

Fig 2.14

Capsule tower exploded diagram (SCI-ARC, 2010)

The Nakagin Capsule tower still stands in Tokyo, but its future is uncertain. The residents of the tower are planning the demolition as the Japanese architecture community searches for alternatives. The capsules are designed as a test in sustainability and temporality, but with no renovations in over 30 years the tower is set to be decommissioned (Yamazaki, 2010). What the Nakagin tower does demonstrate is the fundamental ideology behind the Metabolist movement.

Naive as it may seem, the Metabolists imagined an urban fabric that fit within a constantly developing city. Perhaps it is these essential ideas that can be transitioned to the current architectural discourse, whereby the lifecycle of a building is vital to the design. By utilizing the concepts present in these projects to drive architecture that transcends changing environmental conditions. Concepts of metabolism are implemented into the overall ideology present in this thesis in an attempt to challenge current social settings and disrupt the homogenised building style in affordable housing today.

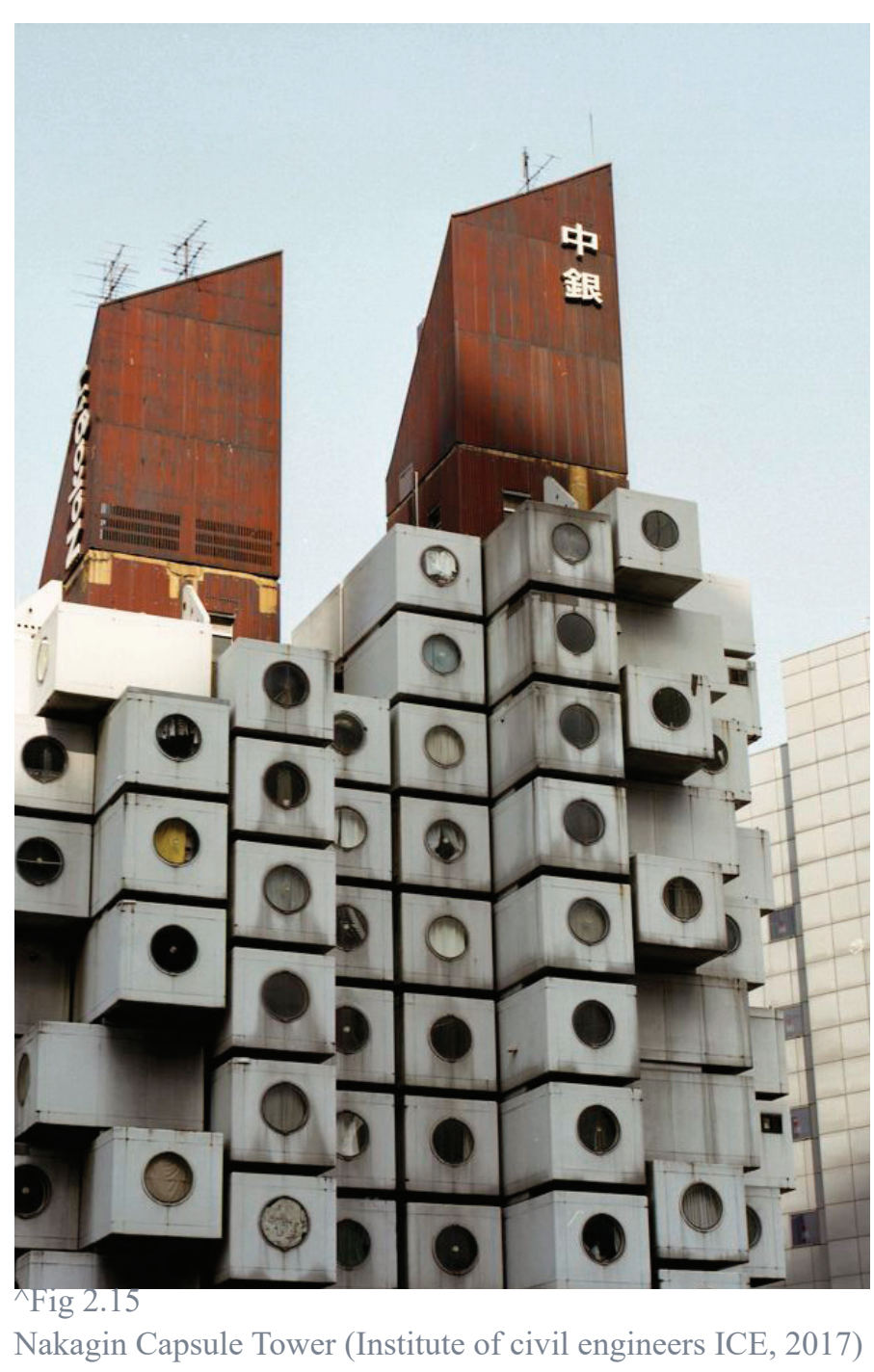




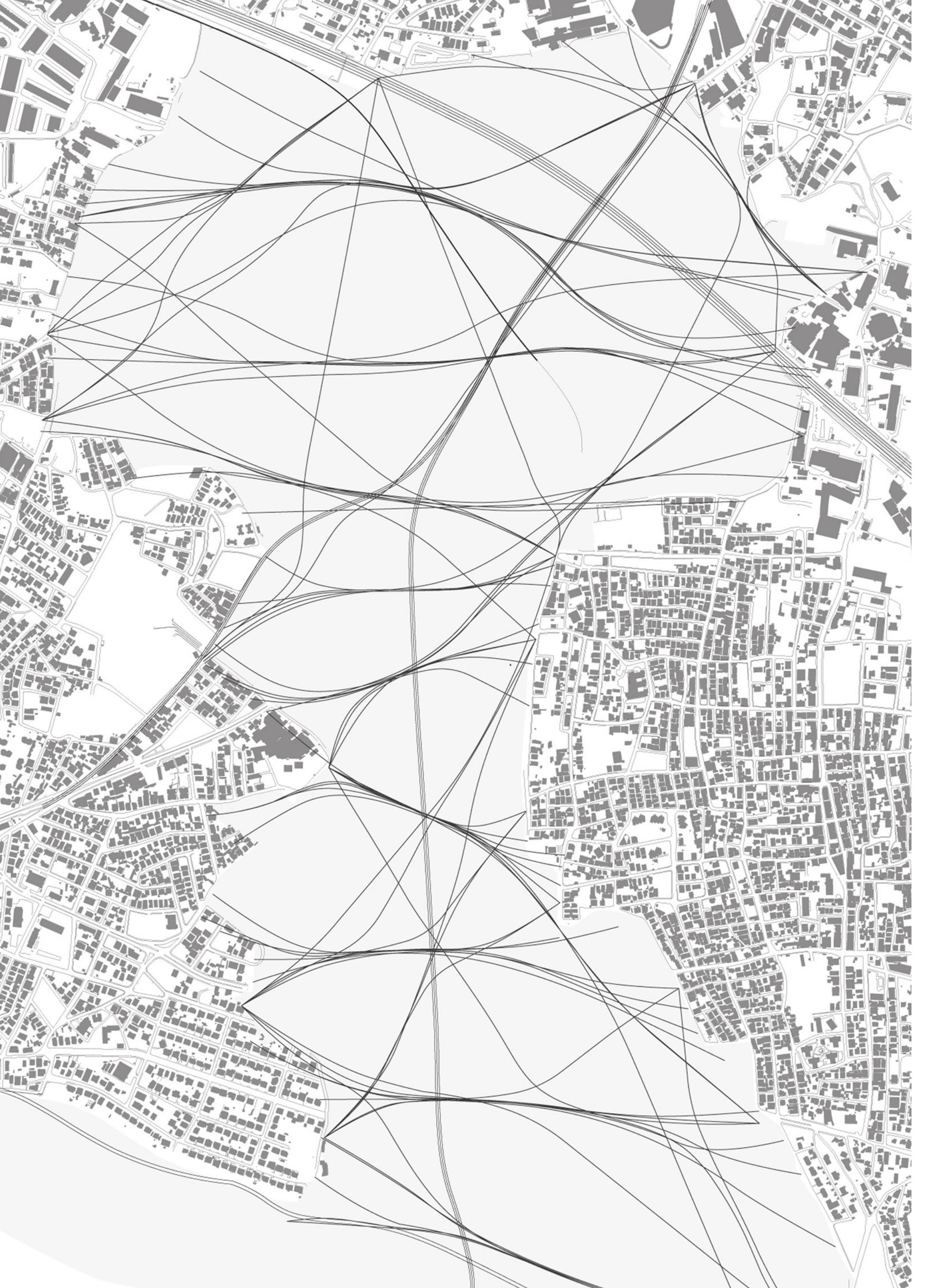

Understanding Parametricism \& the Dynamics of Digital Design

As the use of computer based tools in architecture becomes more prevalent, it is necessary that the use of these tools are continually diversifying. Through this logic we find the essence of this design based research. The use of digital tools in architecture has been in existence over 50 years, but the birth of the underlying theory stems from pre-Socratic ideology which dates back to ancient Greek philosophers (Terzidis, 2007). The modern era of digital design is commonly attributed to Computer aided design (CAD) and emergent post-modern design theories (Terzidis, 2007, p. 69). This section follows the progression of digital design theory and how those concepts are represented in the built environment. The key concepts discussed are digital post-modernism and emergent systems in architecture. Both of which are concepts exemplified in the text The Digital Turn in Architecture 1992-2012.

There are two terms, 'affect' and 'effect' that are discussed in Peter Eisenman's chapter The Affects of Singularity. Both of which represent a reactionary response (in this case architecture) on the subject, but what separates the two is the notion of singularity. Eisenman states that "Effect is something produced by an agent or cause" and "Affect is the conscious subjective aspect of an emotion considered apart from bodily changes". Eisenman refers to watching television to contrast these terms, whereby in a live sporting event we are experiencing "affect" through an emotional response to the live action. While watching a replay of the same event we are being exposed to a simulated reality of the actual event which aligns to the phenomenon of effect (Eisenman, 1992, p. 23). Through the new paradigm of digital emergent design we see a renewal of the affect in design. This occurs through the movement of the expressionist architect, projecting their ego upon a space. Doing so personifies the architecture and reduces the elements to an anthropocentric state. 
'Affect and 'effect' in architecture is a predominant theme arising from the modern architecture paradigm. Since the rise of mass industrialisation in the construction industry through modernism we see a loss in the 'affect' one experiences in a space. Eisenman references gothic cathedrals of the late middle ages as "the symbolic evocation of a town", which contrasts with the anthropocentric conditions seen in cities today. What Eisenman is conveying is a sense of disconnectedness to the inhabitants in modernist architecture and the loss of the emotional response or an 'affect' (Eisenman, 1992, p. 25).

Within the discourse of affect versus effect Eisenman presents 'singularity' as "individuality no longer able to belong to the realm of generality", and this notion is labelled as bringing to digital Architecture what personal expression brought to Architecture premodernism. Singularity differs from expressionism through the definition of the 'I' in the subject, distinguishing the 'I' as a collective or singular. Singularity depicts a point of divergence within architectural discourse and the emergence of unstable systems. What is proposed is bringing architecture back to a state of affect through singularity and the development of system based design, doing this allows the ego to be removed from the design process. Developing a design response that draws from the context, instead of an architect's fulfilment of expressionism. (Eisenman, 1992, p. 26).

Another key role in the development of digital systems is the introduction of the 'contradiction'. In the chapter Architectural Curvilinearity: The Folded, the Pliant and the supple, Greg Lynn states that contradictions are to "embody the differences within and between physical, cultural and social contexts in formal conflicts". Contradiction arise when a design is juxtaposing multiple conditions or strategies within a specific site and programmes. This paradigm forms a platform whereby we can generate heterogeneity through contradictions and formulate systems of regionalism by juxtaposing consistencies in ecology, culture, technologies and materials (Lynn G. Architectural Curvilinearity: The Folded, the Pliant and the Supple, 1993, p. 29). 'Smoothing' is a term used to label a system whereby contradictions form but the internal conditions maintain their integrity the contradiction are spaces formed through the contextual differences and the exploitation of the context. It is through algorithmic based design logic that we can deal with intensive organisations, allowing for a greater relationship to the actual conditions and inhabitants (Lynn G. , Architectural Curvilinearity: The Folded, the Pliant and the Supple, 1993, p. 34).

One of the criticisms of computational design is that some of the architectural forms that arise are merely conceptual. But within Greg Lynn's discourse of computational design we see a shift towards evolving the theories into fabrication methods and overall differing forms of project delivery. Lynn's Embryologic Houses project explores the feasibility of a production method within the bounds of computational fabrication and systematic design processes. Embryologic is a term concerned with the formation or growth of an organism, in this case the development of form within the house.

This project explores the role of mass customization, adaptability, flexibility and the presence of curvilinear forms in a domestic setting (Lynn G. , Embryologica Houses, 2000, p. 126). The homes are designed using undulating surfaces, driven by the local ecology and the geometric limits of the materials. Traditionally, modern domestic buildings have been designed to represent a generic design style that embellishes the factory-line structures developed through an international design style. What is significant about this project is the use of parameters to define overall form and the use of local ecological that informs mutations and adaptations within the architecture (Lynn G. , Embryological Houses, 2000, p. 129).

Parametric design is the application of a tool based process, primarily utilizing algorithmic design and the emergence of a style that contradicts the theories of post-modernism and deconstructivism In the essay "Parametricism: A New Global Style for Architecture and Urban Design", Patrik Schumacher describes this as "Parametricism emerges from the creative exploitation of parametric design systems in the course of articulating increasingly complex social processes and institutions." What is being described is the emergence of a new style, as opposed to the adaptation of parametric tools. The style forms not from the aesthetics, but from the systems and subsystems. The concepts within Parametricism are evident through the holistic processes developed, as opposed to an esthetic concept derived through the modernist style (Schumacher, 2009, p. 243). An architectural style consists of a methodology or set of rules by which we can determine a style based on the functions used for development. Within parametricism we see a broad spectrum of aesthetic styles. Parametricism allows for an evolutionary system that continues to diversify the use of digital tools in the modern architectural discourse (Schumacher, 2009, p. 244)

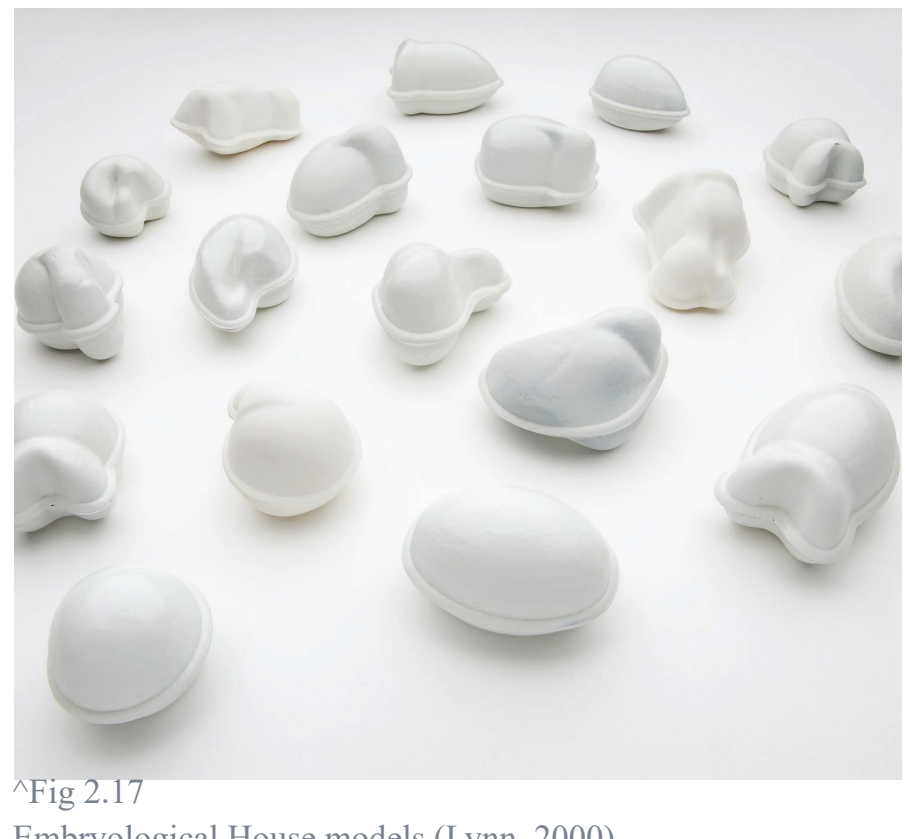

Embryological House models (Lynn, 2000) 


\section{Container Architecture \\ Examples of Adaptible Architecture using Shipping Containers}

Architects of our generation have more access to emerging technologies than any other period. Any researcher can find troves of papers written on social agencies in architecture, sustainable practises and new material processes, but do we see these revolutionary systems implemented in current building practises? Not often, the construction industry relies primarily on technology developed 50 years ago as the 'golden standard'. Avi Friedman discusses this in a talk 'Thinking outside the box on Affordable Housing', referencing the medical industry and the speed in which technology is made available to surgical practises as opposed to the narrow sighted construction industry (SFU, 2012). For the construction industry to progress, we need to be developing architecture that tests the possibilities of social, cultural and environmental harmony throughout.

Building homes using recycled shipping containers are one possible solution to temporary housing, constructing on tough terrain, changeable arrangements and upcycling materials. Furthermore the use of containers in architecture allows for flexible architecture where vernacular building styles are not applicable. Although container architecture can also pose issues with space arrangement and integration of services. This type of building is chosen as a testing for 'Hybrid Papakāinga housing' in this research due to the current issues surrounding affordable housing on Māori owned land. A key issues with multiple owned land is securing loans on permanent housing (WDC, 2015). What container housing presents is an opportunity to have movable housing on land that is jointly owned, and the pods themselves can be owned or rented separate from the overall entity.

This section exemplifies some projects that challenge the role of flexibility and adaptability, shifting the concept of building lifecycle and material diversification. Specifically, this research looks at 'upcycling' used shipping containers for use in a hybrid housing typology for New Zealand through system based architectura practises. This research explores the possibility of modular shipping containers for the purpose of medium density housing. The work applies the principles of digital design and a renewed philosophy of metabolism in architecture within the building restrictions of affordable housing.
The Container Skyscraper design is a competition submission that attempts to ease the increase in slum housing in Mumbai. The concept utilizes the 'stack ability' of shipping containers alongside some environmental control methods such as wind turbines and solar panels. This design collates groupings of 2-3 40 foot containers to form a home, with each storey housing 3-4 homes. The design creates diversity in housing through the varying extrusions from the core tower and through the colouration of the pods (Ganti+Associates, 2015).

Container Skyscraper

Mumbai, India

Ganti + Associates

Competition Design: 2015

Building Area: $450 \mathrm{~m}^{2}$

Total Floor Area: 13, $000 \mathrm{~m}^{2}$

Recycled Shipping containers and Reinforced Concrete

32 Floors

This project exemplifies how container housing can be implemented into conceptual design, although it overshoots the appropriateness of containers in such a large development. Shipping containers are purpose built for longevity and the ability to be stacked 9 high without added structure, but when the arrangement extends beyond this envelope we see a loss in the core attributes and furthermore their appropriateness in the context. Ganti and Associates attempt to engage a dialogue of temporary housing through this project and challenge previous attempts to house India's homeless.

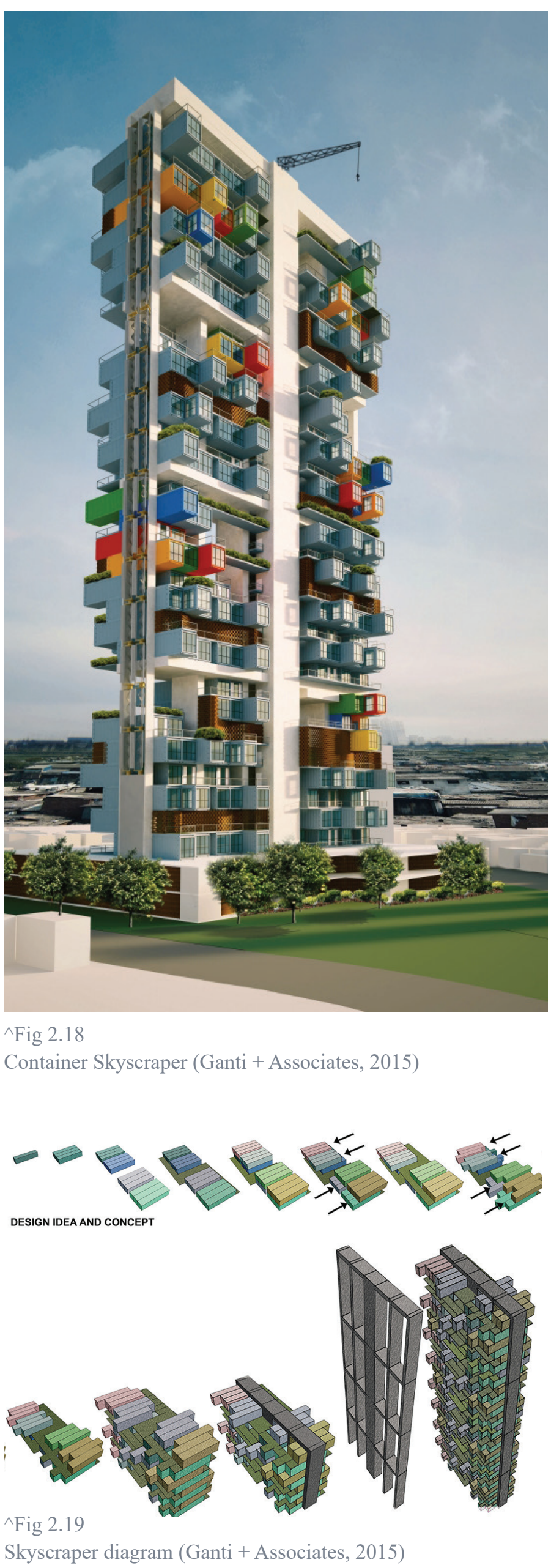

Skyscraper diagram (Ganti + Associates, 2015) 


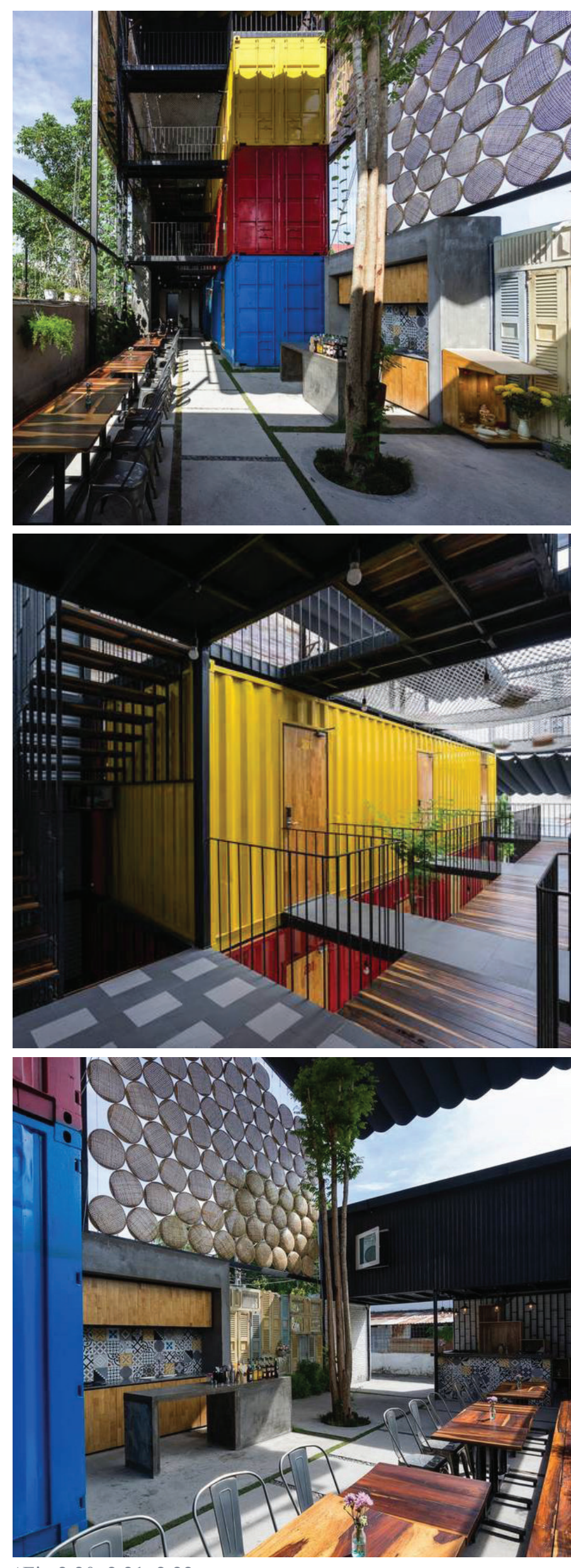

Fig 2.20, 2.21, 2.22

Vietnam (Popup City, 2016)
The CCasa Hostel in Vietnam is an example of container architecture that integrates the pods into a larger social framework, whereby the housing is contained within a large steel structure. The building envelope contains a diverse mix of materials and cladding/shading options that reflect some of the materials seen in vernacular Vietnamese buildings. The upper storeys contain segments with simple open space, allowing for the dead space to be filled and useful. The units themselves reflect a capsule house design and maximize space by providing bunk beds sectioned by curtains (Popup City, 2016).

\section{CCasa Hostel}

Nha Trang, Vietnam

TAK Architects

Competition Design: 2016

Building Area: $125 \mathrm{~m}^{2}$

Total Floor Area: 1,000 $\mathrm{m}^{2}$

Recycled Shipping containers and Steel

4 Floors

(Popup City, 2016)

This example of container architecture makes great use of interior space and utilizing the area within the grid as social spaces. While this is not a housing development, it enforces a similar approach to diversity of materials and construction style utilized in this thesis.
The ideEGE campus design covers 85,000 square metres, with a portion of this being allocated to series of container buildings. The role of the building are to create a modulated building system that allowed for further additions. The construction seamlessly integrates the surrounding environment through the low profile and the use of timber slats neutralizes the industrial steel appearance (Labs, 2014)

ideEGE Campus

Sisli, Istanbul

Atolye Labs

Construction Completion: 2014

Building Area: $1,000 \mathrm{~m}^{2}$

Total Floor Area: 1,400 m²

Recycled Shipping containers and Steel

2 Storey

These examples are used as precedents for constructing in recycled shipping containers and illustrate some of the materialistic properties present in the research. Although these examples do not utilize algorithmic design or parametric theories, they do present the opportunities and issues in working with shippin containers. This thesis explores the collaboration these construction methods alongside a system based approach to housing integration.

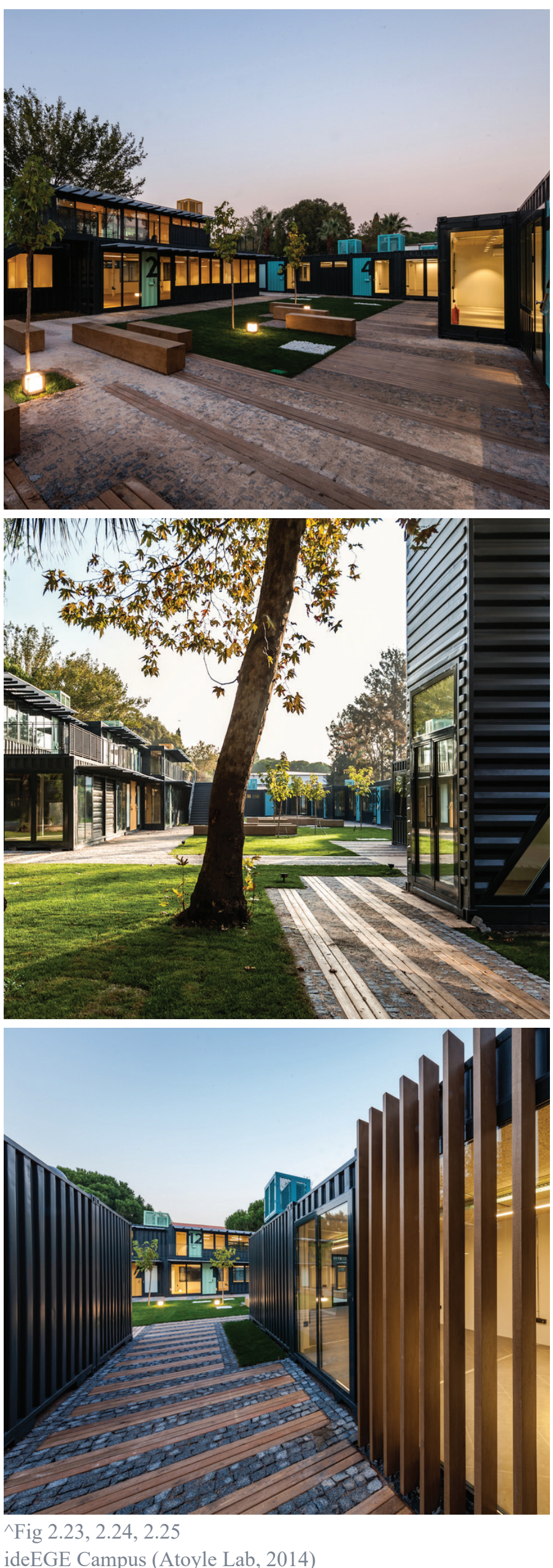





\section{Data Collection}

Initial stage of System Setup and Arrangement

The objective of this research is to test a system that organises a community housing development within a social, cultural and geographical information framework. This process begins with the accumulation of data in two parts. Part one is the Geographical input, including generating a contour mesh that outlines the building footprints, Roads, and zoning. The secondary process is collating social and cultural data on residents, whereby a questionnaire is completed by future residents that is fed into the arrangement matrix. From this point the family information directs the social organization within the parametric modelling. Site specific climactic data allows for specific module orientation, controlling opening ratios in housing modules and cluster arrangements. Cultural resilience and diversity is built into the clusters by utilizing culturally significant colouring, patterning, arrangements and complex family connections. The final output of the social systems is to appropriate modular housing blocks that interact on social, cultural and multi-generational levels.

Fig 3.02

Process Diagram

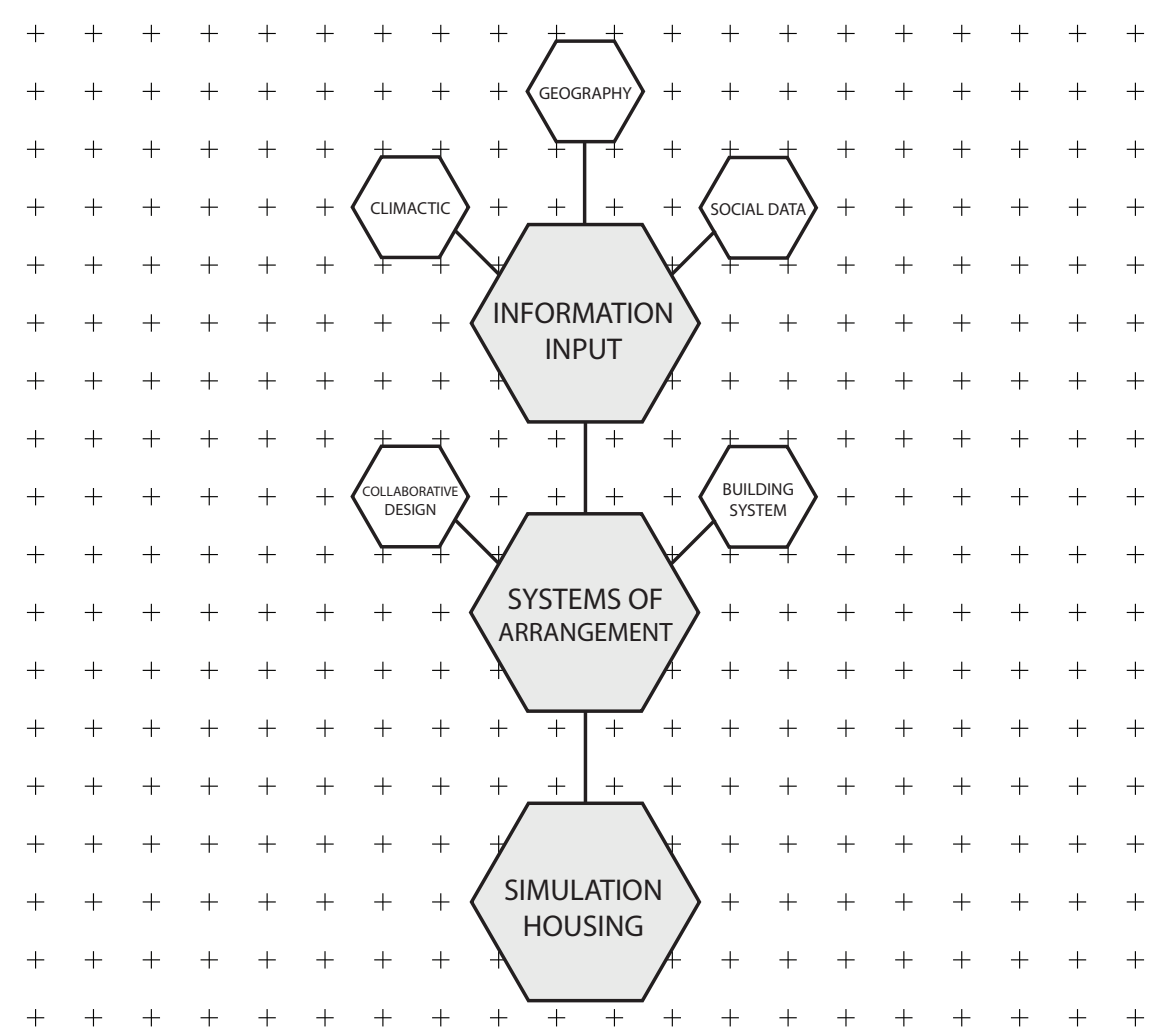




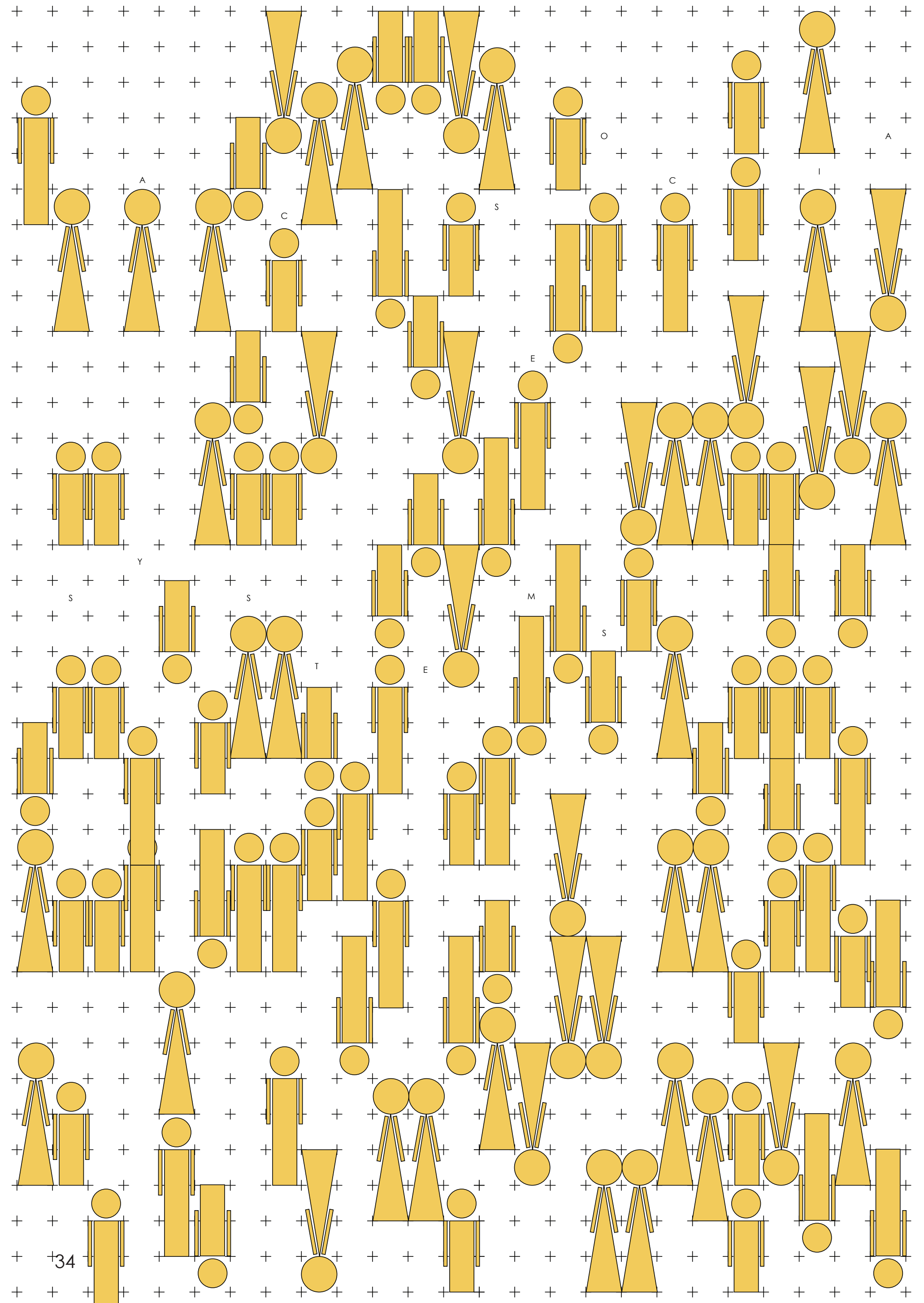

\section{Social Profiling}

Collaborating Social, Cultural, Personal Information

This section of the research seeks to implement family specific data through a database that feeds into the arrangement matrix and ultimately influences the parameters of occupation. Including this information in the overall process allows the system to stem from a more responsive parameter. In turn constructing social domains that contrast with the current approach to privatization in housing.

Social profiling attempts to formulate an arrangement in the housing development that places clusters of diverse module interactions alongside communal outdoor space that are informed through the questionnaire input phase. Shown in figure 3.04-3.05 is some examples of family profiles, depicting the variety of modules, demographics and social situations that form the diverse mix to be simulated.

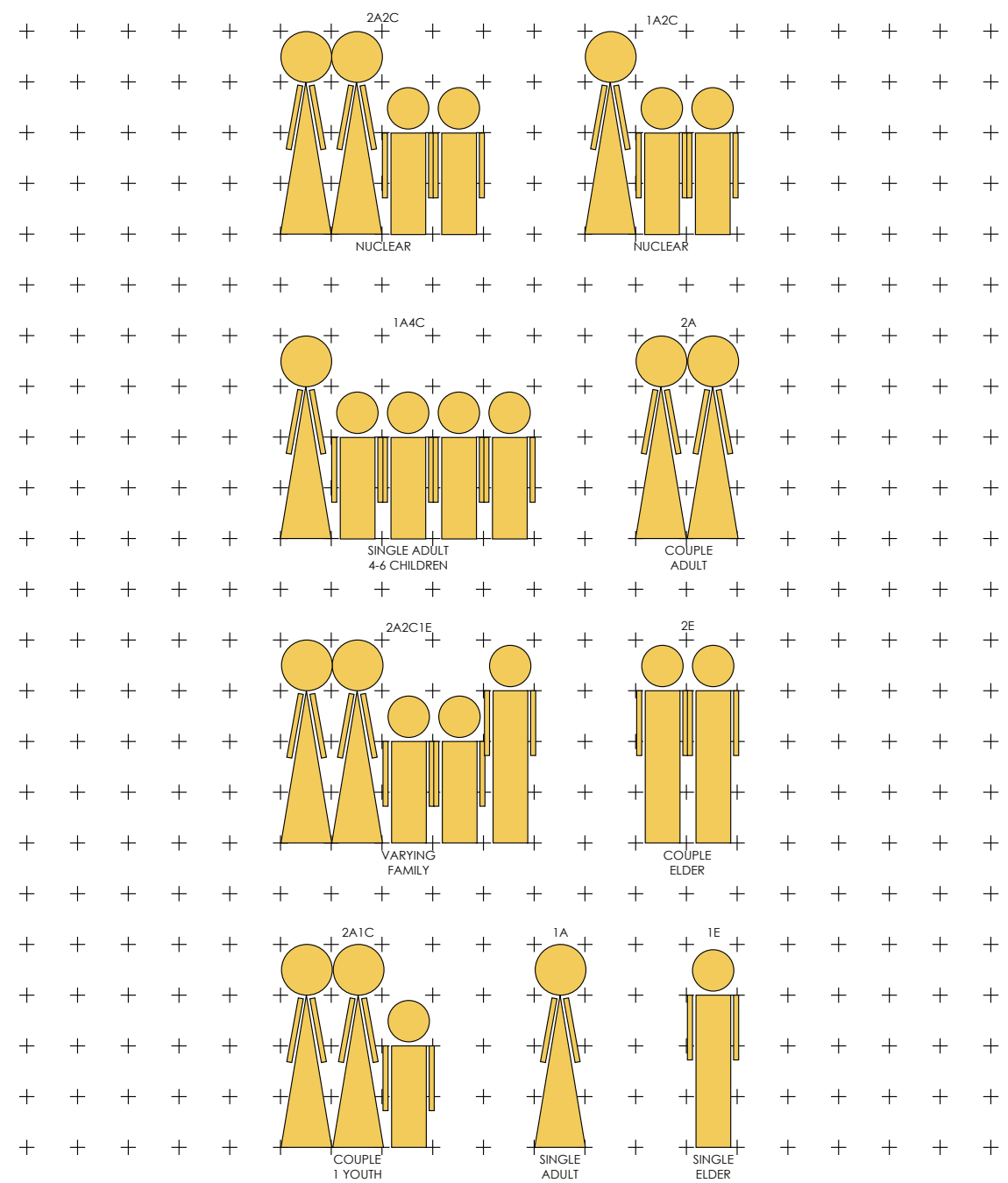




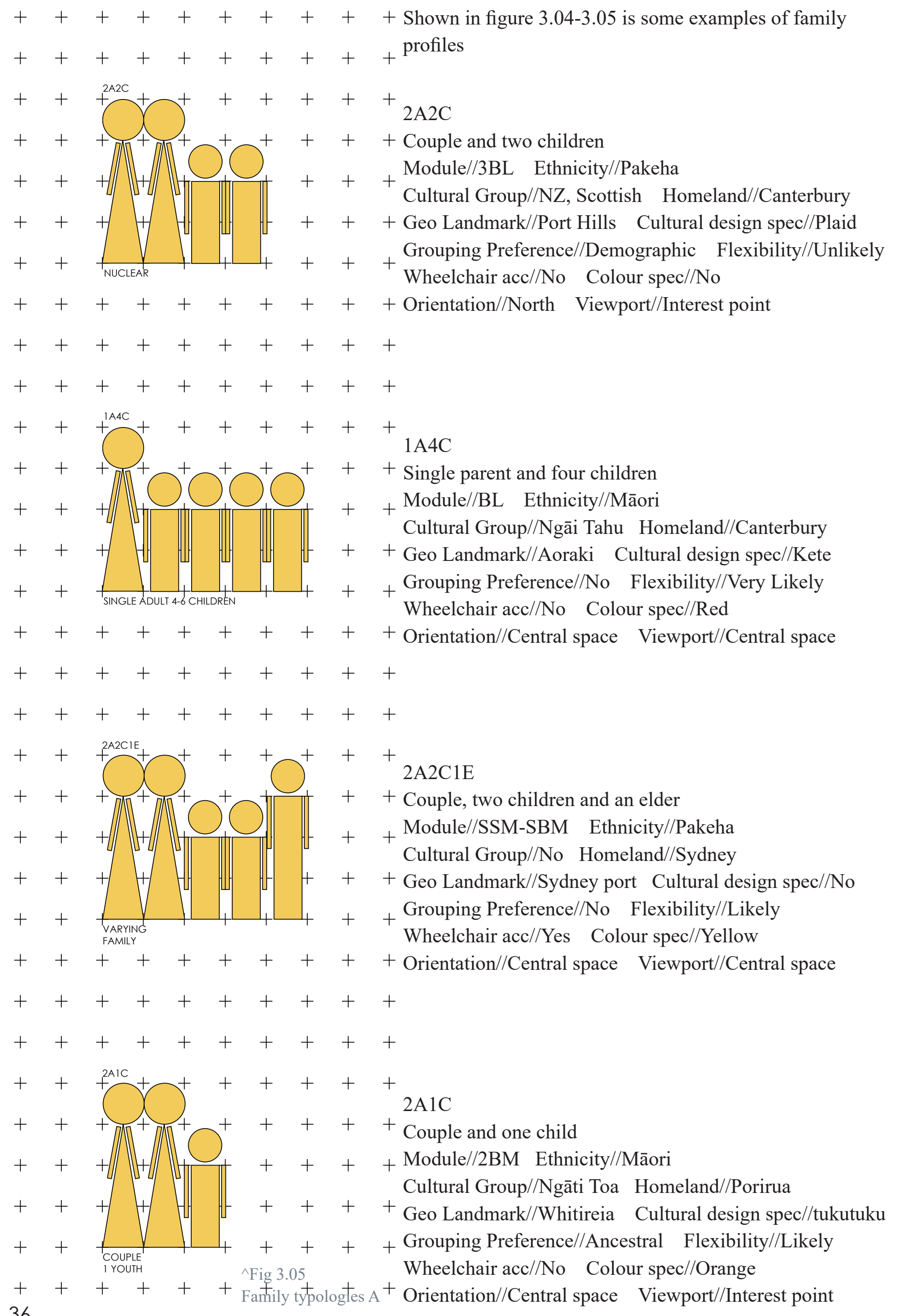

Cultural Group//Samoan Homeland//Apia

Geo Landmark//Apia Harbour Cultural design spec//No + Grouping Preference//No Flexibility//Very Likely

Wheelchair acc//No Colour spec//Blue Orientation//North Viewport//North +

Module//1BS Ethnicity//Pakeha Cultural Group//No Homeland//Invercargil Geo Landmark//Takitimu Cultural design spec/No Grouping Preference//Demographic Flexibility//Likely

Wheelchair acc//No Colour spec//Blue

Orientation//North Viewport//Interest point +

couple

Elder Couple

Module//1BS Ethnicity//Māori

Cultural Group//Ngāti Toa Homeland//Wellington + Geo Landmark//Tangi te Keo Cultural design spec//

$$
\text { Tukutuku }
$$

Grouping Preference//Cultural Flexibility//Very Unlikely + Wheelchair acc//Yes Colour spec//Red Orientation//Central space Viewport//Interest point

Adult Flat

Module//3BL Ethnicity//Mix Cultural Group//No Homeland//Wellington Geo Landmark//Aoraki Cultural design spec//Kete Grouping Preference//No Flexibility//Likely Wheelchair acc//No Colour spec//Yellow Orientation//North Viewport//North 
Illustrated in figure 3.06 is the resident questionnaire, The questionnaire follows a rating system of input, which is the initial document that is used to inform whereby nodal connections are made by determining the arrangement simulation. This document ascertains the required access to certain shared resources and the cultural, social and physical needs of each family other housing clusters.

typology through a series of questions.

\begin{tabular}{|c|c|c|c|}
\hline & RESIDENT QUESTIONNAIRE & & \\
\hline QUESTION & ANSWER & $\begin{array}{l}\text { ADDITIONAL } \\
\text { INFO } \\
\end{array}$ & CODE \\
\hline Housing Development Name? & \begin{tabular}{|l} 
Name of Overall system configuation (eg. \\
Kelburn Hybrid Housing
\end{tabular} & & \\
\hline Current Date? & Current date when filling form & & \\
\hline Family Name? & Family Name & & \\
\hline Address of Housing Development? & Expected address of Development & & \\
\hline $\begin{array}{l}\text { What Ethnicity do you relate most closely } \\
\text { with? }\end{array}$ & $\begin{array}{l}\begin{array}{l}\text { Ethnicity (eg. Maori, Pakeha, South African, } \\
\text { Pakistan) }\end{array} \\
\text { (a) }\end{array}$ & & \\
\hline Grouping preference for Ethnicity Similarity & Preferential link to others of similar ethnicity & & \\
\hline |wi/Tribe/Cultural group & $\begin{array}{l}\text { Name of Tribal group (if any), (eg. Scottish } \\
\text { heritage, Iwi, Hapu, Arabic, Muslim) }\end{array}$ & & \\
\hline Grouping Preference for Cultural Similarity & $\begin{array}{l}\text { Preferential link to others of similar Cultural } \\
\text { distinction }\end{array}$ & & \\
\hline Ancestral Homeland & Site of geography linked to & $\begin{array}{l}\text { Image submit } \\
\text { seperately }\end{array}$ & \\
\hline Grouping Preference for Ancestral Similarity & Preferential link to others of similar ethnicity & & \\
\hline $\begin{array}{l}\text { Geographic landmark with strong } \\
\text { significance? }\end{array}$ & $\begin{array}{l}\text { A site, mountain, shore edge, any land mass } \\
\text { strongly linked to the resident }\end{array}$ & $\begin{array}{l}\text { Image submit } \\
\text { seperately }\end{array}$ & \\
\hline $\begin{array}{l}\text { Cultural/social//preferential design specific to } \\
\text { you/your family and cultural group? }\end{array}$ & $\begin{array}{l}\text { A pattern, style, image, system you would like } \\
\text { to see implemented in panel design }\end{array}$ & $\begin{array}{l}\text { Image submit } \\
\text { seperately }\end{array}$ & \\
\hline $\begin{array}{l}\text { Colour most linked to } \\
\text { family/culture/ethnicity? }\end{array}$ & $\begin{array}{l}\text { If irrelevant leave blank, Colour that could } \\
\text { differentiate your module if wanted }\end{array}$ & $\begin{array}{l}\text { Image submit } \\
\text { seperately }\end{array}$ & \\
\hline \# Adults (age 18-65)? & Amount of Adults in household & & \\
\hline \# Children (age 0-18)? & Amount of Children in household & & \\
\hline \# Elders (age 65+)? & Amount of Elders in household & & \\
\hline Grouping Preference for demographic? & $\begin{array}{l}\text { Preferential link to others of similar } \\
\text { demographic in the overall system }\end{array}$ & & \\
\hline Wheelchair Access needed? & $\begin{array}{l}\text { Do the residents (future or current) require } \\
\text { accessable pathways and modules }\end{array}$ & & \\
\hline Specific Access to local resources? & $\begin{array}{l}\text { Preferential link to resources (eg. Local shop, } \\
\text { Medical, sporting) }\end{array}$ & & \\
\hline $\begin{array}{l}\text { Probability of Future change (Flexibility } \\
\text { score)? }\end{array}$ & $\begin{array}{l}\text { The level of flexibility in personal module, } \\
\text { option of addititional module }\end{array}$ & & \\
\hline $\begin{array}{l}\text { Proximity to Central Social Space (maybe } \\
\text { more than one)? }\end{array}$ & $\begin{array}{l}\text { Preferential link to the central Social space in } \\
\text { development }\end{array}$ & & \\
\hline $\begin{array}{l}\text { Proximity to Central Services Space (maybe } \\
\text { more than one)? }\end{array}$ & $\begin{array}{l}\text { Preferential link to the central Services space } \\
\text { (eg. Washing, cooking }\end{array}$ & & \\
\hline $\begin{array}{l}\text { Proximity to Shared Garden Spaces (maybe } \\
\text { more than one)? }\end{array}$ & $\begin{array}{l}\begin{array}{l}\text { Preferential link to the Shared Garden space } \\
\text { (eg. Vege garden) }\end{array} \\
\end{array}$ & & \\
\hline $\begin{array}{l}\begin{array}{l}\text { Module Choice determined via module } \\
\text { matrix? }\end{array} \\
\end{array}$ & $\begin{array}{l}\text { Based on the applicable modules, which one } \\
\text { bestf fits (may be more than one) }\end{array}$ & & \\
\hline Climactic Orientation of Module? & Orientation to East, North, West & & \\
\hline Primary Viewport? & $\begin{array}{l}\text { Primary viewport (eg. Seaview, Mountain, } \\
\text { Social space) }\end{array}$ & & \\
\hline
\end{tabular}

This document is digitally linked to the overall implications are used throughout the planning and arrangement sheet shown in figure 3.08 , which is documenting stages. This wide variety of family the collaboration of all housing modules/groupings. typologies is accompanied by a diverse mix of module Shown in figure 3.07 is some of the numerous typologies explored in section 4.2.

groupings of family typologies explored in this thesis. In this spreadsheet the terms $1 \mathrm{~A}, 2 \mathrm{C}$ etc. are simplified from 'one adult', 'two children' and these

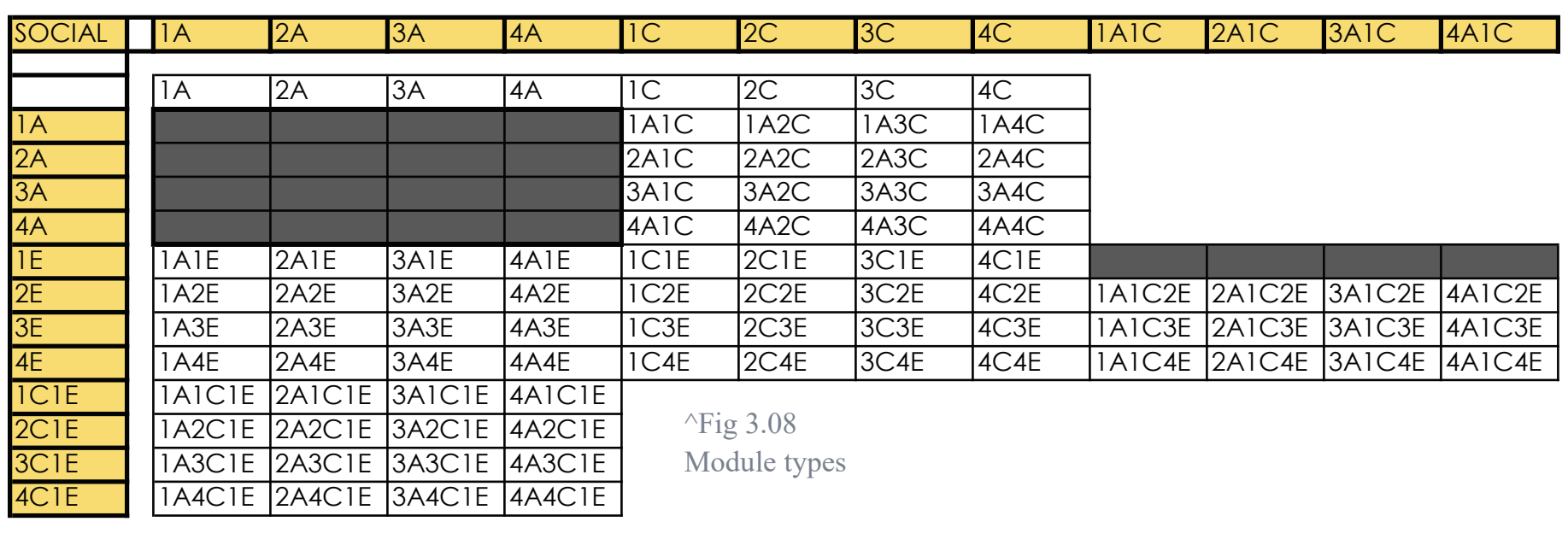

The social code is one component of the overall With all of the parameters of arrangement displayed as typology configuration system, leading on from this a numerical value (1-10). This aids in transferring the is the assignment of a module to the family type. This data to the spring strength simulation in grasshopper section is proposed as a choice section in the resident $3 \mathrm{~d}$ visual programming and helps to determine questionnaire, as differing families will have varying a modules relationship to local resources. In this spatial needs. The module code can be a combination example, a central space is the control point whereby of modules to collaborate a whole home. Figure 3.08 all other modules are arranged about.

is a section of the arrangement sheet that directly influences the arrangement matrix.

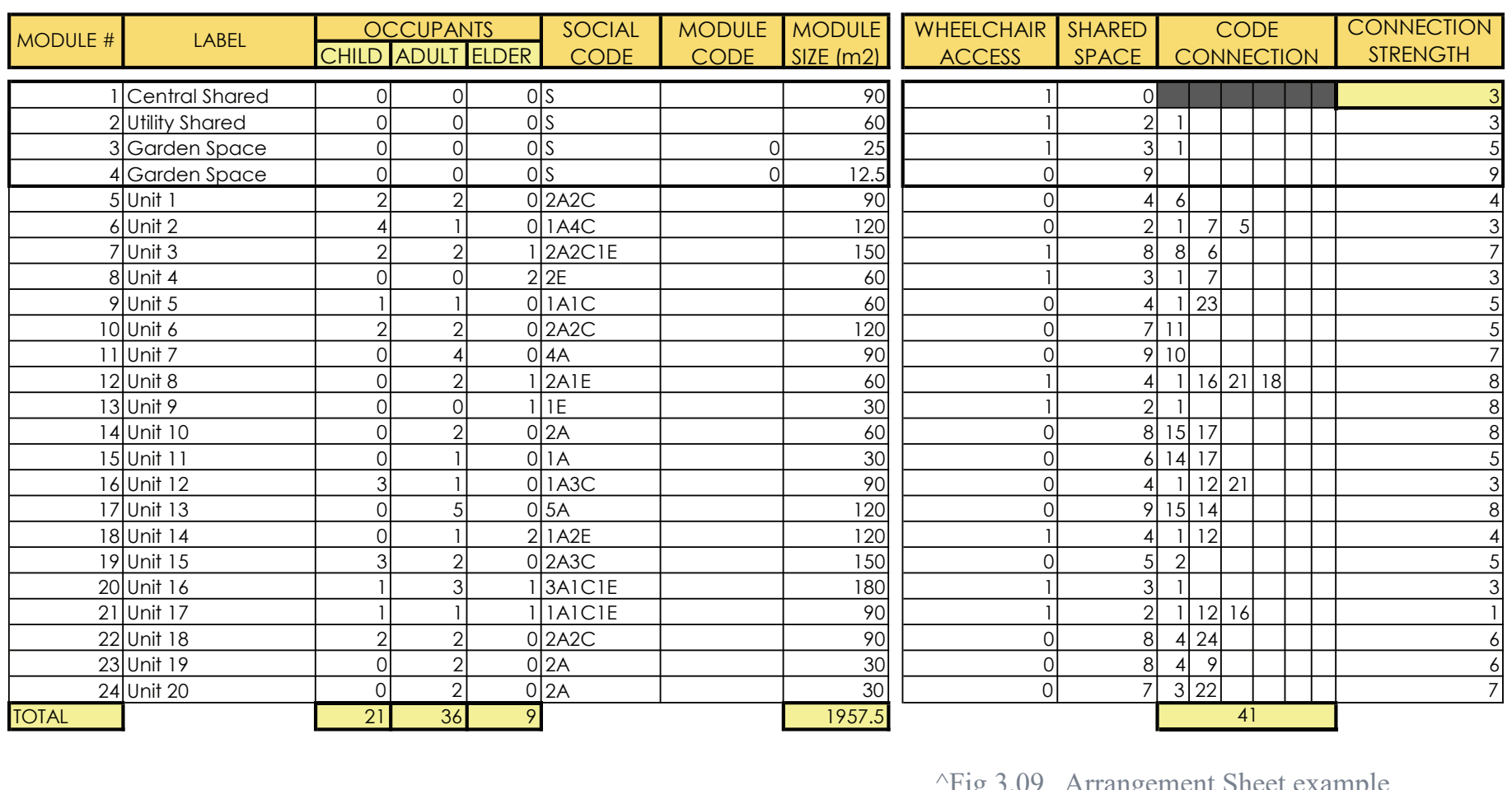

Fig 3.09 Arrangement Sheet example 

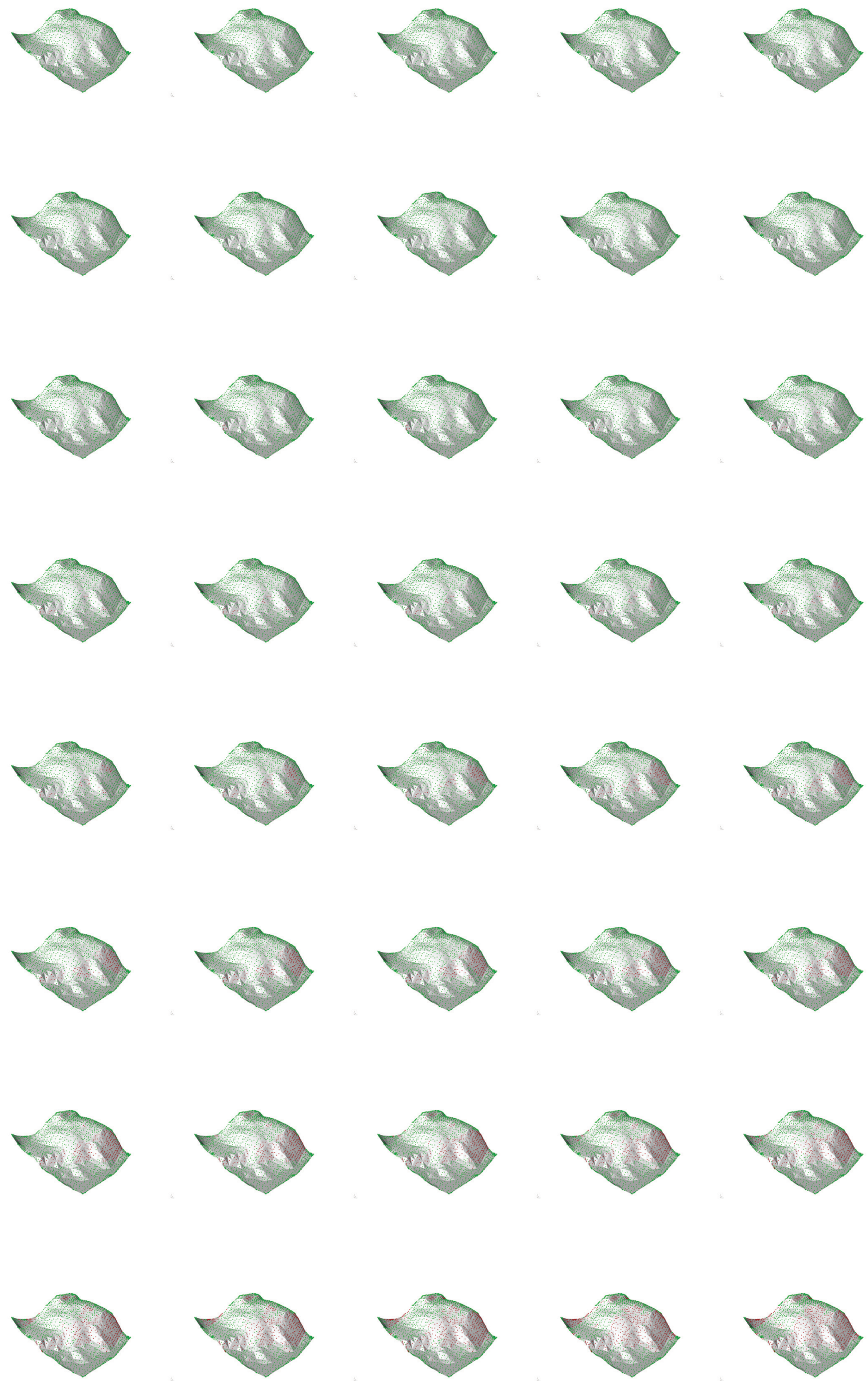

\section{Geography Mapping}

Generating detailed mesh mapping for simulations This section introduces the development of a digital landscape. The process begins with open sourcing geographical data through websites such as Koordinates (https://koordinates.com/) and transferring GIS information into 3d mapping and massing. From here, the landscape undergoes a series of parametric simulations to gain further understanding of the ecology present. This is carried out by utilizing a series of digital simulations and systems that evaluate the ecology through a set of developed tools.
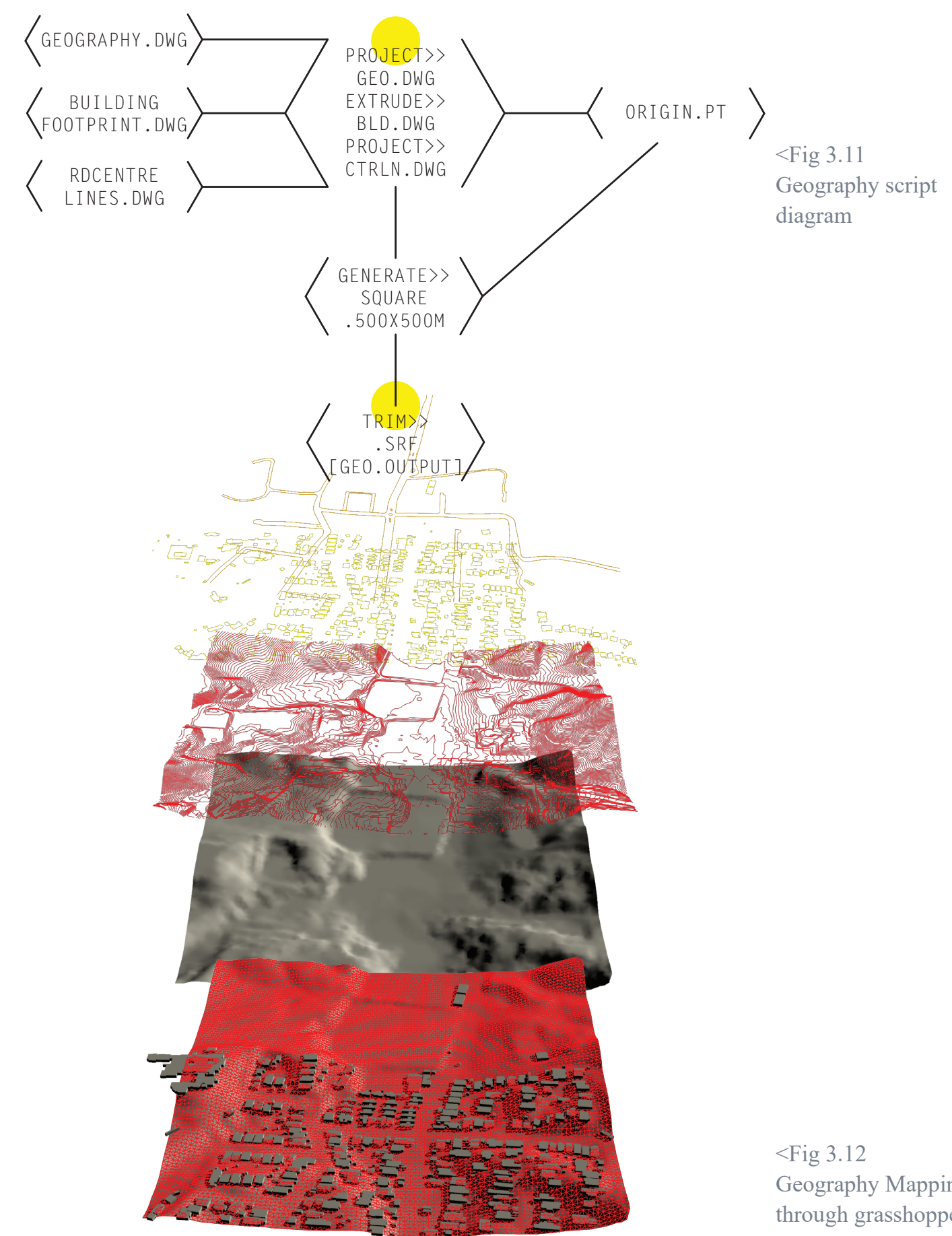
$85 \%$

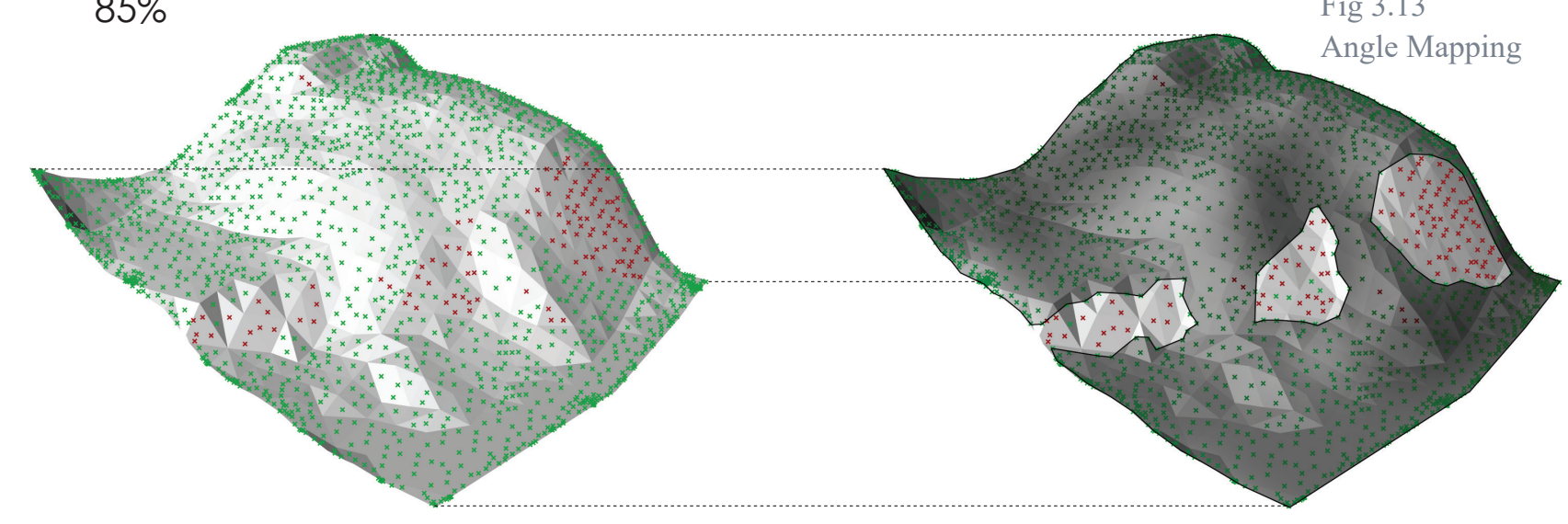

$60 \%$

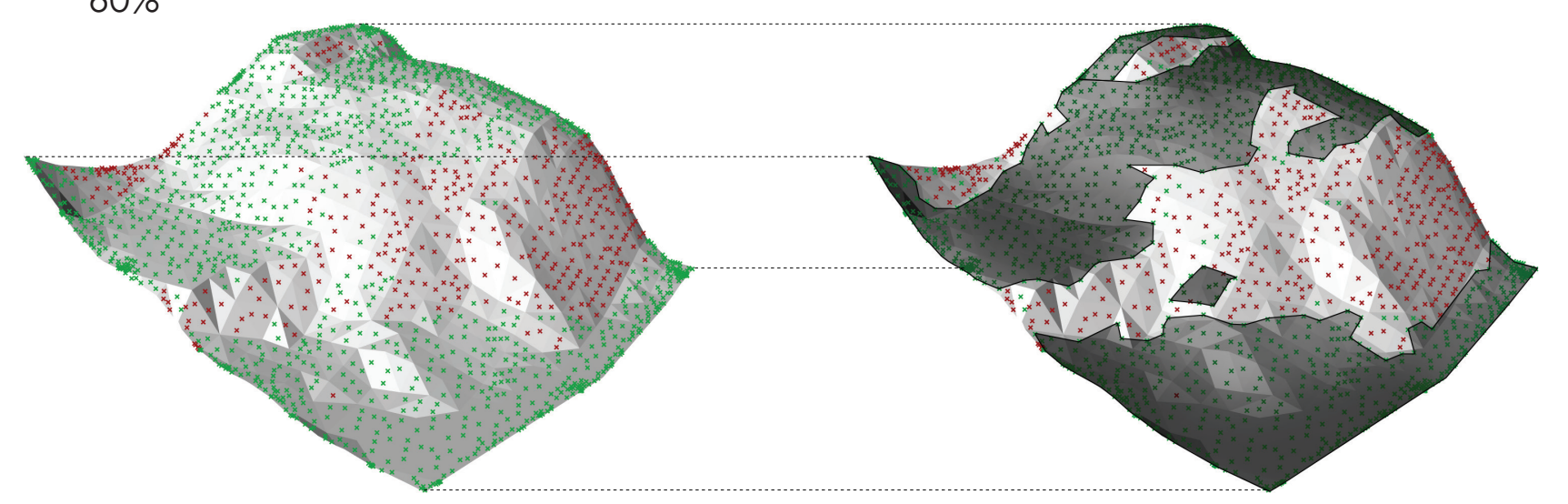

$35 \%$

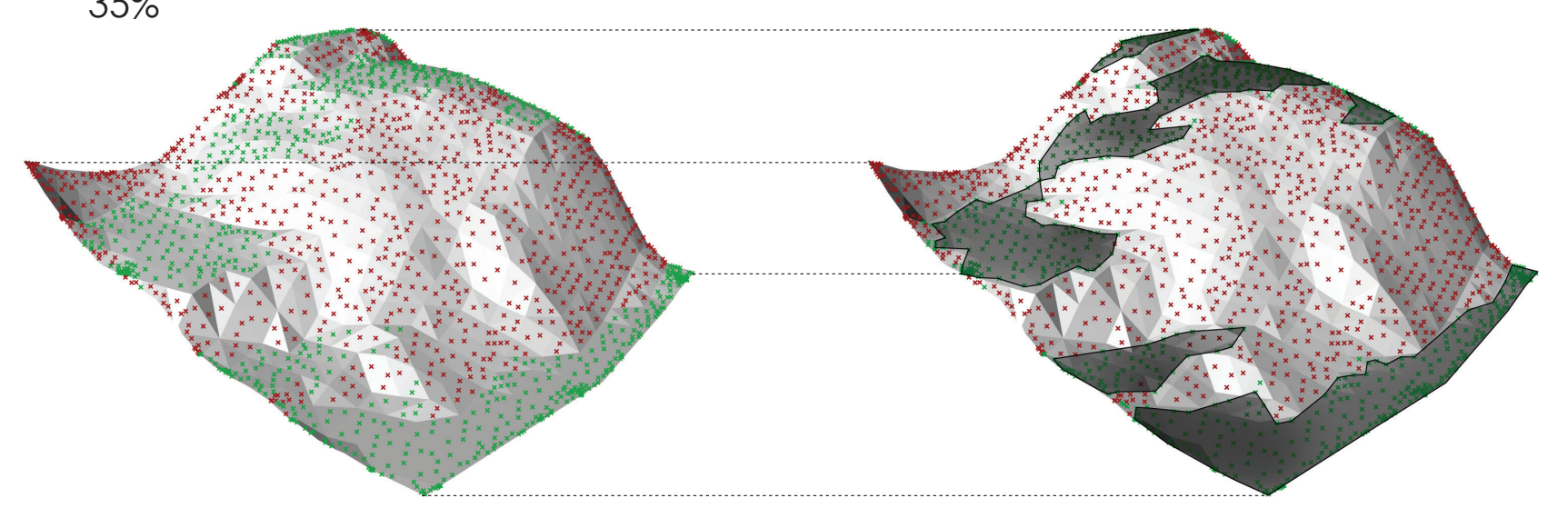

$10 \%$

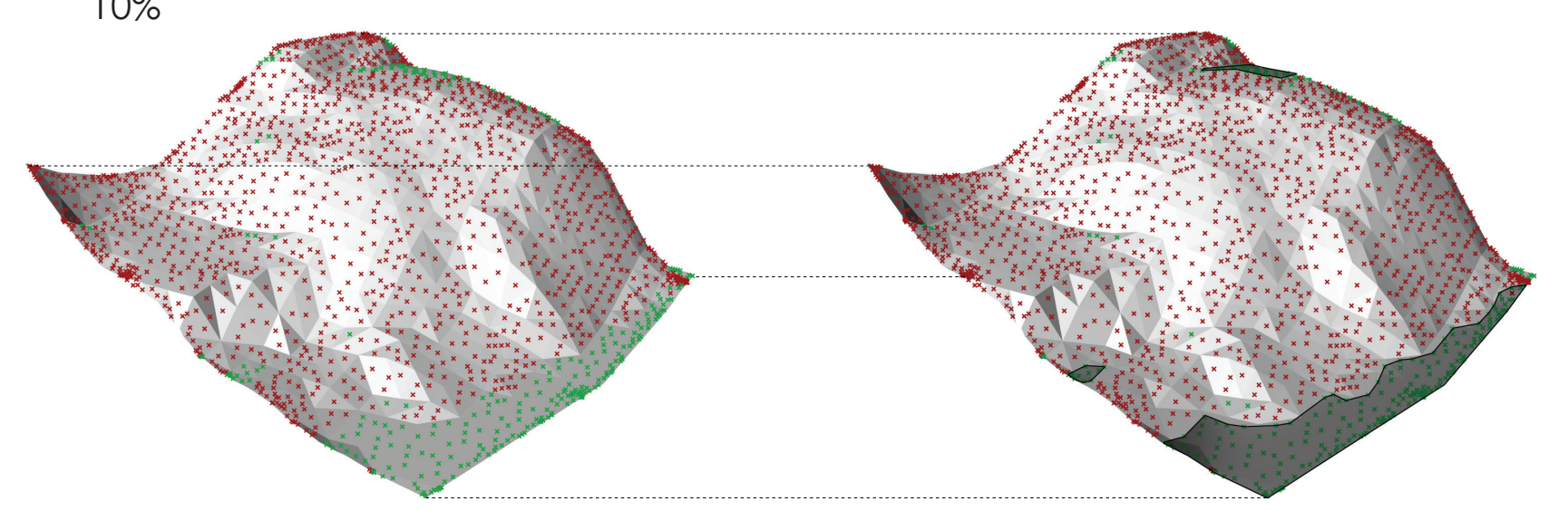

Mapping of the topography stems from the input data and plays a crucial role in the arrangement simulation. Once the dwg files are put through the initial trimming script there is a series of simulations to determine attractor/ repulsion nodes for the simulation. These nodes relate to all aspects of the system such as sun direction, centralized spaces and related modules.

The initial testing is on usable space on site. This is determined by topography terrain and ecological systems on site such as native plants and streams. Figure 3.11 depicts this test and illuminates the optimum zoning for residential development considering terrain angle by calculating the face vertices and zoning sections based on the parameters required. A key attribute of this test is to illuminate the initial stages in master planning and influence the overall arrangement matrix. Testing of repulsion and attraction nodes is shown in section 3.4 .

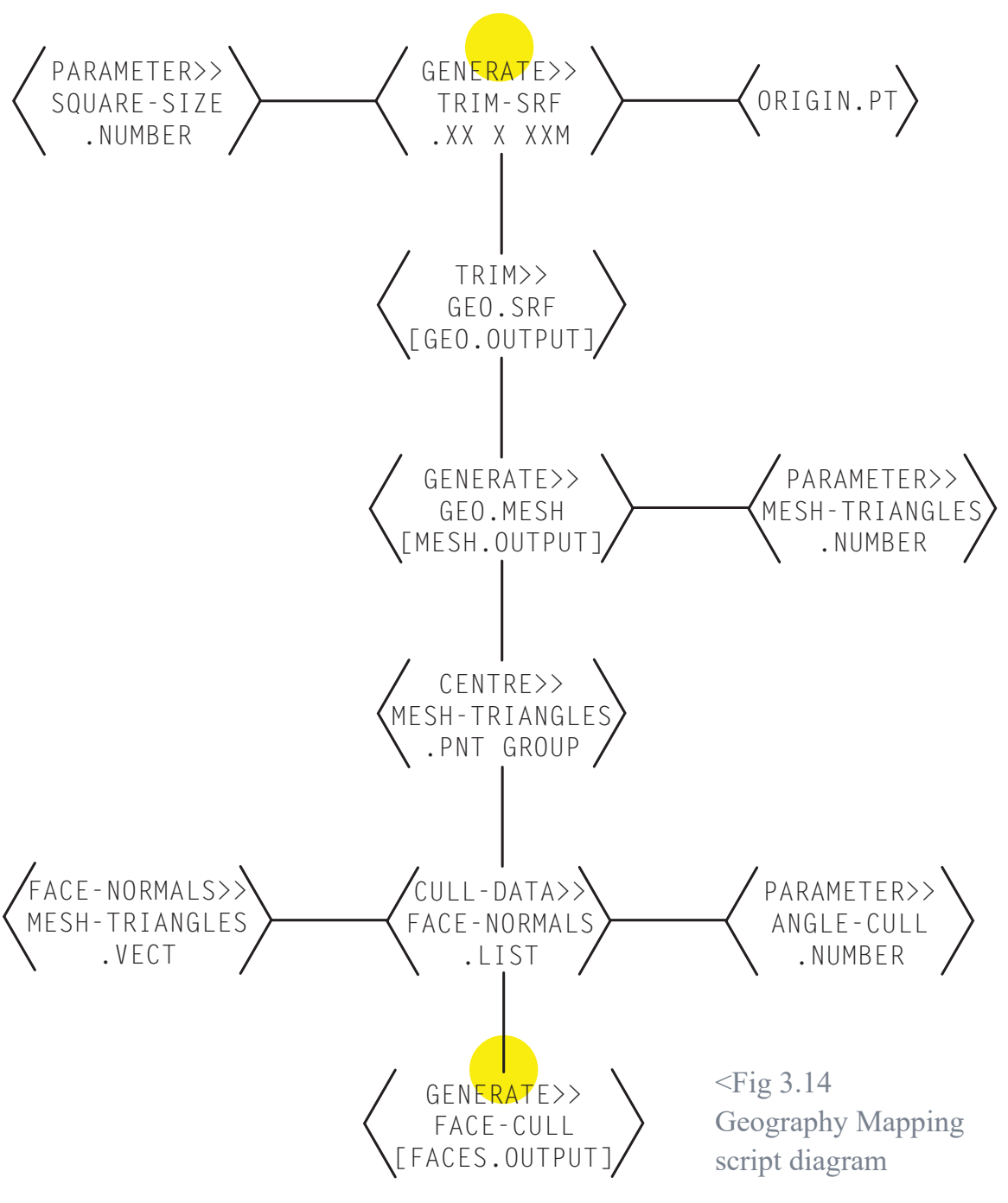




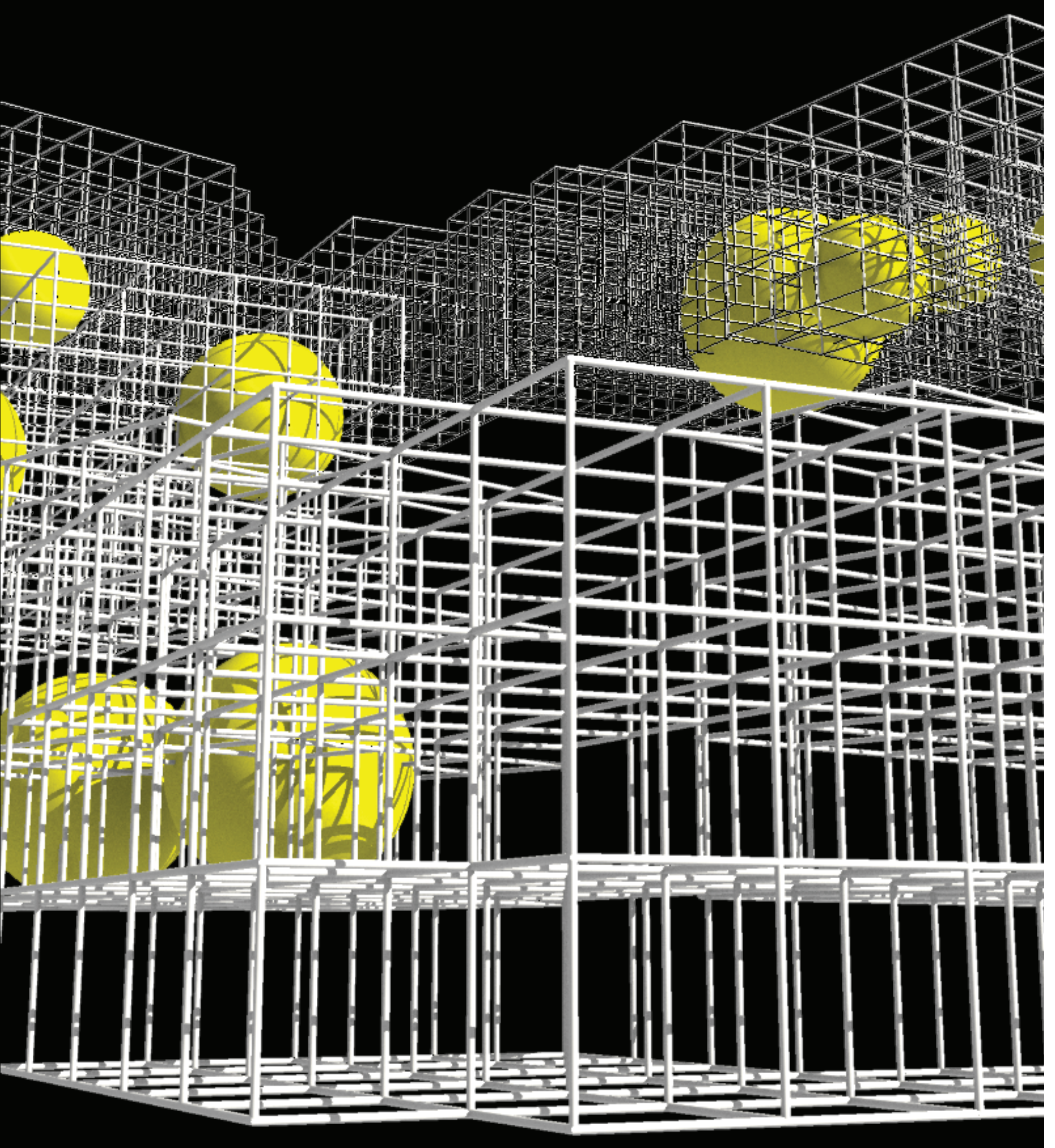

Organizing Initial Data into Tangable Parameters

The process of organisation relies on the input data from section 3.2 and the geographical data explained through section 3.3. The organisation matrix begins with the input of geographical data, developing the contour mesh and infrastructure networks. Secondly the social information questionnaire defines the key parameters in the organisation matrix. This information is transcribed from numerical data to the Grasshopper plugin for McNeel's Rhinoceros 5. The plugin works by illustrating the social and cultural forces as physics forces. This is made possible by the spring relaxation function 'Kangaroo physics' and basic components through the grasshopper parametric plugin.

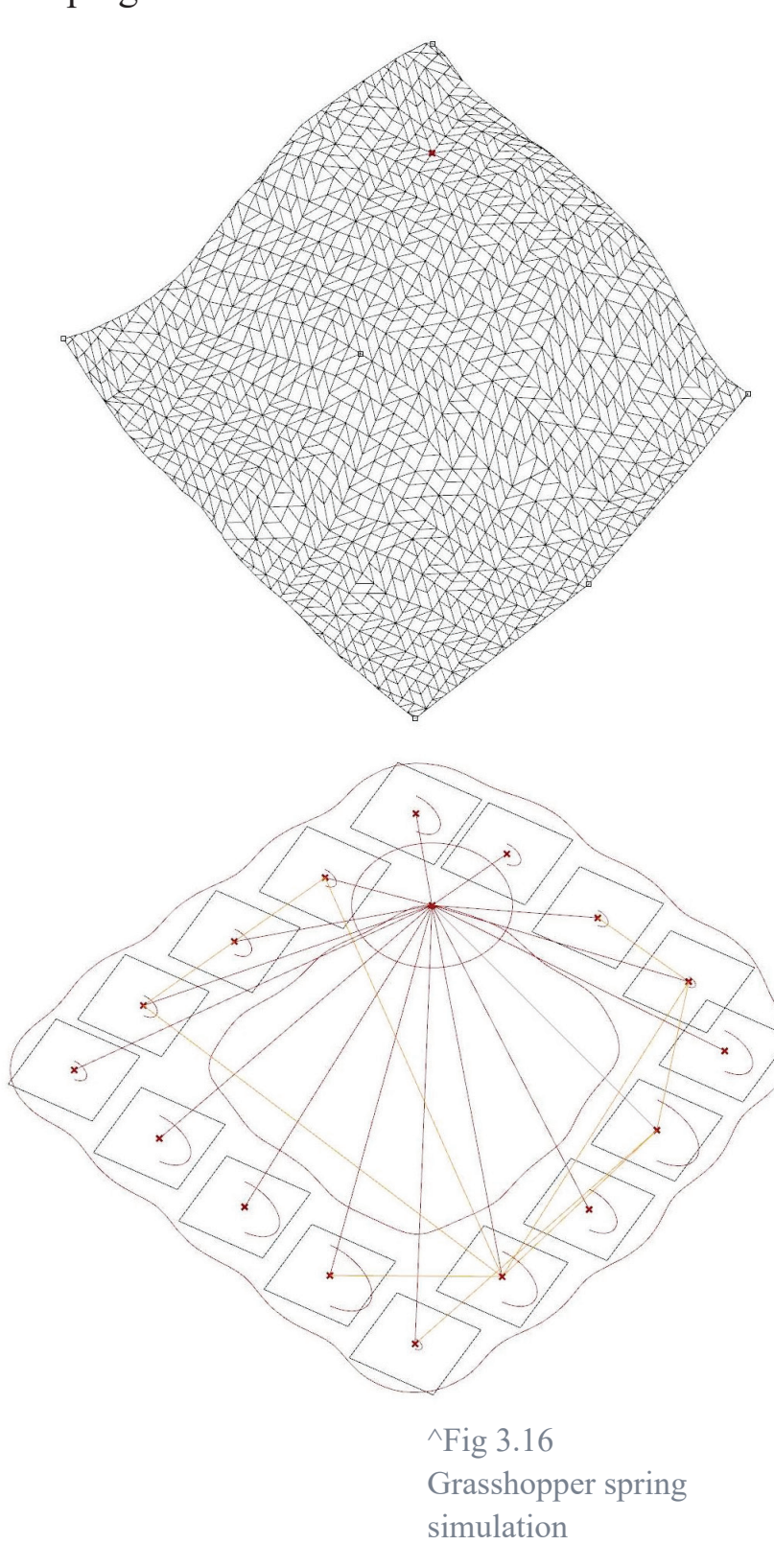




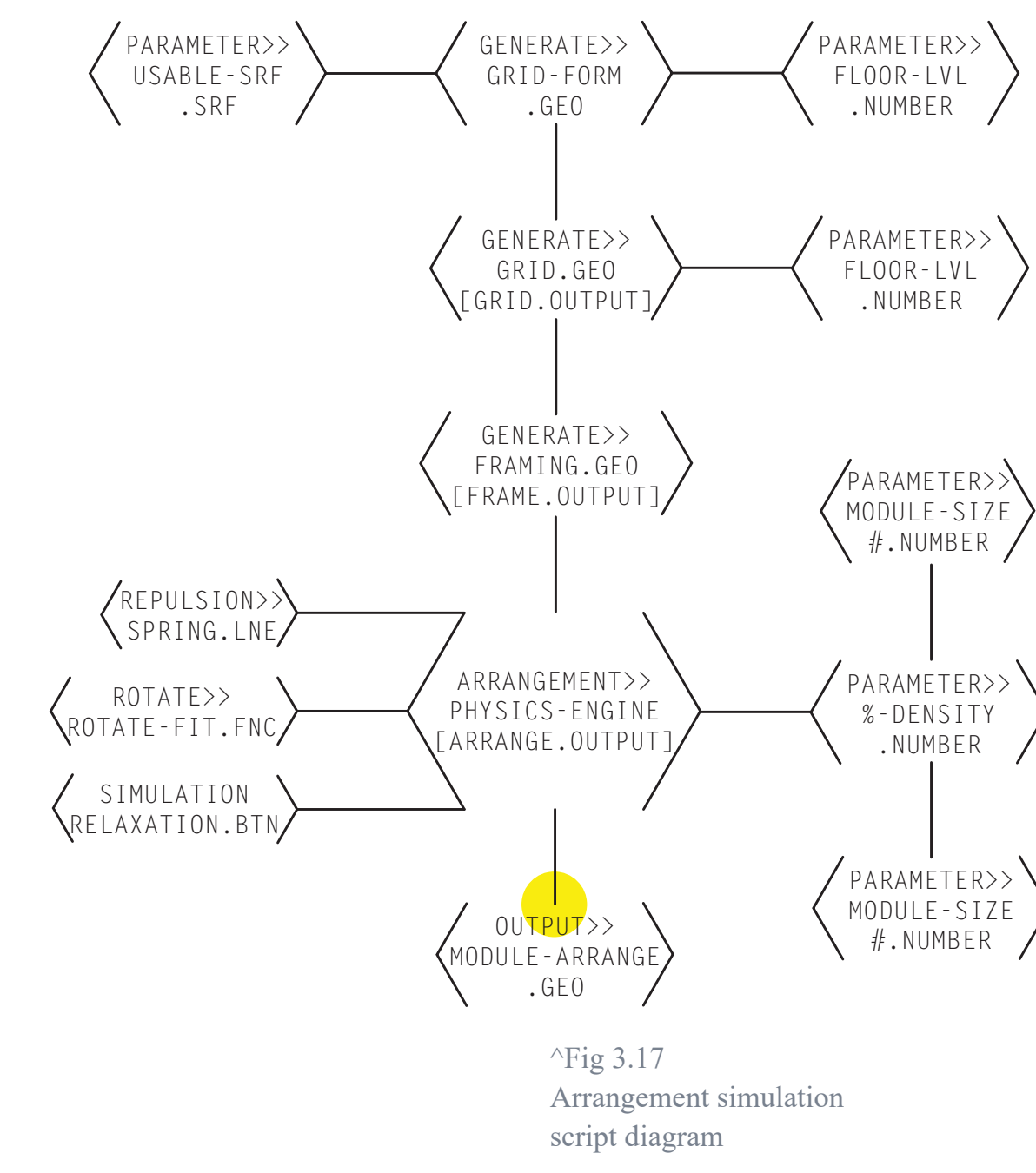

The approach to housing taken in this research is based on a form of hybrid metabolism using parametric design tools. This is prevalent through the integration of digital design technologies and the reflection of the Takara Beautilion exhibition through the framing system. Arrangement simulations are carried out to test the capability of such tools and differing ways of utilizing the system to simulate climactic, social and cultural conditions present in a multi-generational development. Shown through figure 3.14 is the diagrammatic example of the physics simulation developed through Grasshopper 3d and 'kangaroo 2'. These visual scripting tools allows us to quantify complex social and cultural entities and results in a more responsive arrangement system.
The major challenges in developing this system are in the formulas used to quantify the social and geographical information. Whereby the arrangement of housing clusters relies on a number of complex spring connections alongside the testing of different 'rest lengths', malleability and configuration within the set grid.

Simulation are carried out for testing general random arrangements, where the program relaxes a set of springs tying all entities together and rotates the rectangular boxes throughout the bounding box. Firstly the program is set to move the boxes about the space while keeping pathways between the spaces. What this test measures is the programs ability to simulate varying levels of density and module sizes within a defined grid. In the later stages this system is influenced directly by the parameters set through the information input phase (see section 3.2).

This simulation sets the basis for the final arrangement matrix and illustrates the parametric design tools being used. By using these simple rules of arrangement throughout the process we are able to simulate more complex connections through the integration of multiple parameters.
Arrange.1

Density//20/10/05

mix

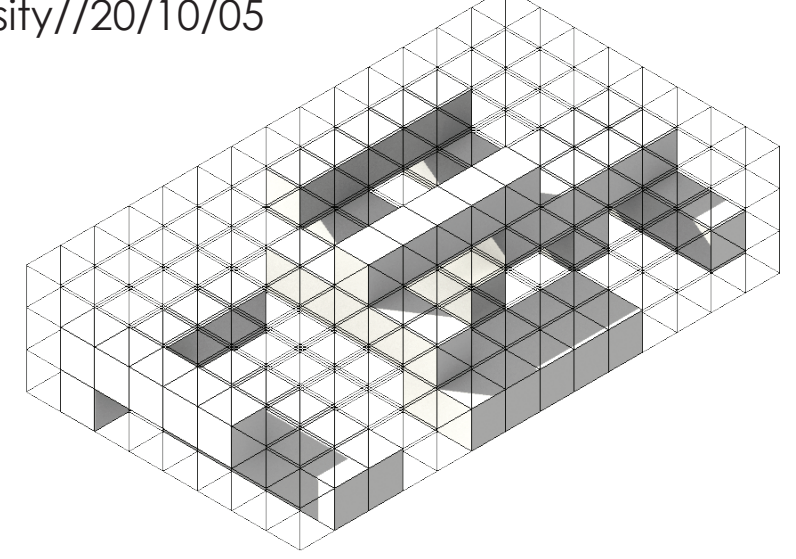

Arrange. 2

Density//40/20/10

mix

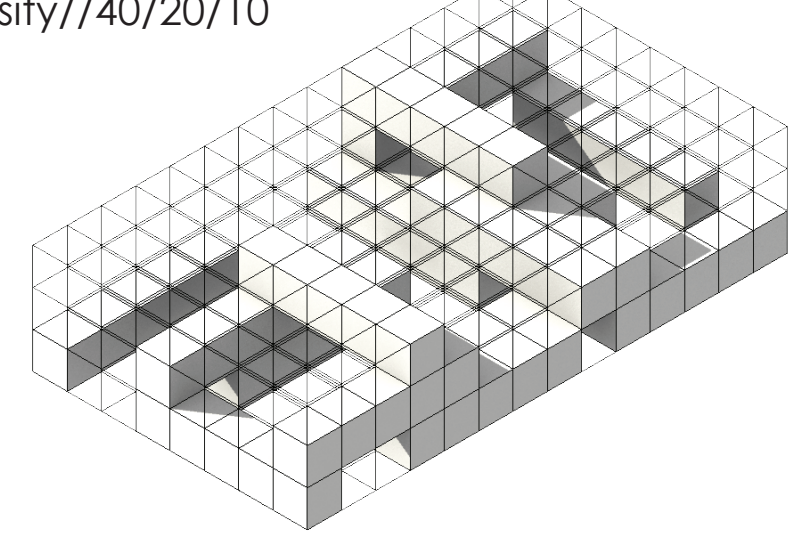

Arrange.3

Density//60/30/20

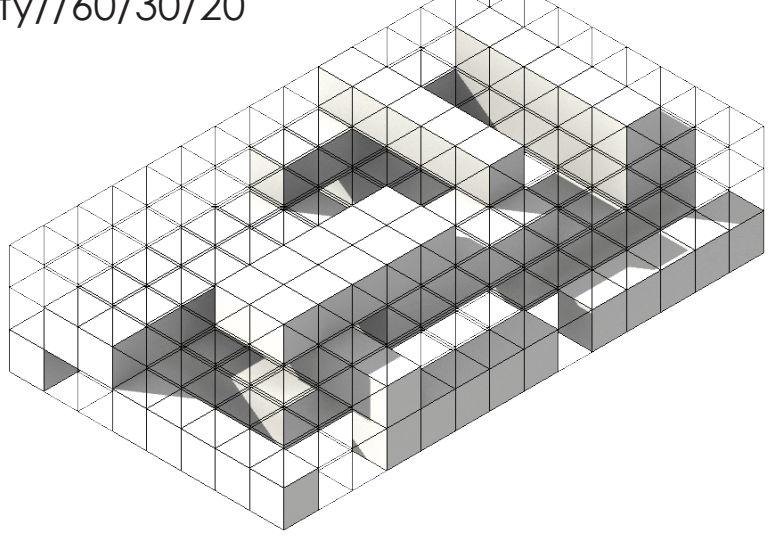

Arrange.4

Density//70/40/30

mix

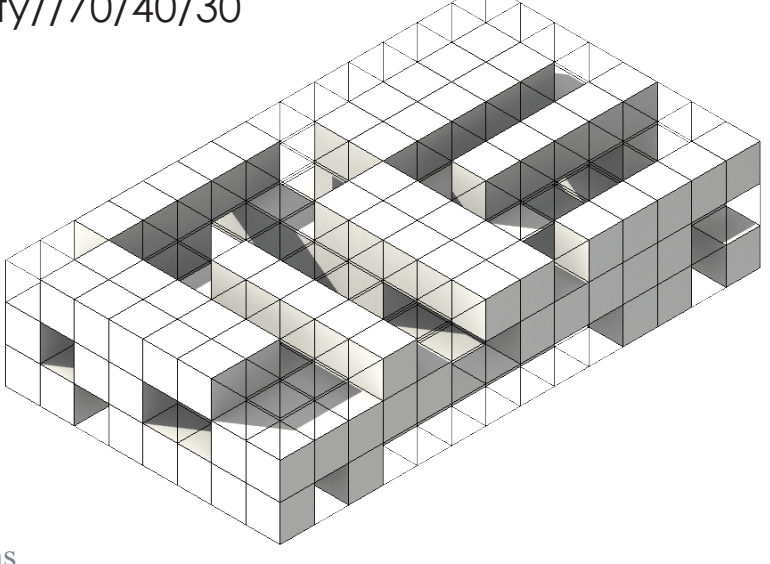



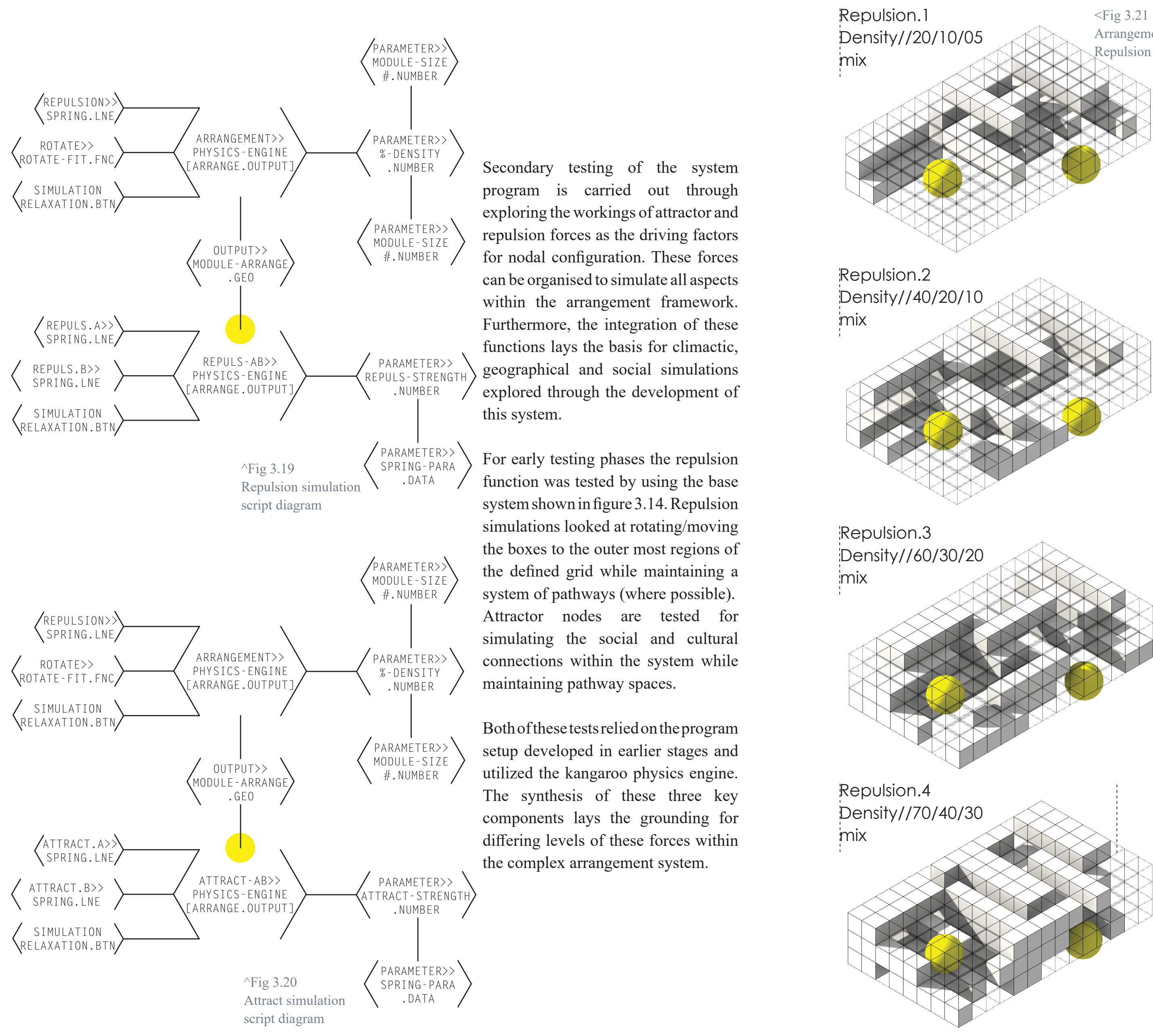

Repulsion.2

Density//40/20/10

mix

S

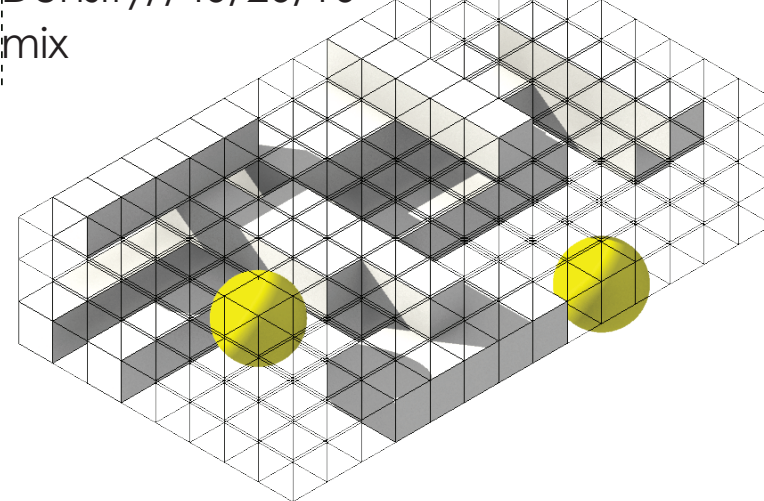

Repulsion.3

Density//60/30/20

mix

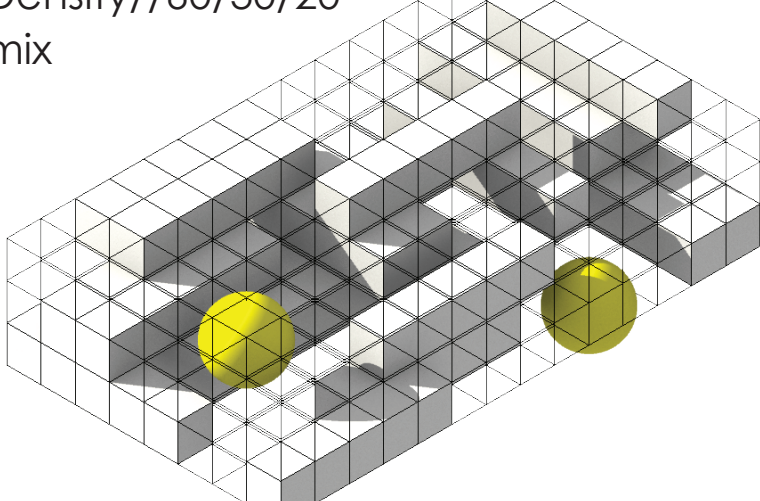

Repulsion.4

Density//70/40/30

mix
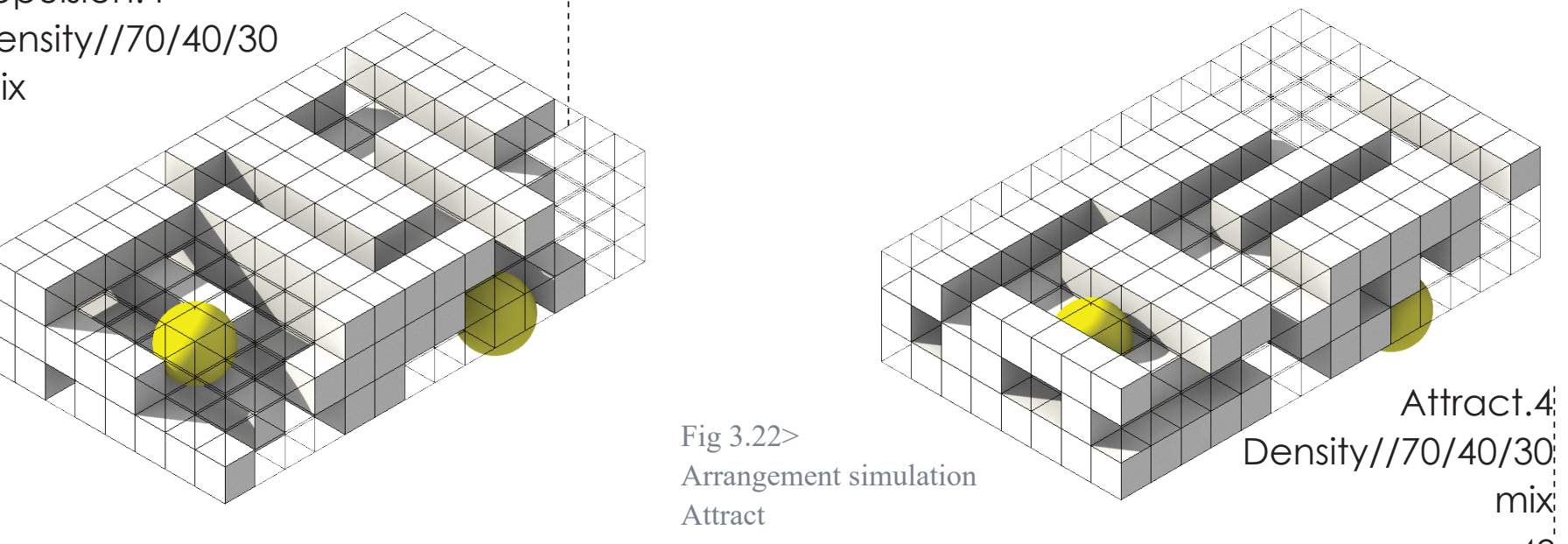

A common issue in integrating parametricism and housing systems is the lack of current construction implications. What this thesis tests is the crossover of modular housing systems and parametric simulation to increase social connectivity and diversity throughout. The construction assembly begins with the arrangement of an optimized grid formation that is dictated through geographical massing simulations described in section 3.3. Whereby the grid is generated about the usable space simulation, this in turn articulates the zoning of the housing development. The grid structure provides the scaffolding for the integrated arrangement through force based simulations. The structure itself acts as the modulation parameter the starting point for structural integration. For these simulations a structure of square hollow core steel $(120 \times 120 \mathrm{~mm})$. The grid is based on the parameters of a shipping container dimensions; $2438.4 \times 2438.4 \mathrm{~mm}$ as a 12 metre shipping container is $2438.4 \mathrm{~mm}$ wide and $12,192 \mathrm{~mm}$ in length. The modules primarily use the 12 metre container as it offers the greatest cost per square metre, whereas the 6 metre container is used primarily for add-on housing needs and services localization.

One of the major challenges when working with container architecture is detailing the construction in a way that allows for maximum interior floor space. To accomplish the seamless integration of the housing modules, a series of modules are designed to accommodate most living situations. This stemmed from a social profiling database described in section 3.2 and changes on a case-by-case situation. The modules are created with built in adaptability, whereby the orientation and social data diversifies the module set.

Secondary to the module arrangement is the treatment of the surrounding surfaces. This is identified as a systematic approach to collaboration and space continuity throughout the system. Again this portion is driven through the social profiling data and the weather data analysis of the site and integrated modules. This section explores differing ways of representing ones cultural background while stimulating shared resources and changeable shading systems All physical components in the system are designed to fit within the parameters of the grid while acting in isolation so that each grouping of modules can be independent from the collective. 
Structural Envelope of the System

The formation of the grid as described in section 3.4 creates the scaffold for the module clusters. Based on the dimension of a shipping container, the grid formulates a regimented arrangement that amplifies the diversity of materials and forms within the $2.4 \times 2.4$ Metre spaces. The construction of the space frame is made from filleted square hollow core steel members and insertion six way joints.

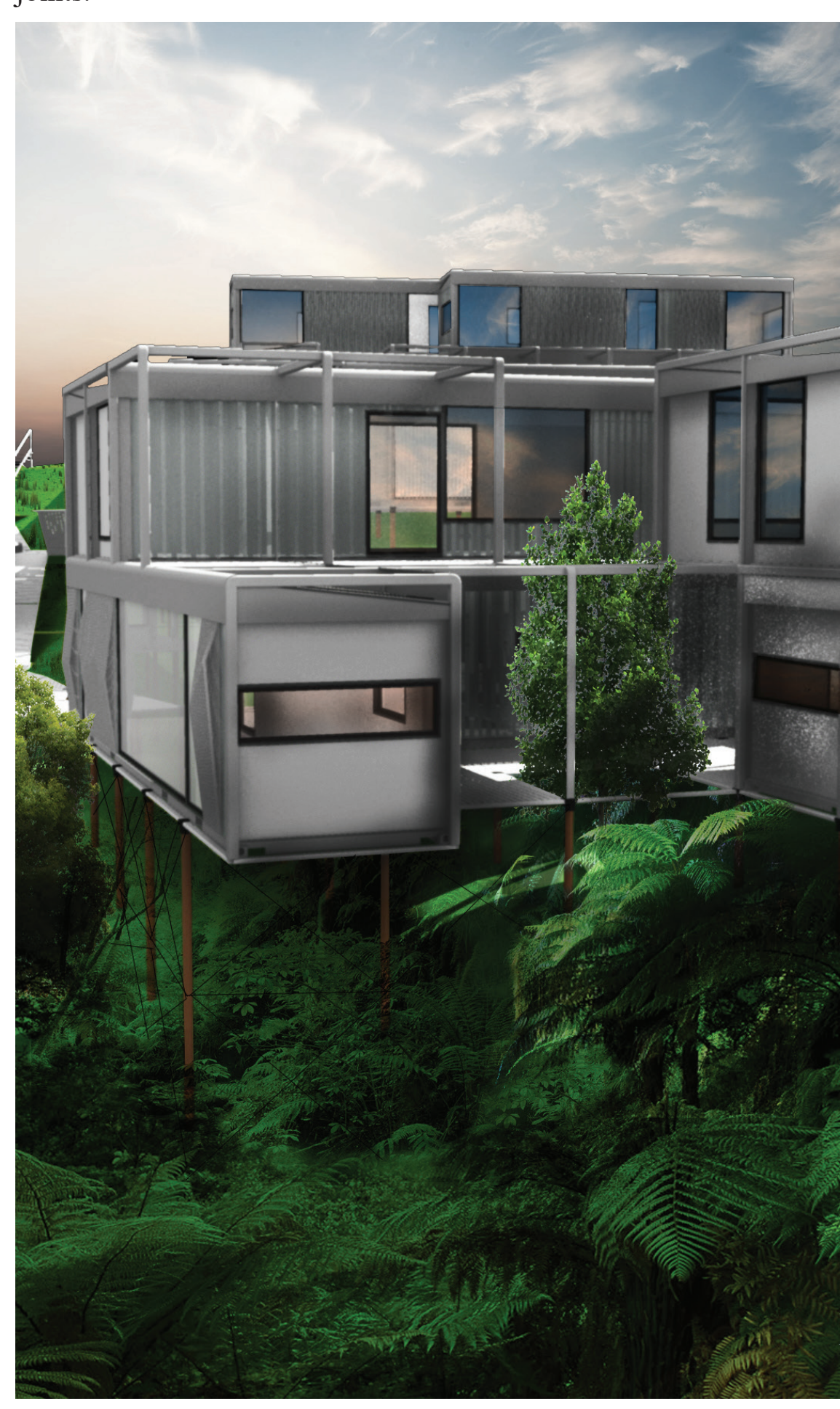

The grid setup stems from the geography mapping simulations described in section 3.3 an formulates the bounding spaces by which the arrangement simulation take place. The concept of the grid framing system is to allow for natural undergrowth in and around the modules, over time growing into a housing development that lodges the inhabitants in nature. This is utilized as a way of inducing topophilia (sense of place) and seek to positively influence peoples "subjective perception of their environment" (Najafi, 2011, p. 3)

The design of this system emphasises on the construction of an environmental psychology that links people back to their land. The undergrowth would also require the inhabitants to take care of their land as a collective whole, removing some of the antisocial behaviour induced by the privatization of communal living. Fig 4.03
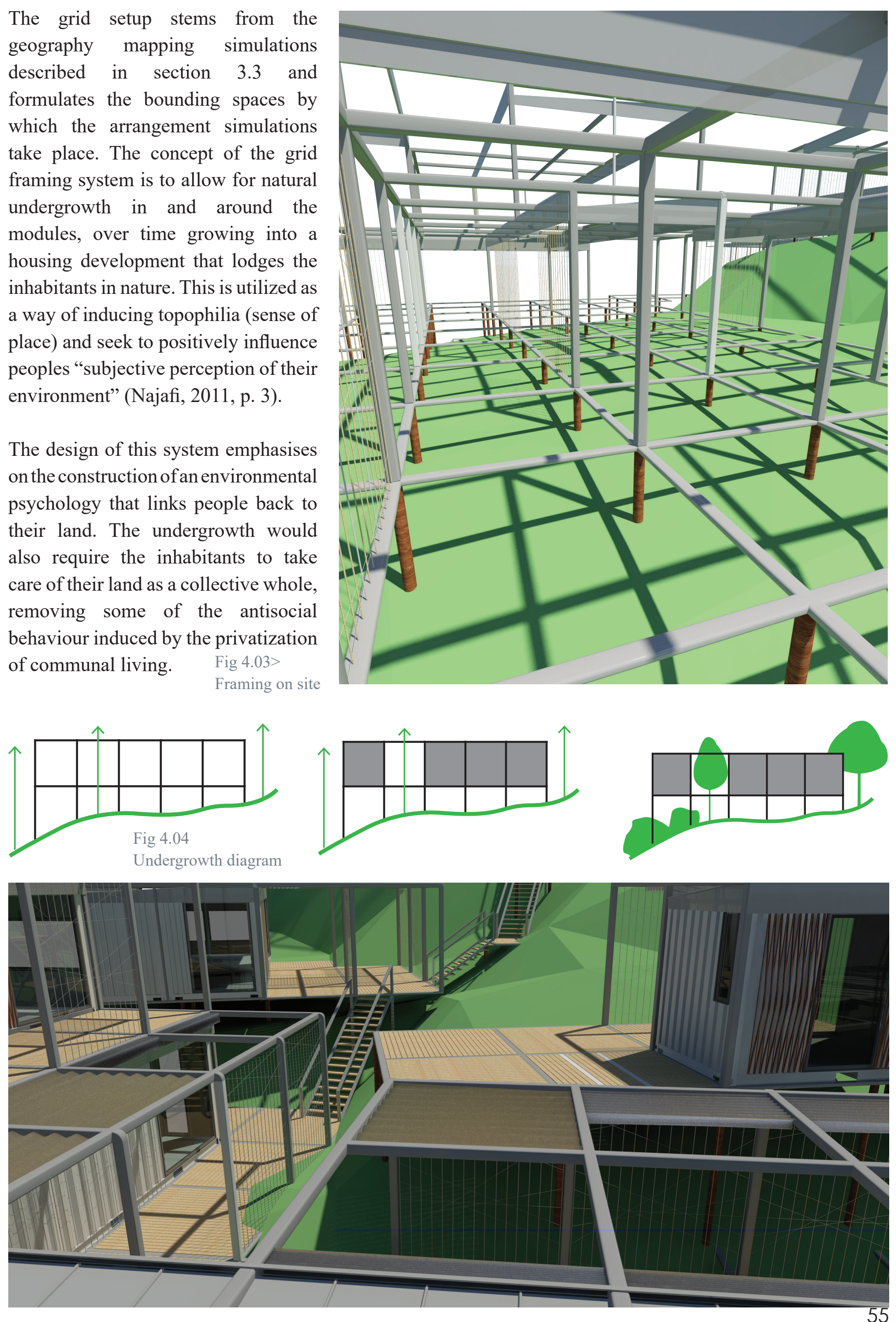


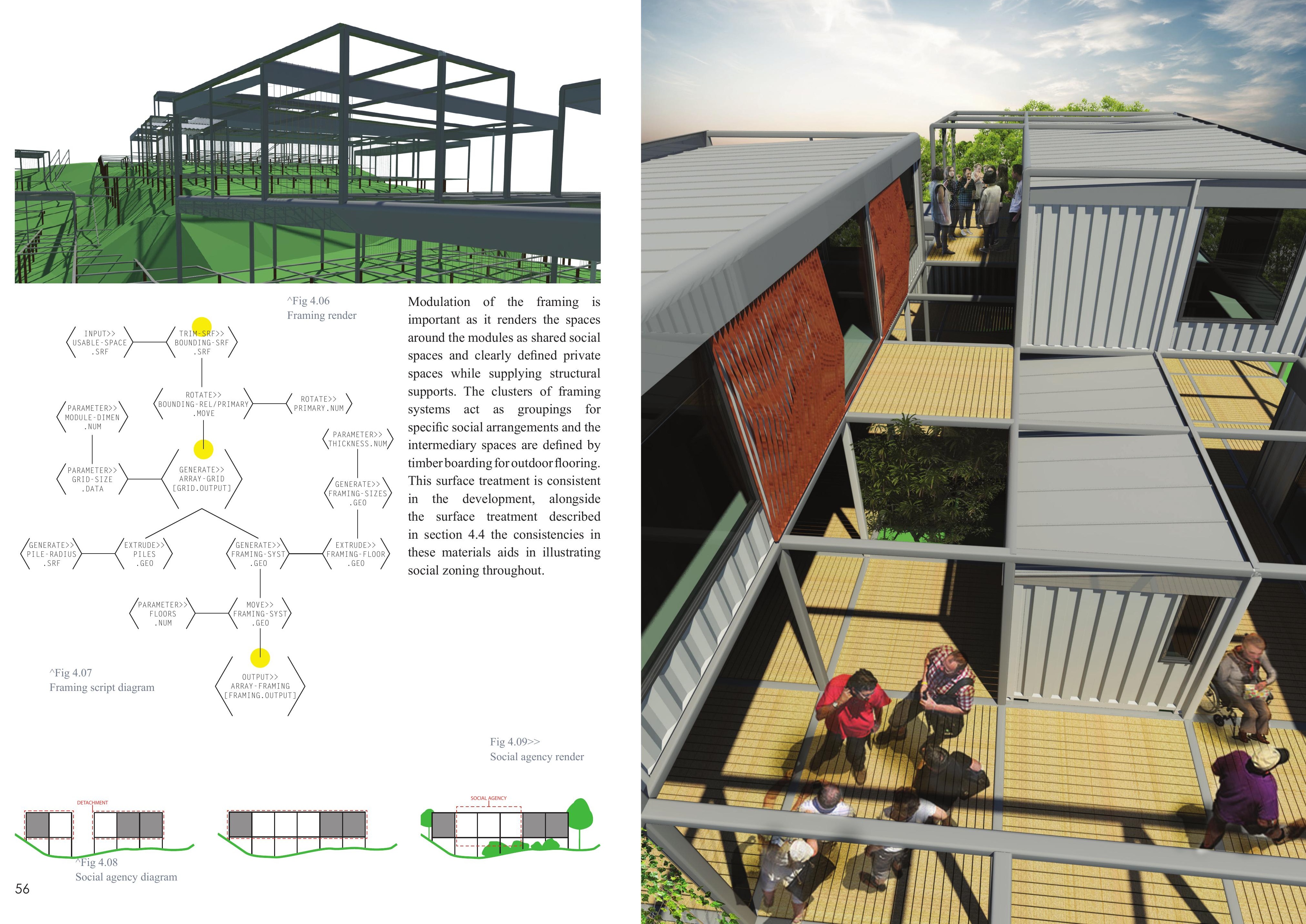



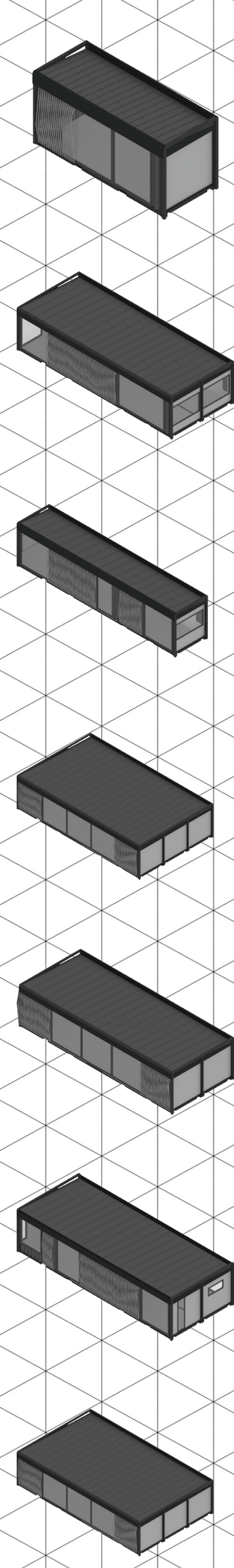
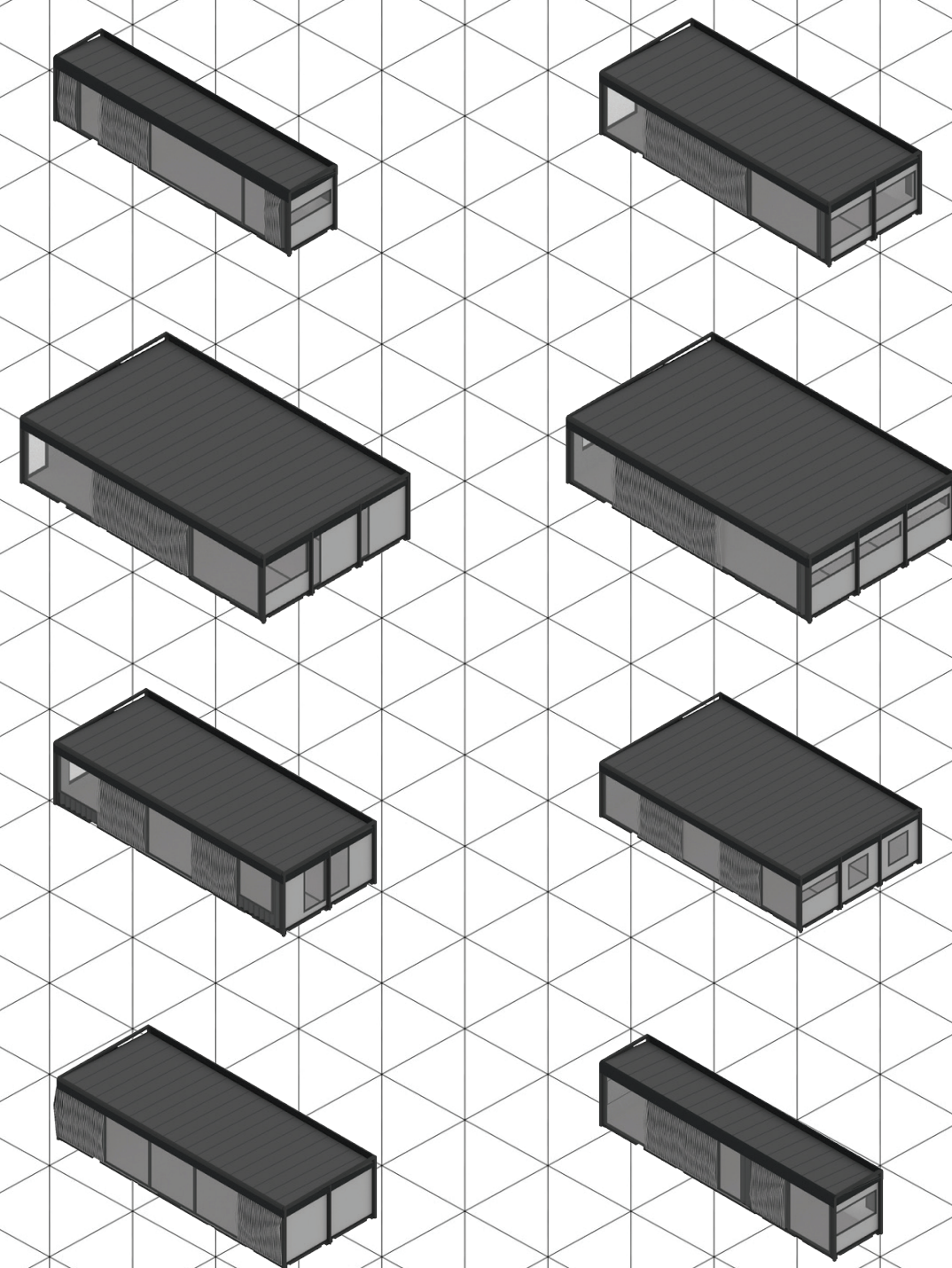

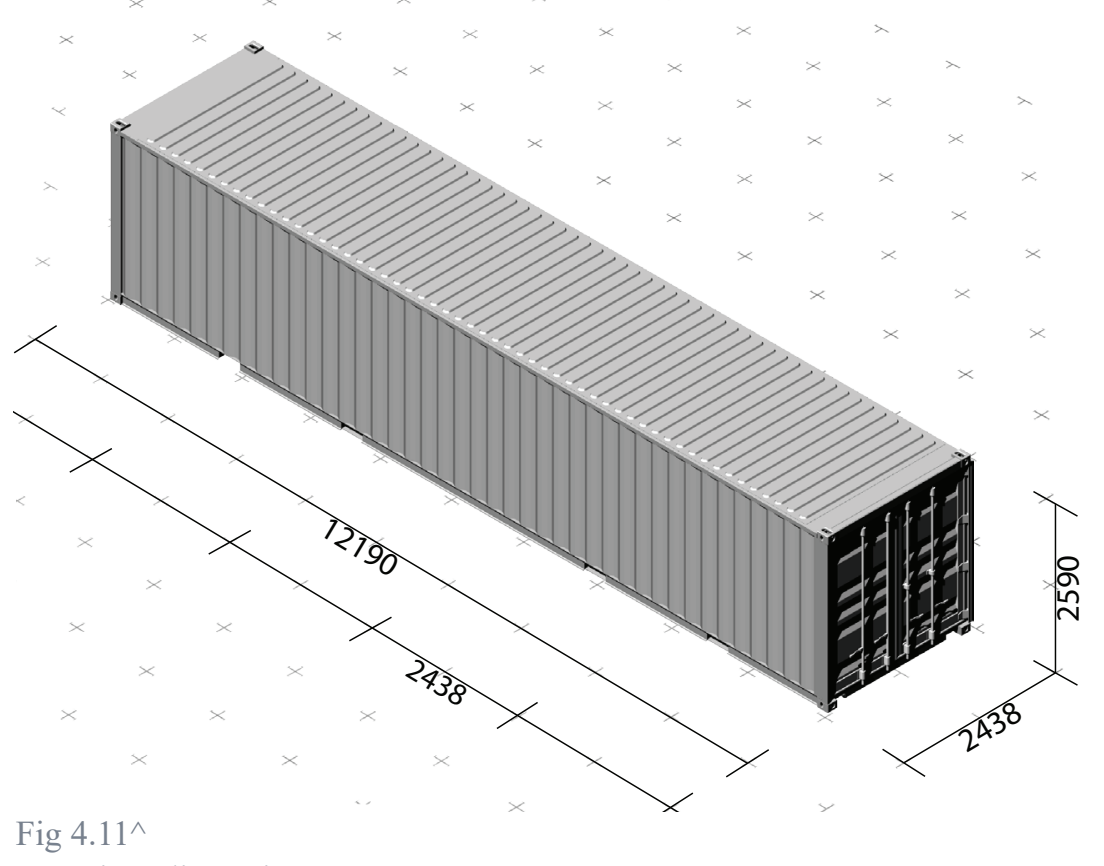

\section{Module Setup}

Collaborating Social, Cultural, Personal Information

The module units designed are an attempt to minimize the impact on the localized ecology by compressing the living spaces into the $2.4 \times 12$ modules. Living in smaller spaces changes the social dynamic of communities, what this seeks to accomplish is reduce the aspect of private ownership and encourage community housing that enforces aspects of safety and collaboration. The units are designed and arranged so that each module has its own aspects of privacy while adding to the social dynamics of the development.

In total there are 12 units designed, all with variations driven through the family questionnaire stage and post rationalization in following the arrangement matrix. Each module has an interior layout that seeks to compress the living quarters while allowing for ample space for expansion.

The glazing percentage of the homes follows a $50-65 \%$ South, 20 $30 \%$ East/West and 0- 20\% South, for glazing coverage around each module. This follows the passive heating requirements set out by the 'Branz: Passive solar Design Fact Sheet' (BRANZ, 2014). The modules are defined by their functions, the basic modules are illustrated as 1BM (one bedroom, medium), 2BL (two bedroom, large) etc. and this labelling format follows along with the systematic approach to arrangement and configuration. 


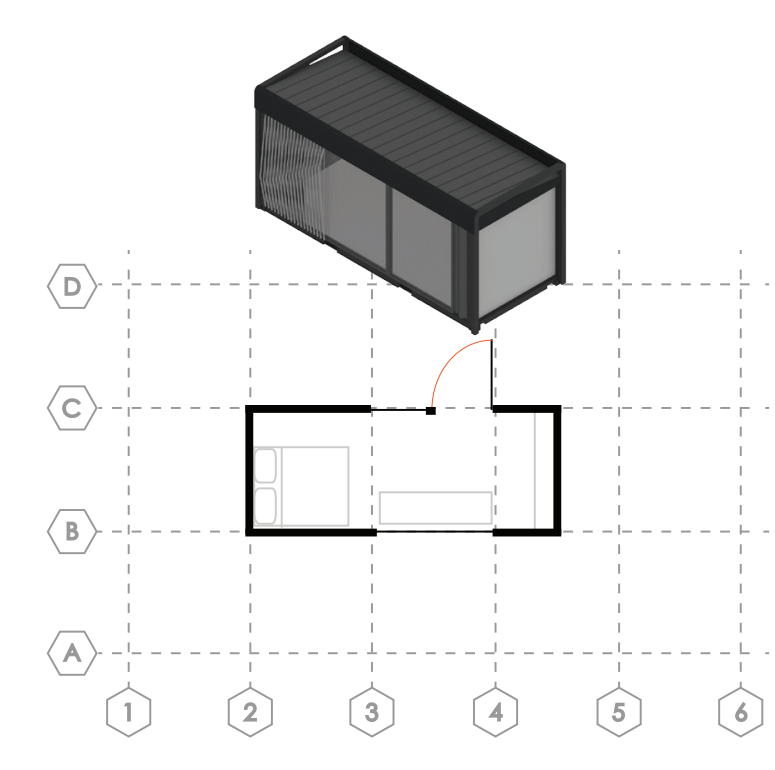

${ }^{\wedge}$ Fig 4.12
1BXS

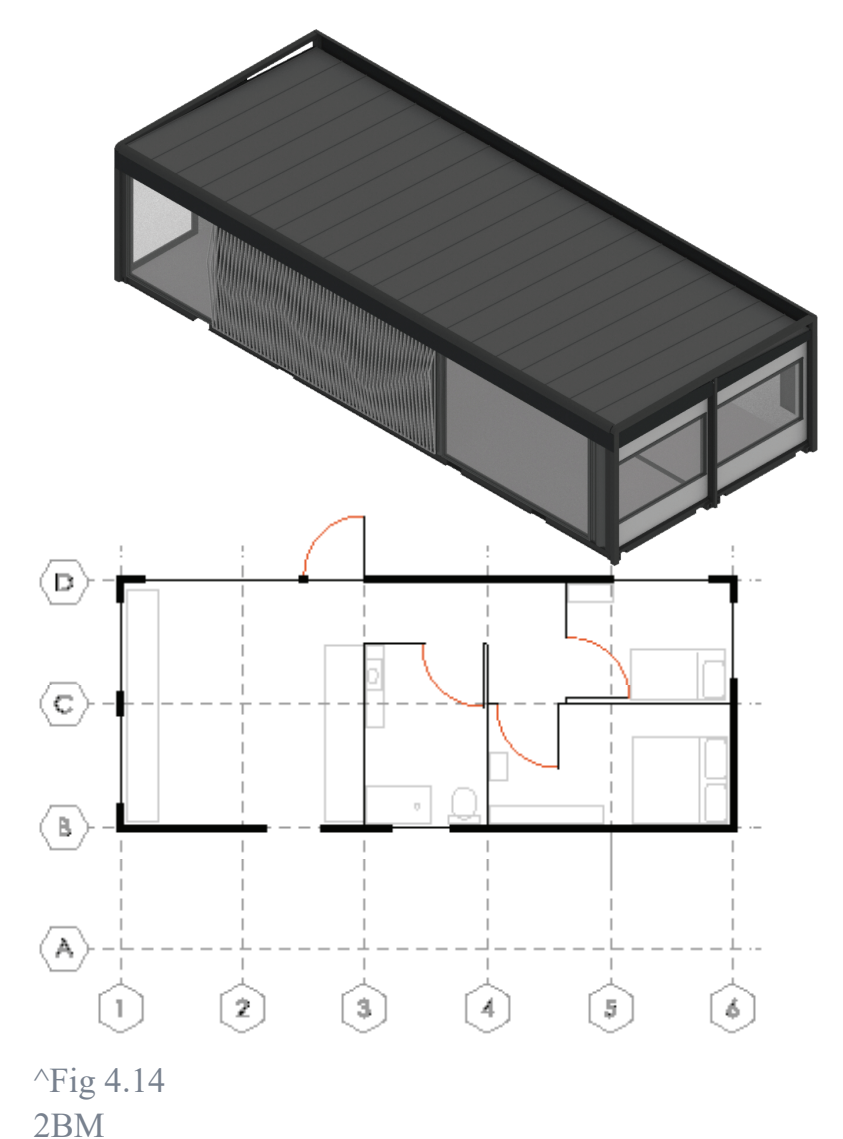

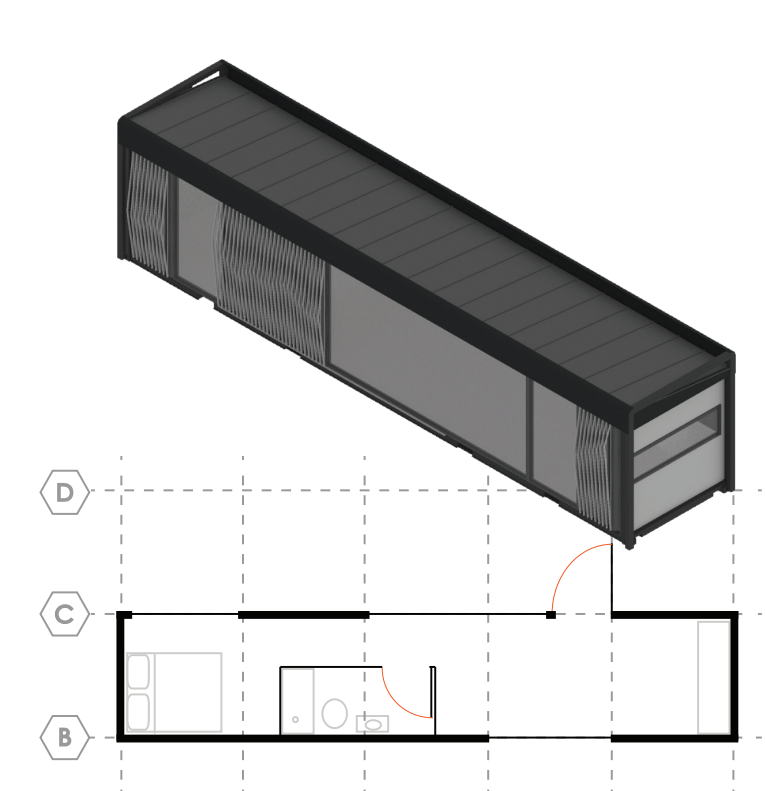

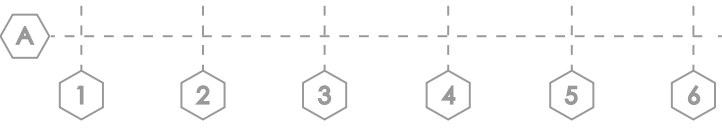

$\wedge$ Fig 4.13
1BS

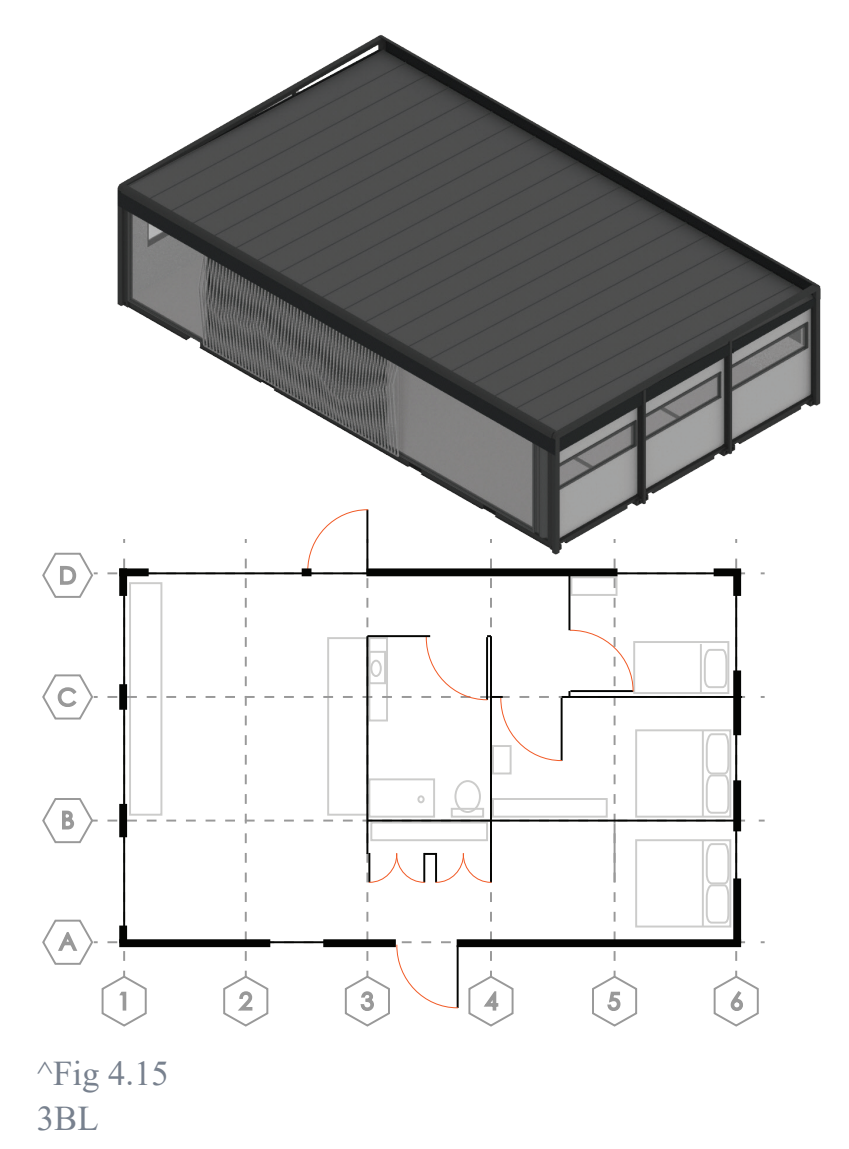

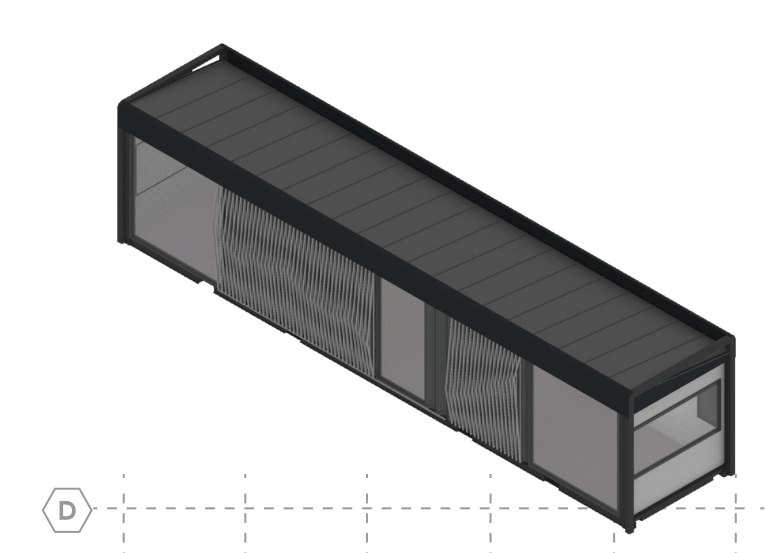
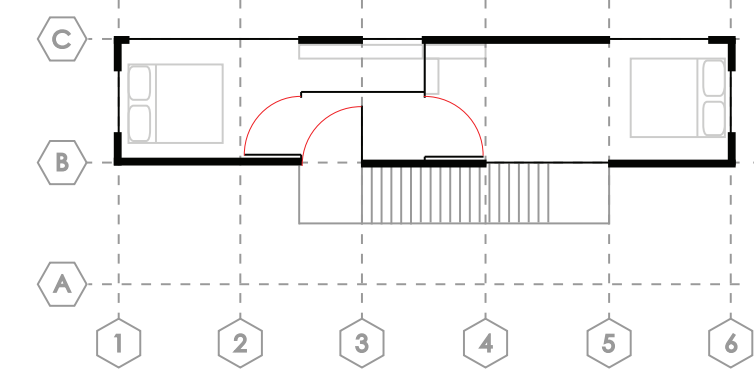

${ }^{\wedge}$ Fig 4.16
SBS
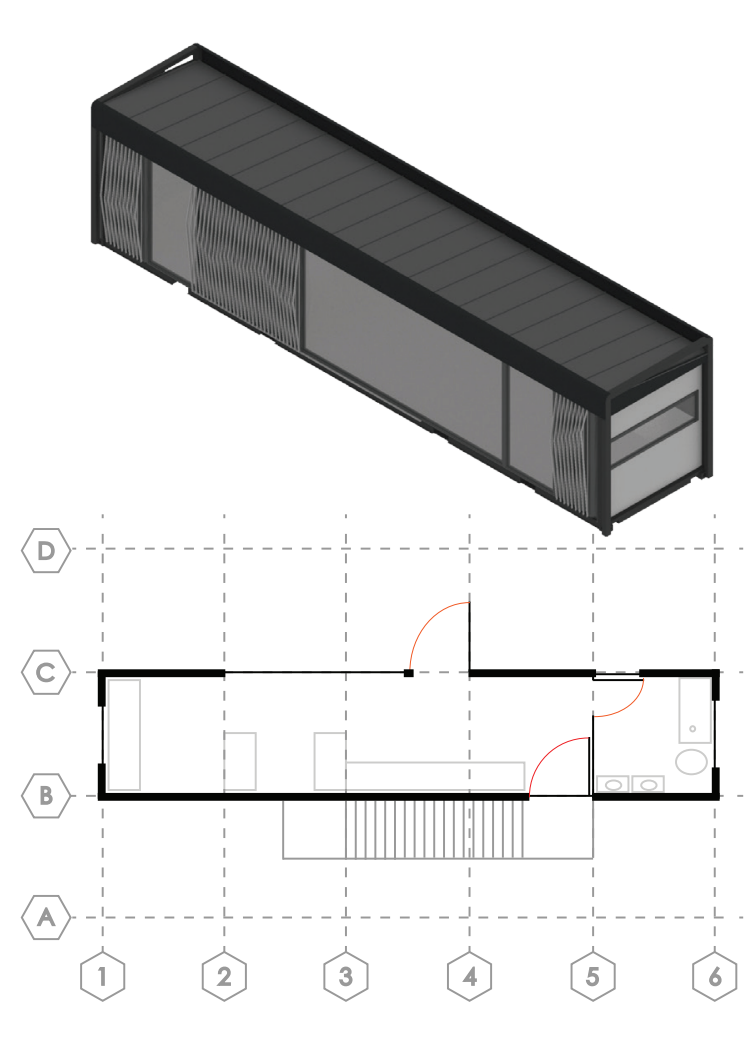

${ }^{\wedge} \mathrm{Fig} 4.18$
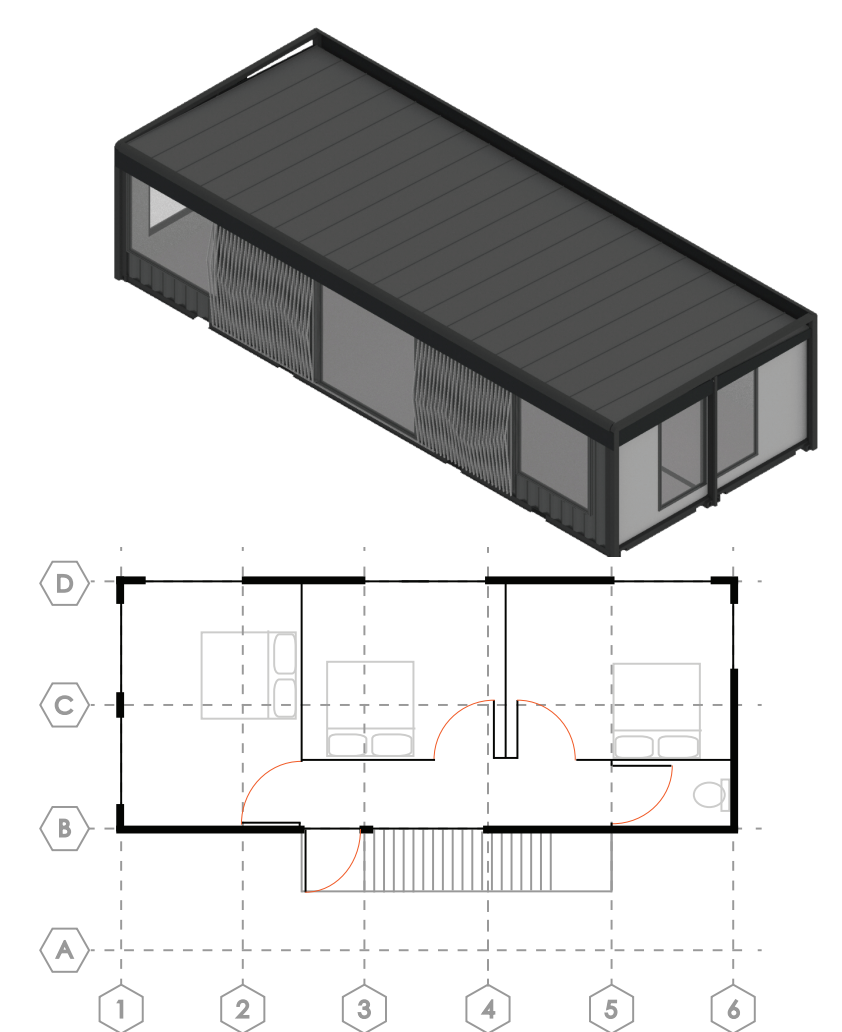

^Fig 4.17
SBM

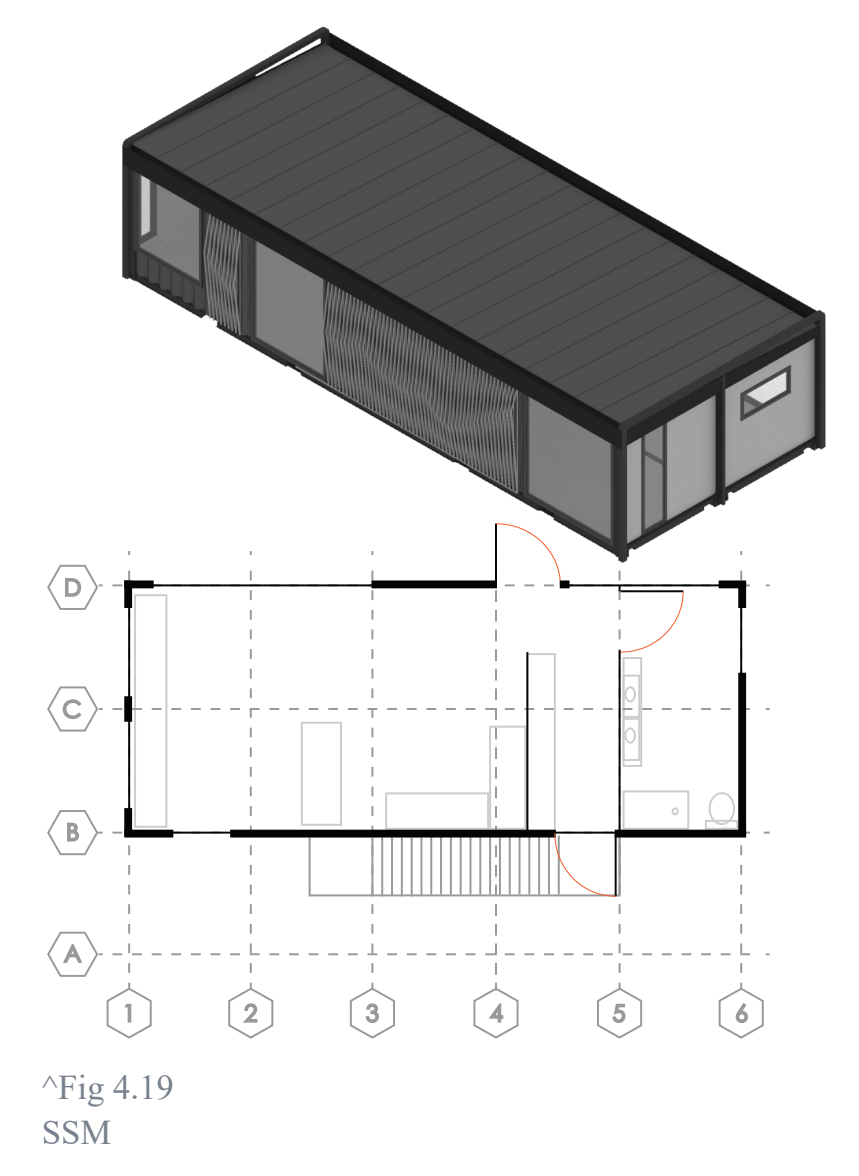




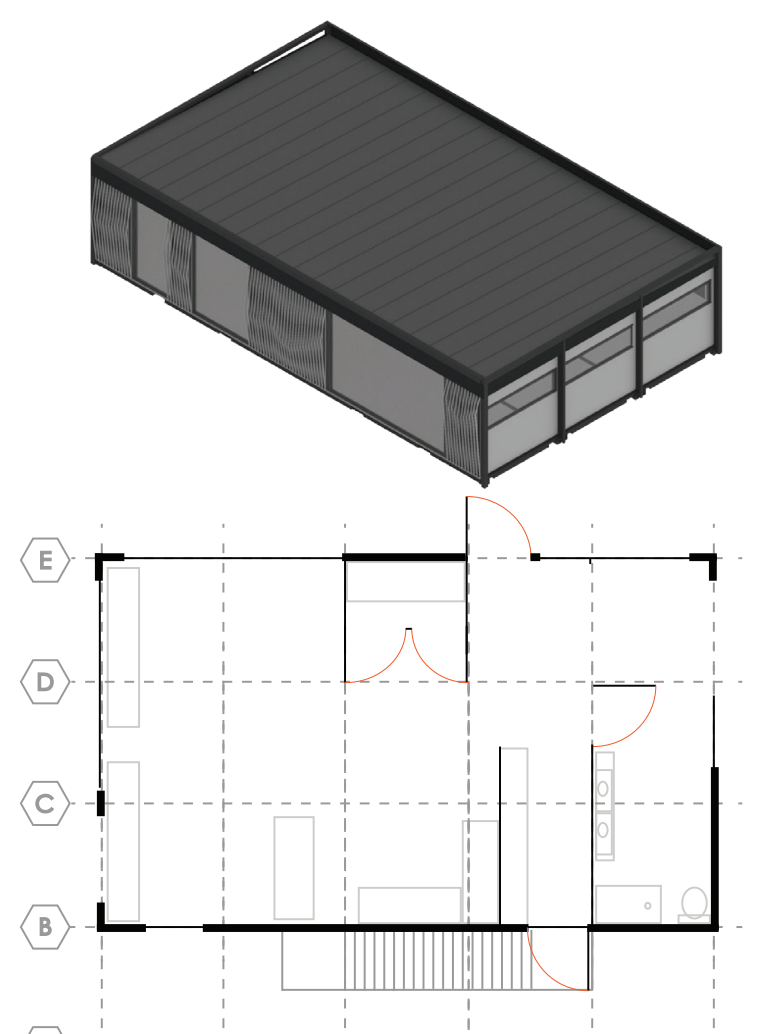

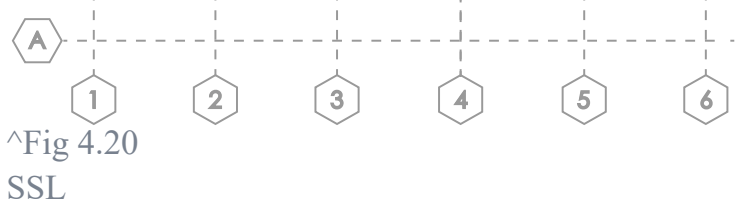

$$
\begin{aligned}
& \wedge \text { Fig } 4.20 \\
& \text { SSL }
\end{aligned}
$$

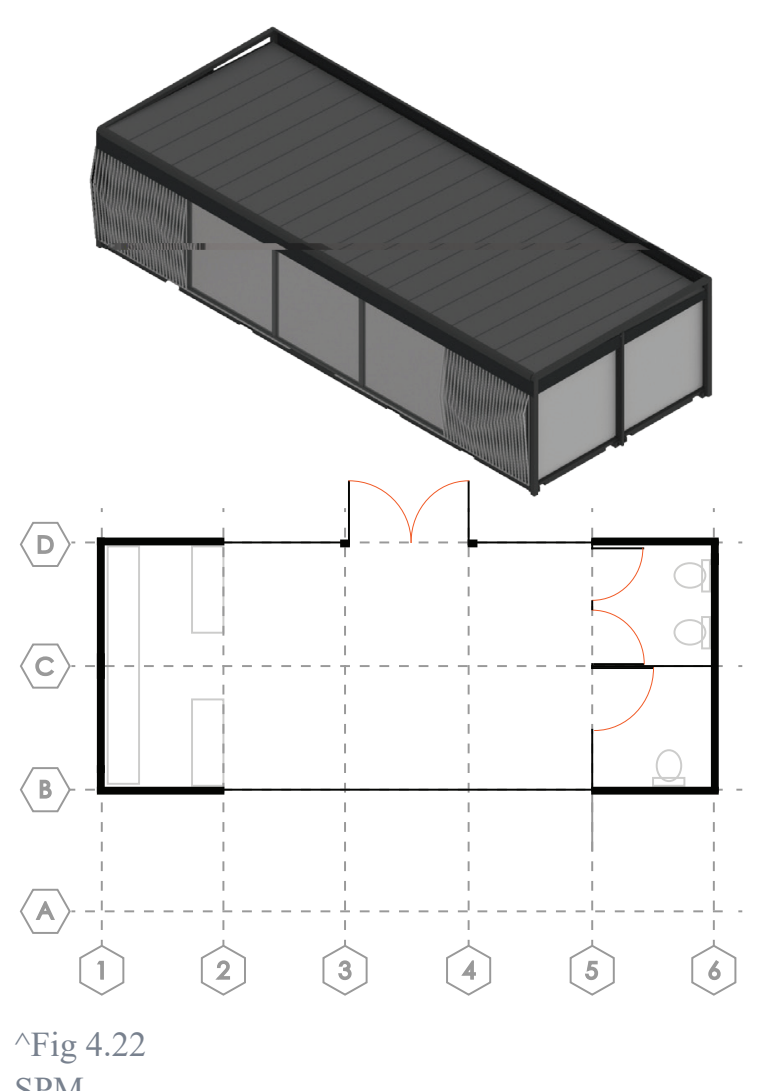

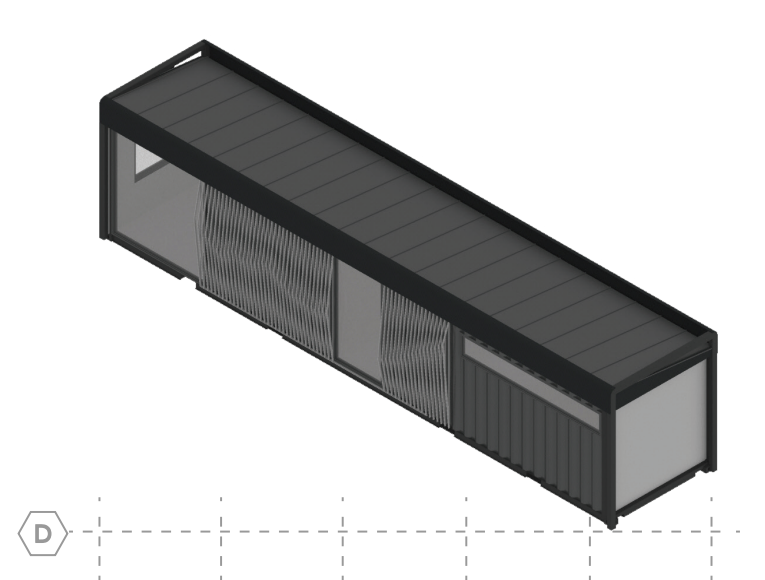
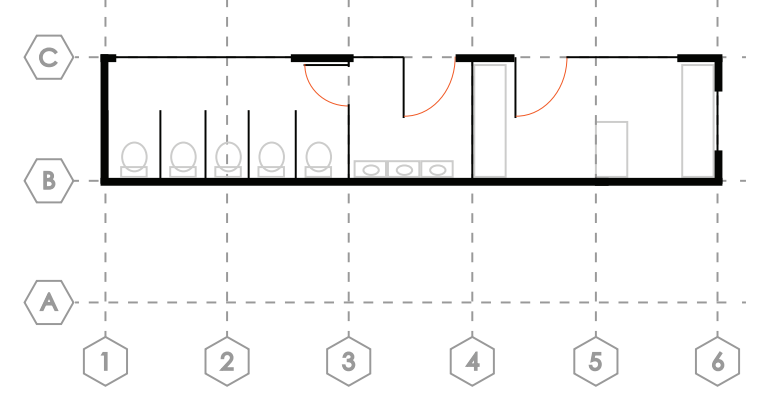

${ }^{\wedge}$ Fig 4.21

SPS

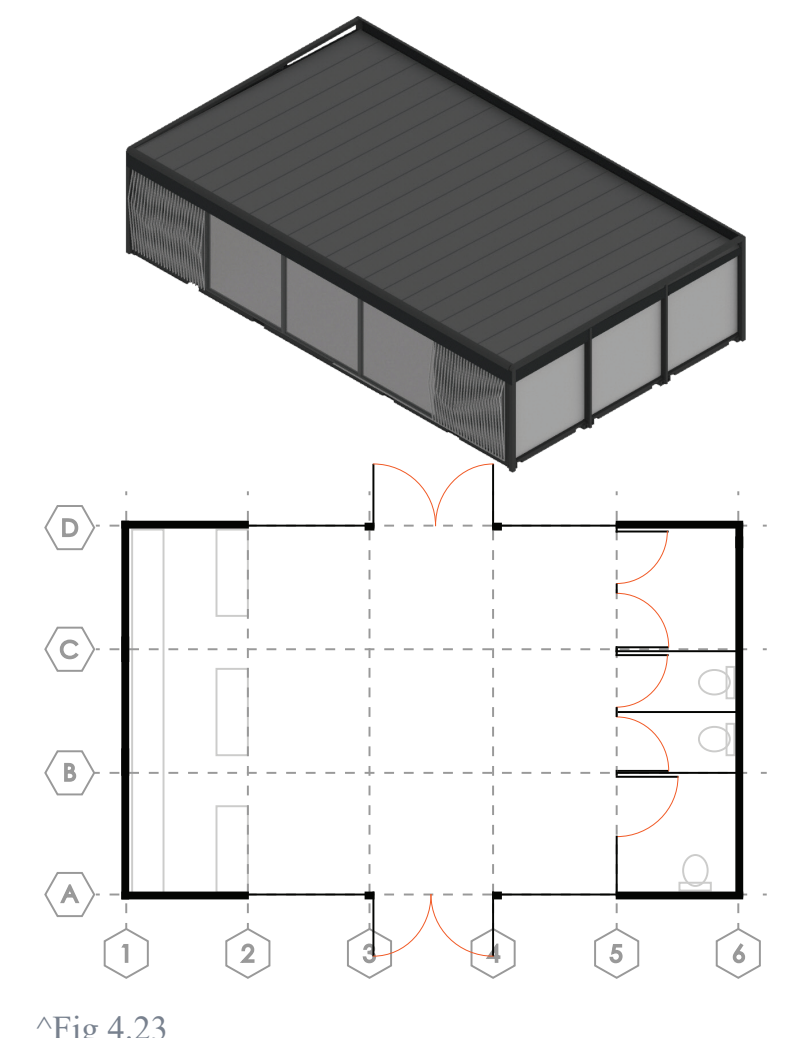

Fig 4.23
- Steel framing, roofing system, gutter, solar panel runners, upper exterior lining

\section{- Plywood timber fitout, built in} furniture

- 80mm insulation lining with reflective backing, timber stud lining

- Core-ten steel perforations, weld plate steel around perforation, aluminium window mullions, double glazed glass

- Framing platform, Timber board $40 \times 85 \mathrm{~mm}$ depth, joint connection to piles

- H3 treated piles to grounding surface
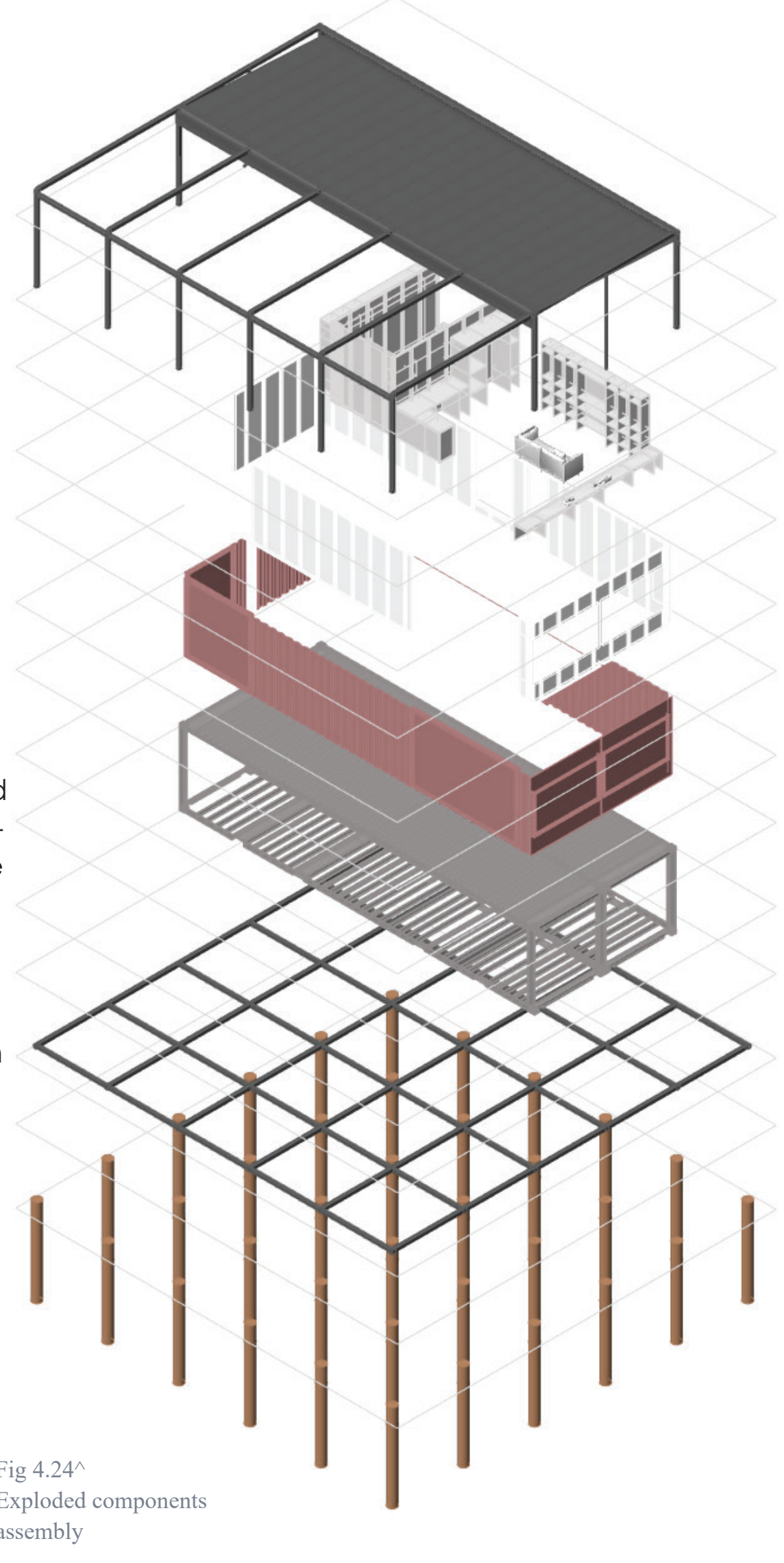

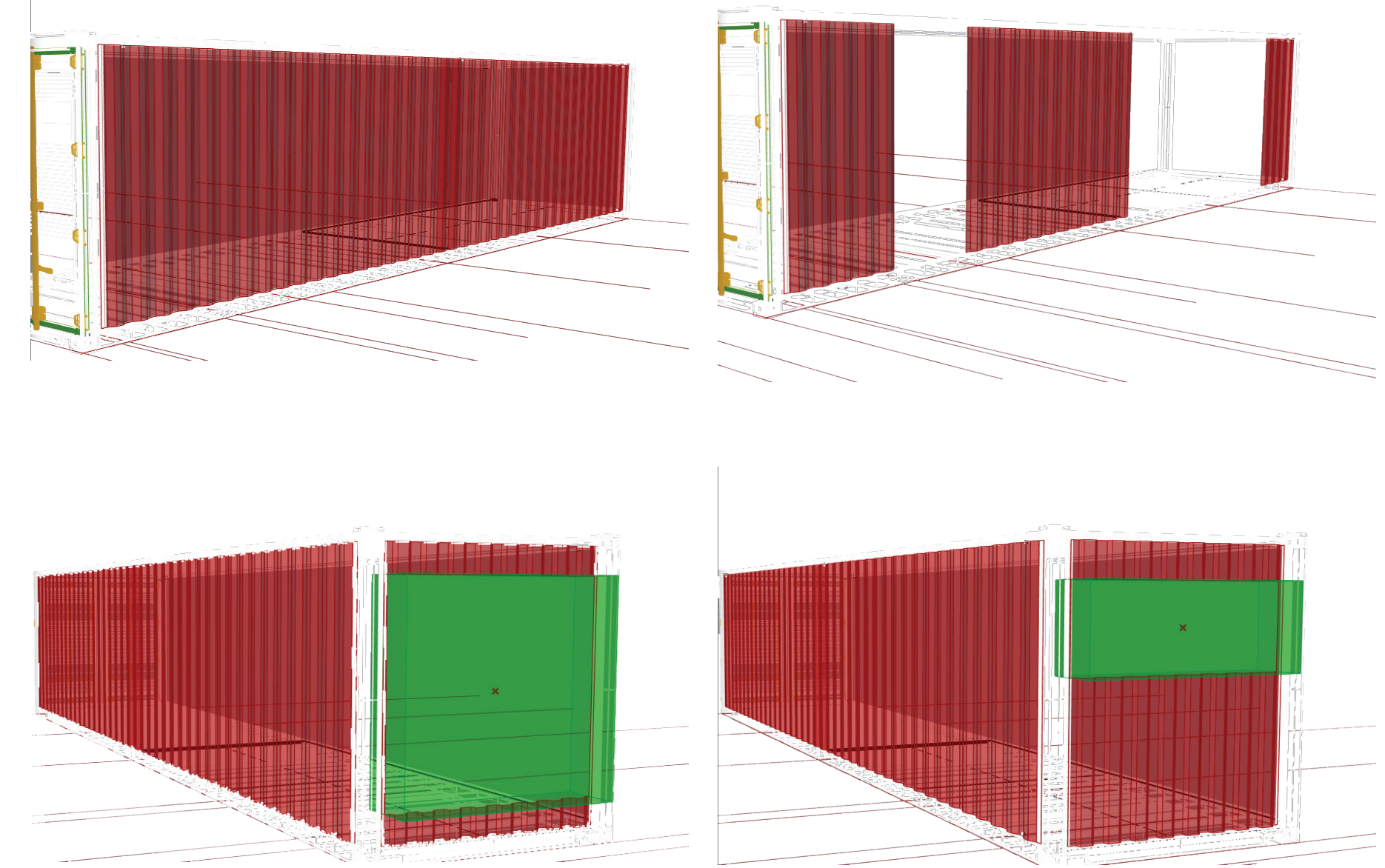

$\wedge^{\wedge}$ Fig 4.25

Module perforation exploration

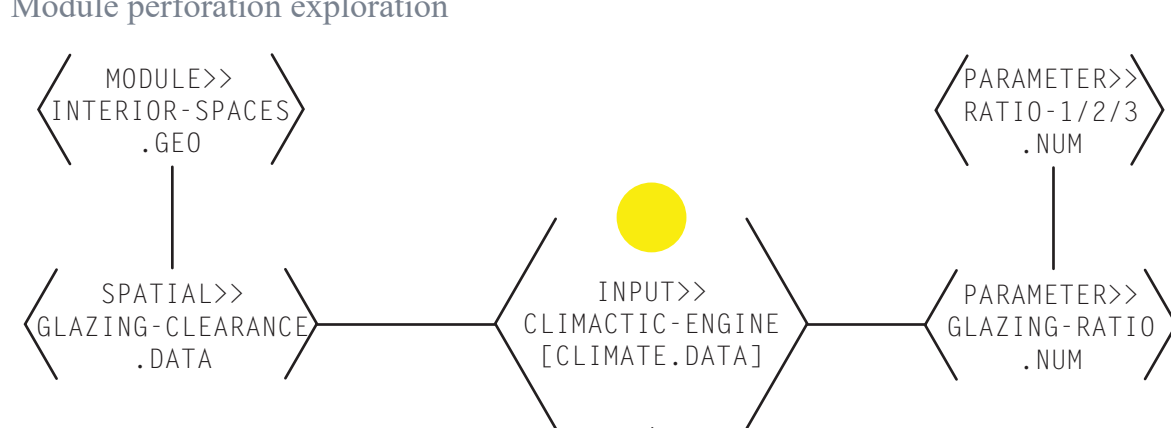

The construction of the modules begins with stripping the containe of interior floor linings as these often contain harmful chemicals. Secondly the door and window sections are cut individually to size, as specified through the glazing script. This script is integrates weather and shading data and generates sizing for all perforations about the module.

$$
\text { (1) }
$$

The interior linings are The interior linings are dictated through the module choice and makes use of space saving systems such as built in furniture and multipurpose living spaces. The exterior is made up of a timber filter system that sits on rails to be easily moved. The filter componentry is sheathed by the upper coverings that wrap the structural framing and additional structure needed when cutting sections in the core-ten steel.
The overall design of the modules seeks to remove which disguises the joints and ultimately removes the the stigmatism of industrial steel and rough joints stigma of container housing. This technique makes from traditional shipping container housing. This is the raw core-ten steel walls appear to be a cladding as accomplished while attempting to use as little amount opposed to an industrial shipping material.

of additional exterior cladding as the core-ten steel is

designed to last years on harsh sea terrain.

The connections to the framing are made through an insertion joint that is specifically designed to

The design of the module is an attempt to minimize be removed for future alterations to modules or recosts while implementing a modern structuralist arrangement of the system. Designing for future style through exposed framing and lightweight steel adaptation allows the housing system to sit within structures. The capping around the top section of the the planning difficulty of papakāinga housing module is to hide the gutters and filter rail mechanisms, developments.

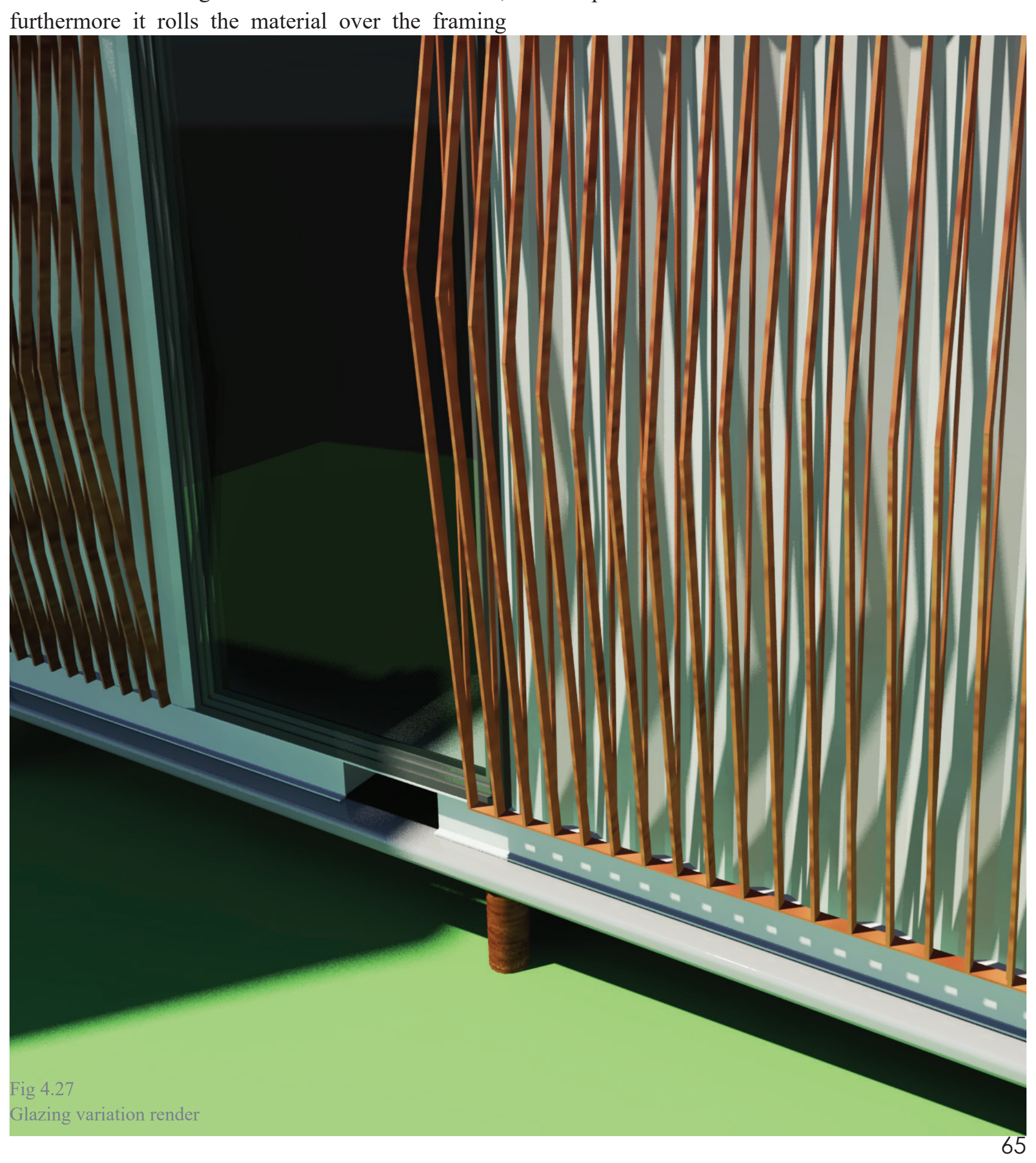




\section{4}

\section{Surface Treatment}

Timber shading, Living walls and cladding systems

The concept of diversity in materiality is enforced through the multitude of differing shading techniques and the integration of living wall systems. The surface treatment of the surrounding environment is dictated through the cluster specific needs and the customization of more intimate outdoor spaces. The concept of topophilia (relationship to the land) is introduced, both through the encouragement of undergrowth and the access to modulated living wall systems. The occupants have a constant link to culturally and ecologically specific environments through the surface treatments and appropriation of these elements eases new tenants into a new living arrangement.

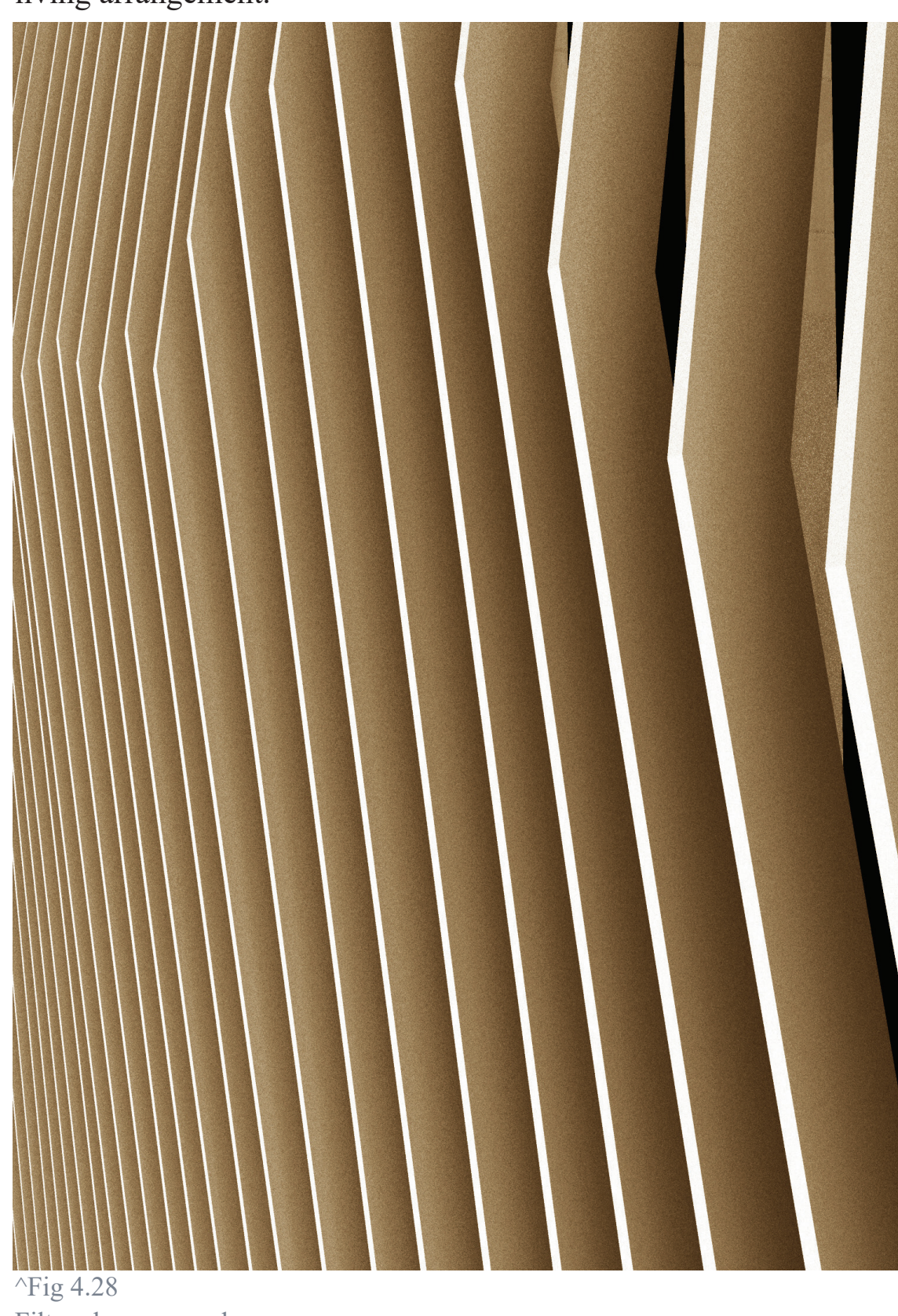

The filter rail system is implemented as another way of encouraging a 'sense of place' within the housing development through material alteration. The filters act as sun shading and a way of providing private zoning in the modules. The timber filters sit on steel runners which lie underneath the upper capping that wraps the framing and module. Using parametric design techniques and the input data of site specific silhouettes we are able to create a link to a family's home geography.

Accompanying the treatment of the timber filters and modules are the implementation of sun shading, vertical garden space and green living wall systems. The sun shading is generated on all exposed surfaces of the grid and allows for changeable shading options through the roller detailing of the shades. These shades can be changed through user interaction. The green living wall systems are used to cultivate social spaces within the complex. This is yet another attempt ${ }^{\wedge}$ Fig 4.29

to emphasis the link to the natural ecosystem and Filter scrpit diagram encourage family preservation of living systems.
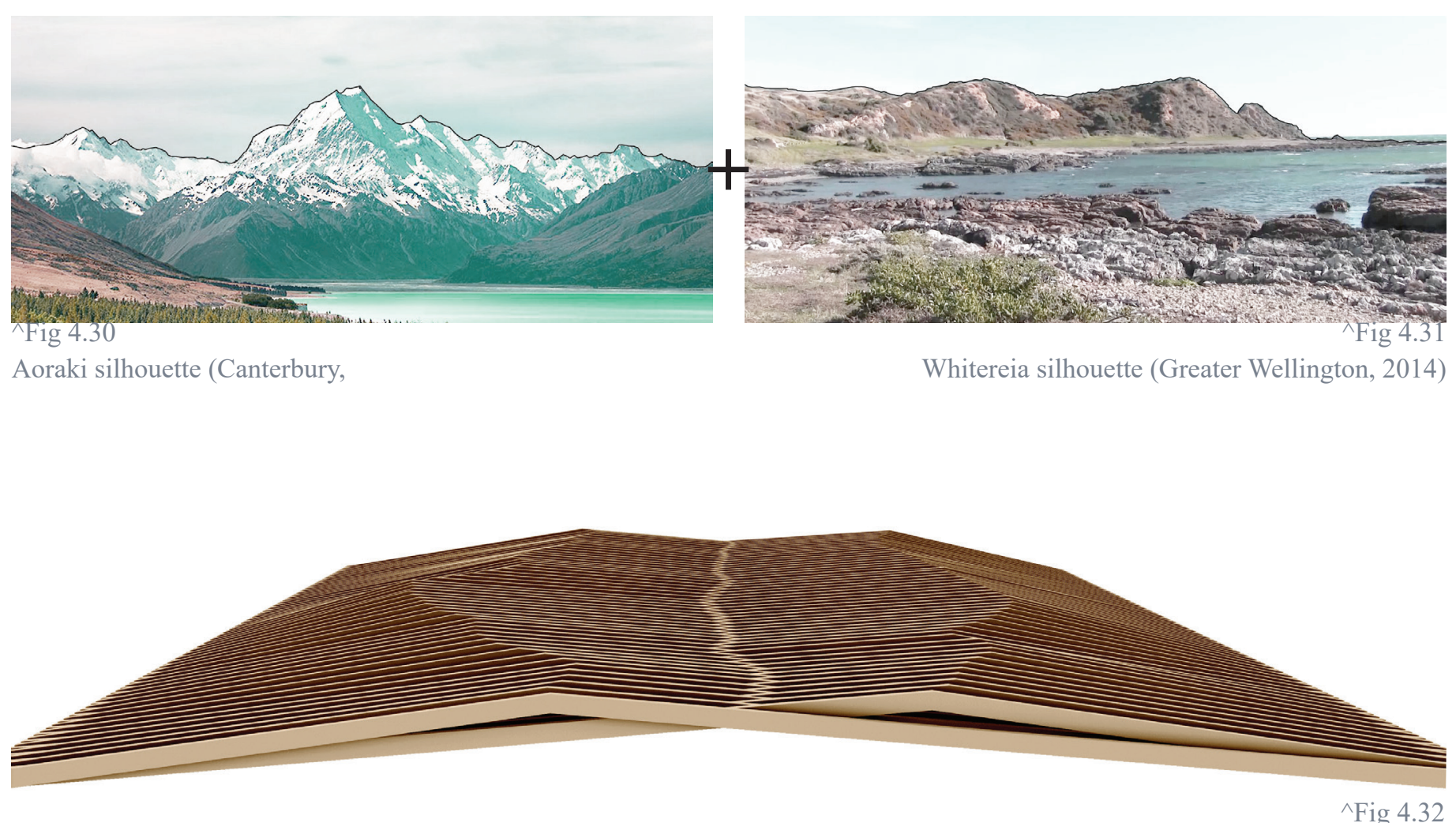


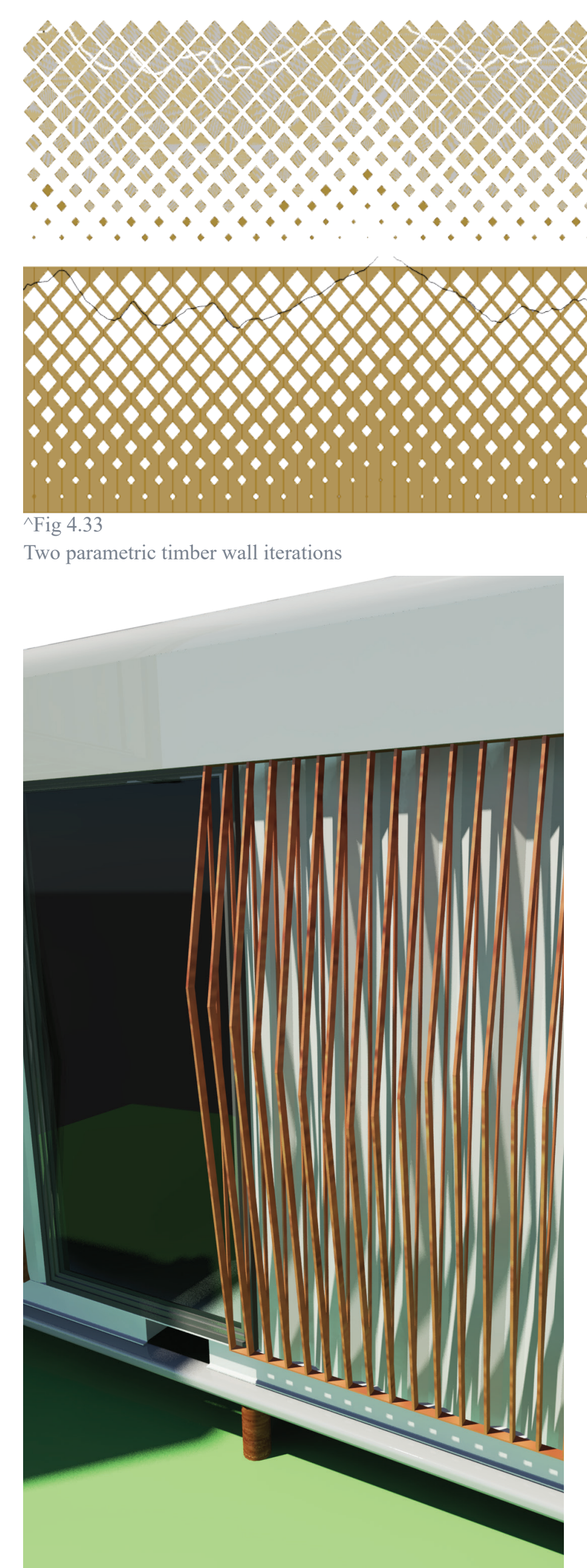

timber filter perforation of window

68

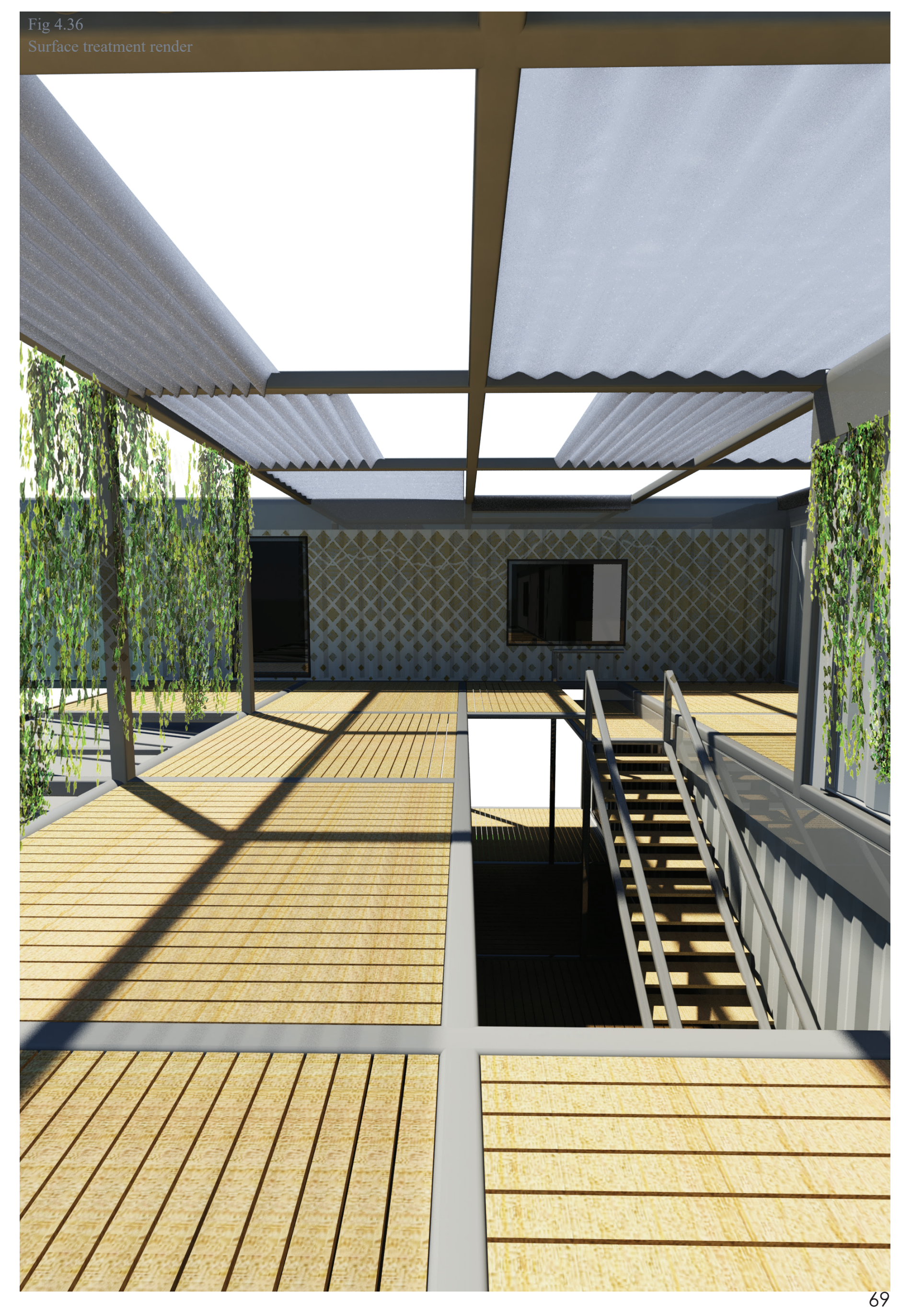




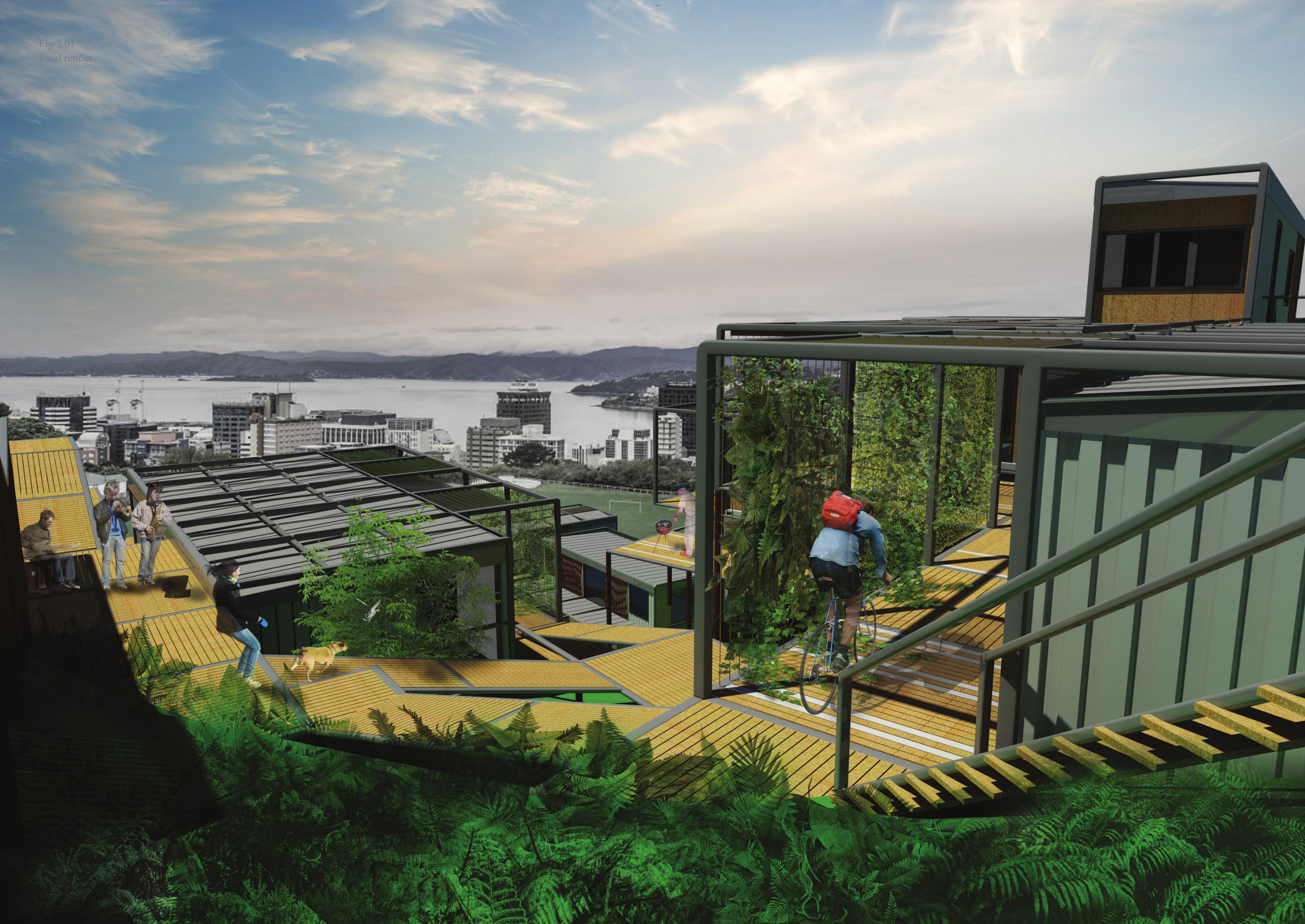






\section{Test Site}

Kellburn, Wellington Medium Density Housing

The chosen test site is located at 78-84 Salamanca rd Kelburn, Wellington. This site was chosen because it is geographically challenging and is an underutilized section of land. The site overlooks the city and has a strong South/West gradient of undulating surfaces. This research seeks to find alternatives to housing implementation and therefore does not follow the traditional design approach of conceptual development and master planning. This system attempts to implement these conditions through the adaptation of climactic, social and cultural data and result in a more responsive development based information based modelling.

Fig 5.03

Kelburn aerial image (Victoria, n.d)

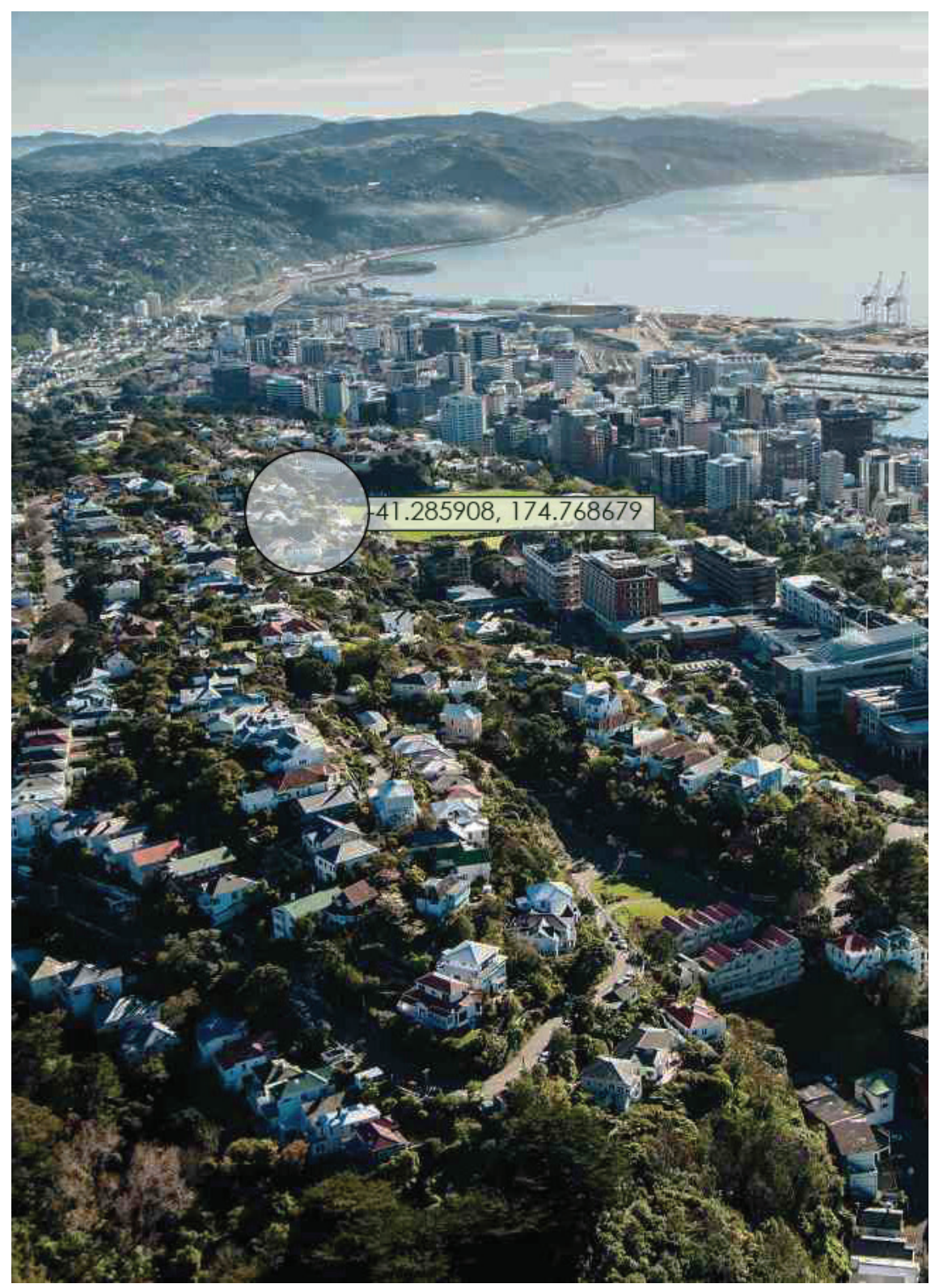




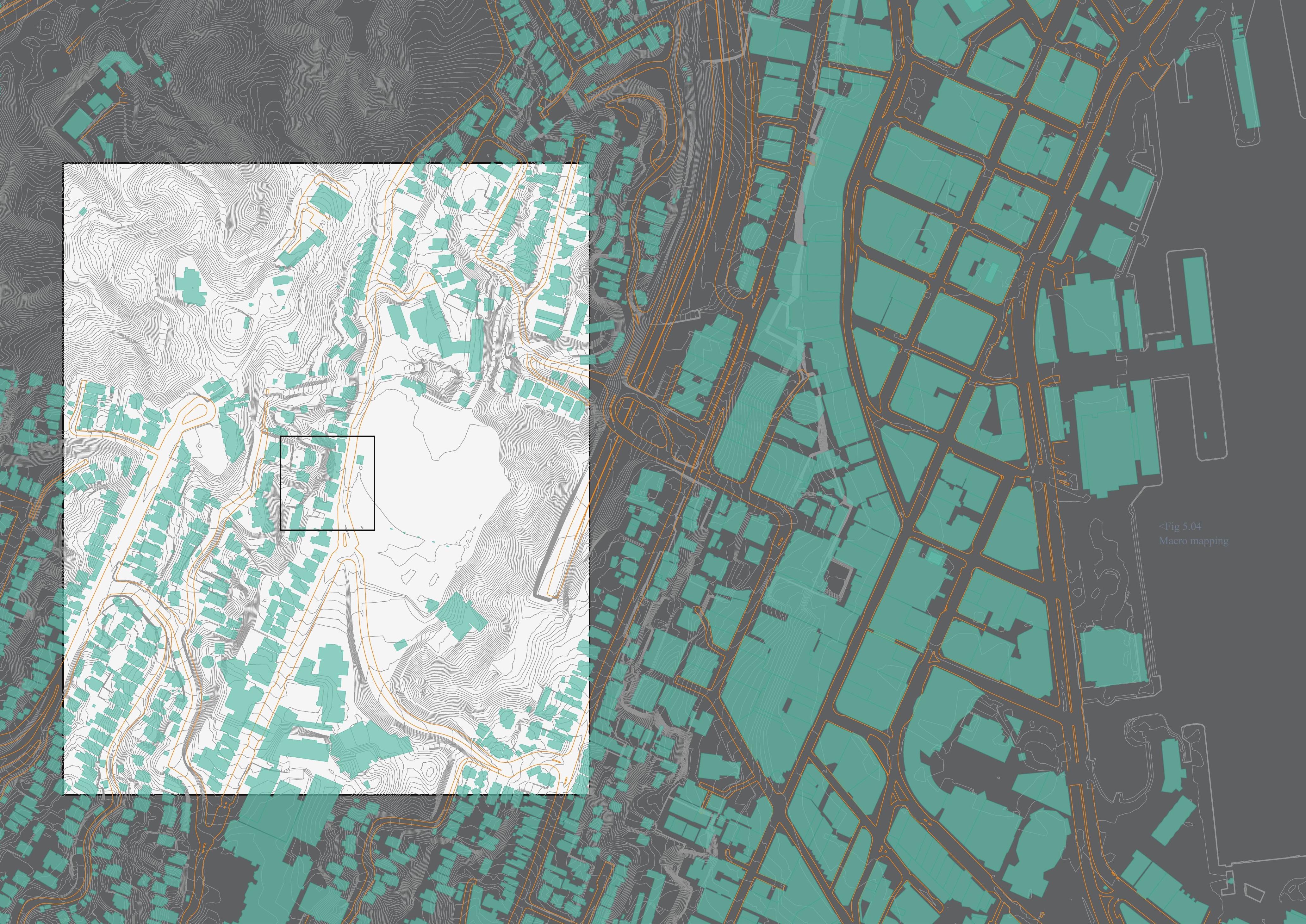




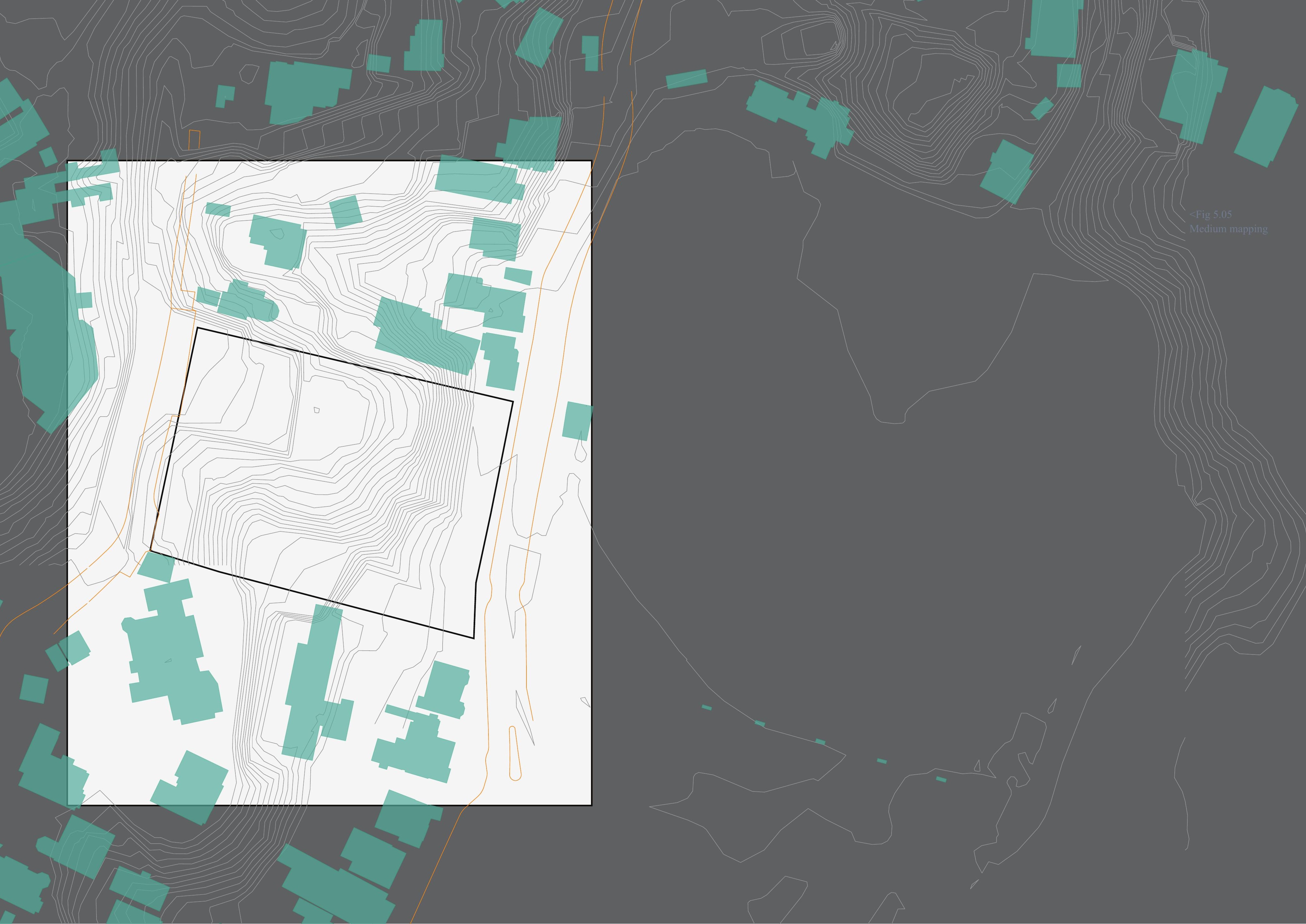




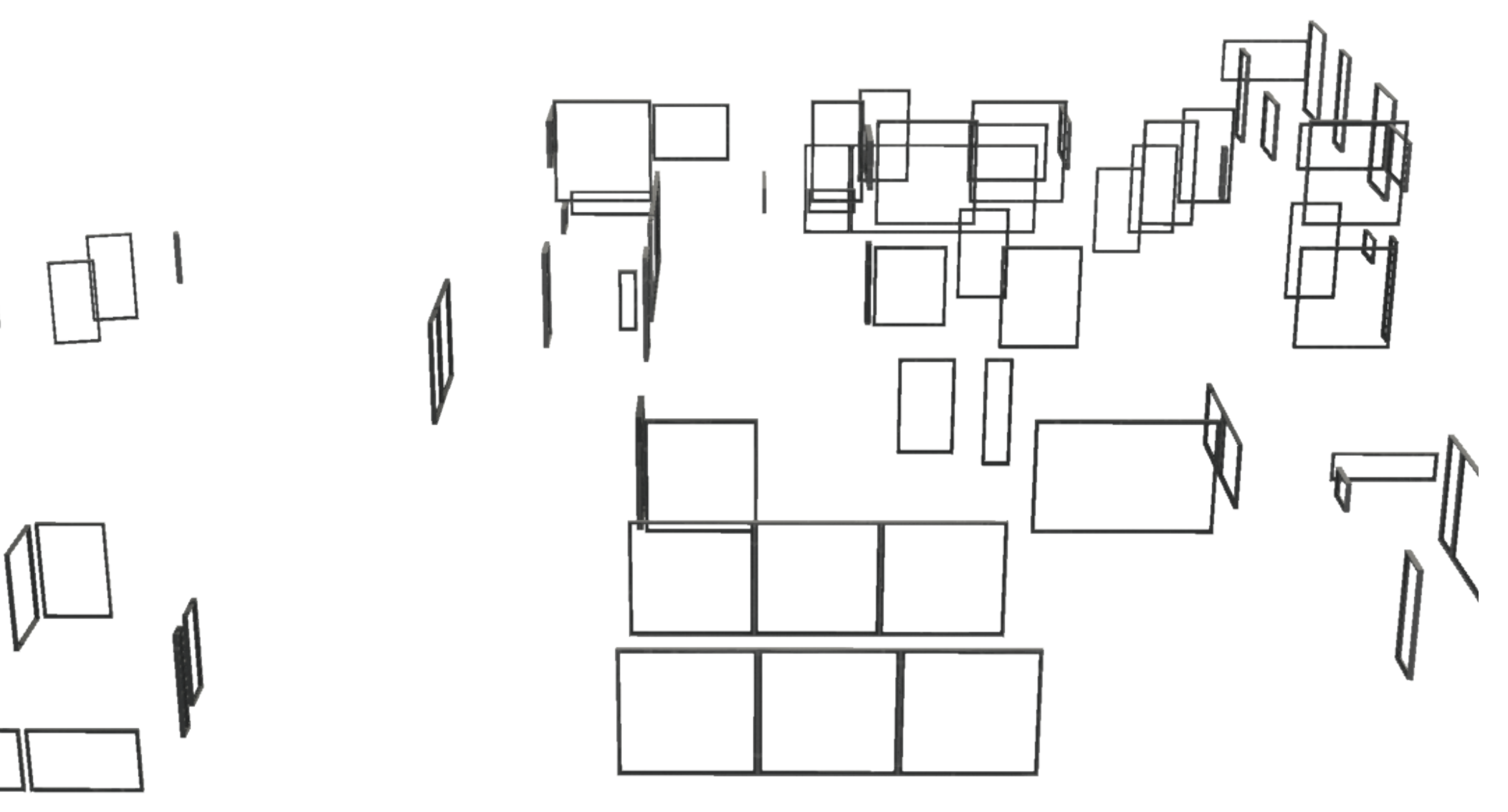

\section{Simulation Data}

Input Data for Simulation

The geographical simulation data is collected from the Koordinates website through dwg format and climactic data through the ladybug simulation plugin. From here the information plugs into the programs described in section 3.0. Following on from the input data is the simulation through the arrangement matrix. Due to the scale and variation in site conditions this simulation generates several pockets of family groupings that contribute to the development as a whole.

Fig 5.07

Input geography data

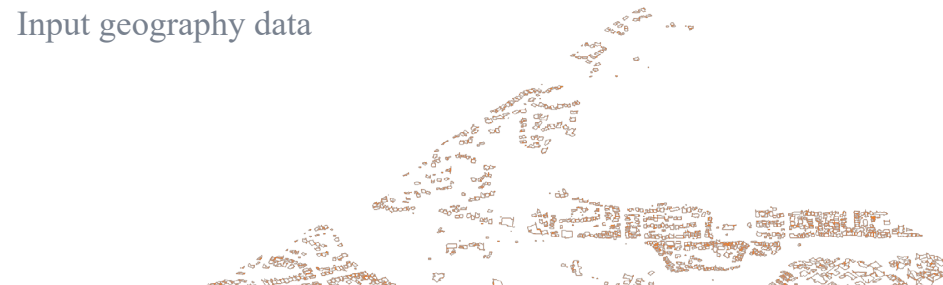

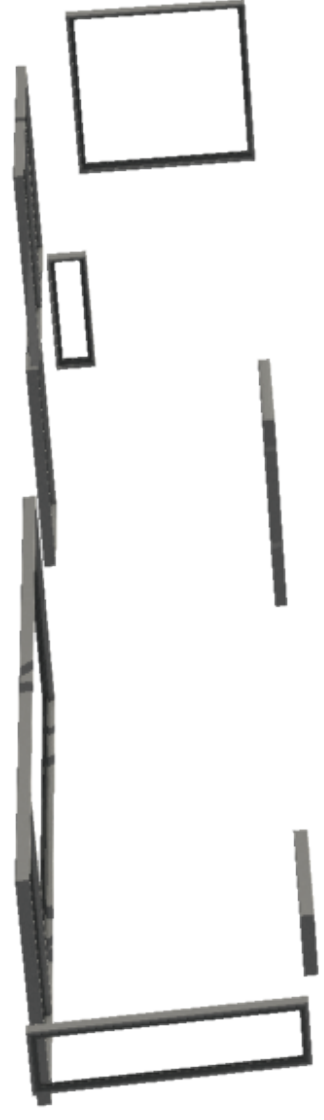
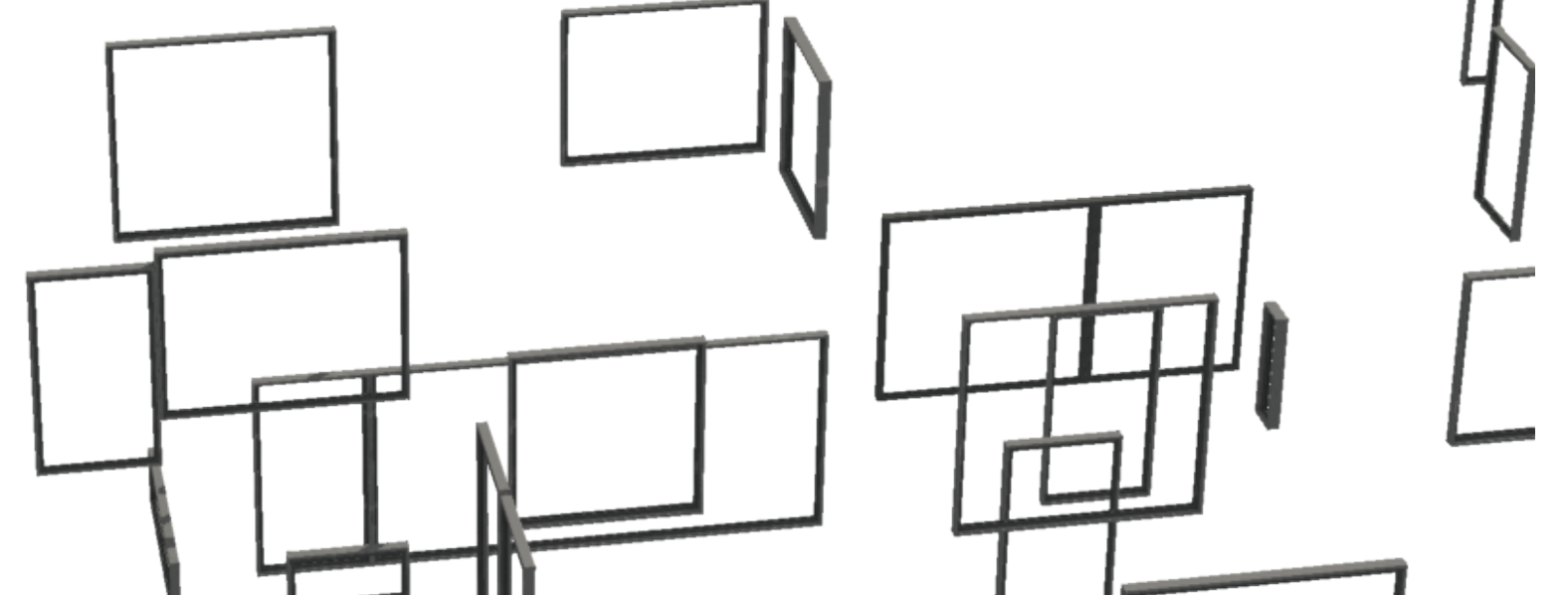


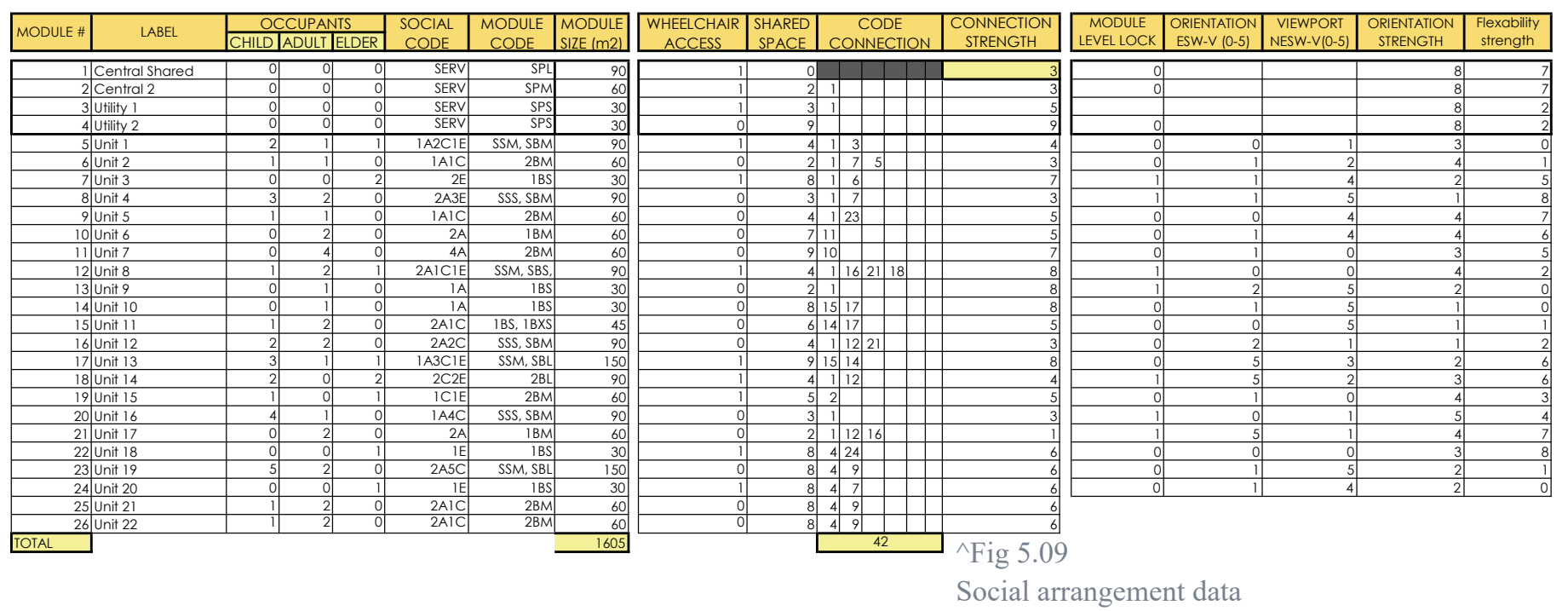

The social arrangement data is linked to the simulation which contains 22 housing modules, 2 arrangement matrix through excel read formatting shared utility spaces and two central organization which translates connection strengths to coded spaces. The central organization spaces are used for modules. Figure 5.09 refers to the input data used social functions, club meetups and general shared for this simulation, which emulates a diverse family space with kitchen, bathroom and computer facilities. typology mix resulting in an arrangement of complex The shared utility spaces are utilized mainly for connections and social situations. Depicted in figure laundry and storage in this simulation.

5.10 is the resting position of the arrangement

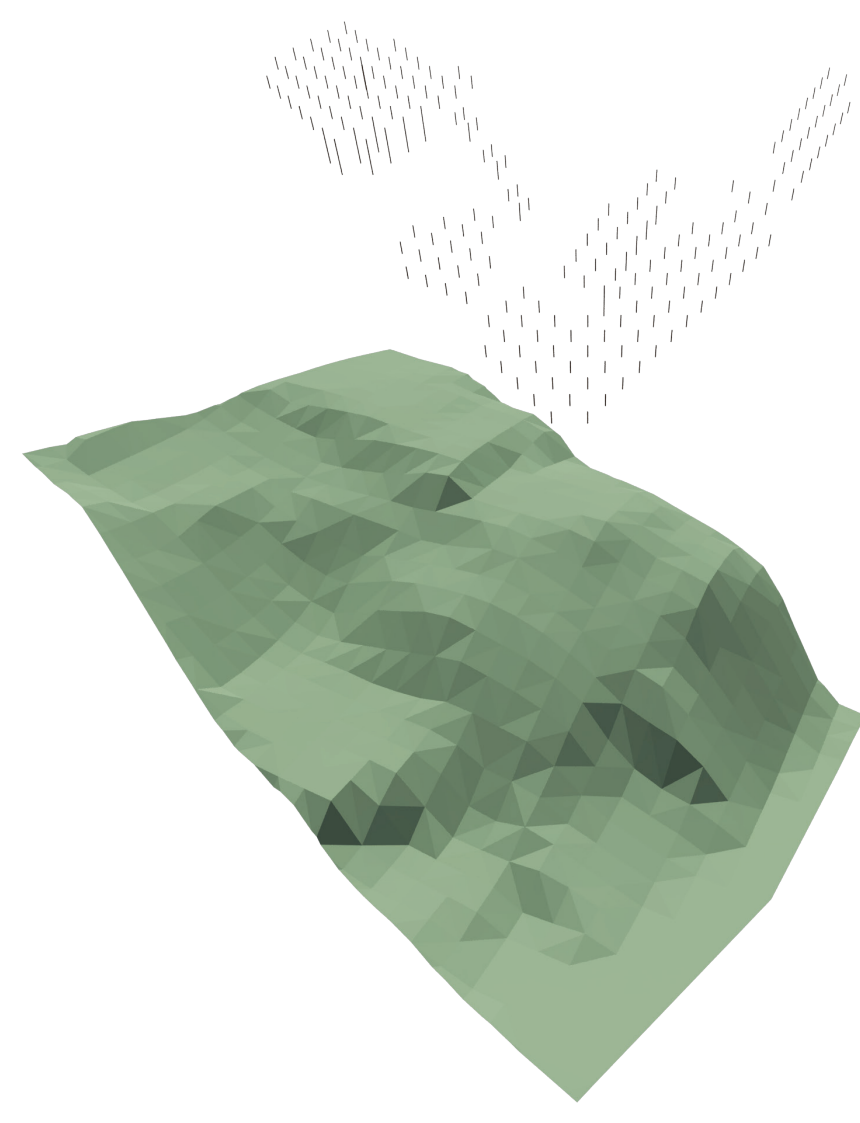

$<$ Fig 5.08

Framing boundary simulation

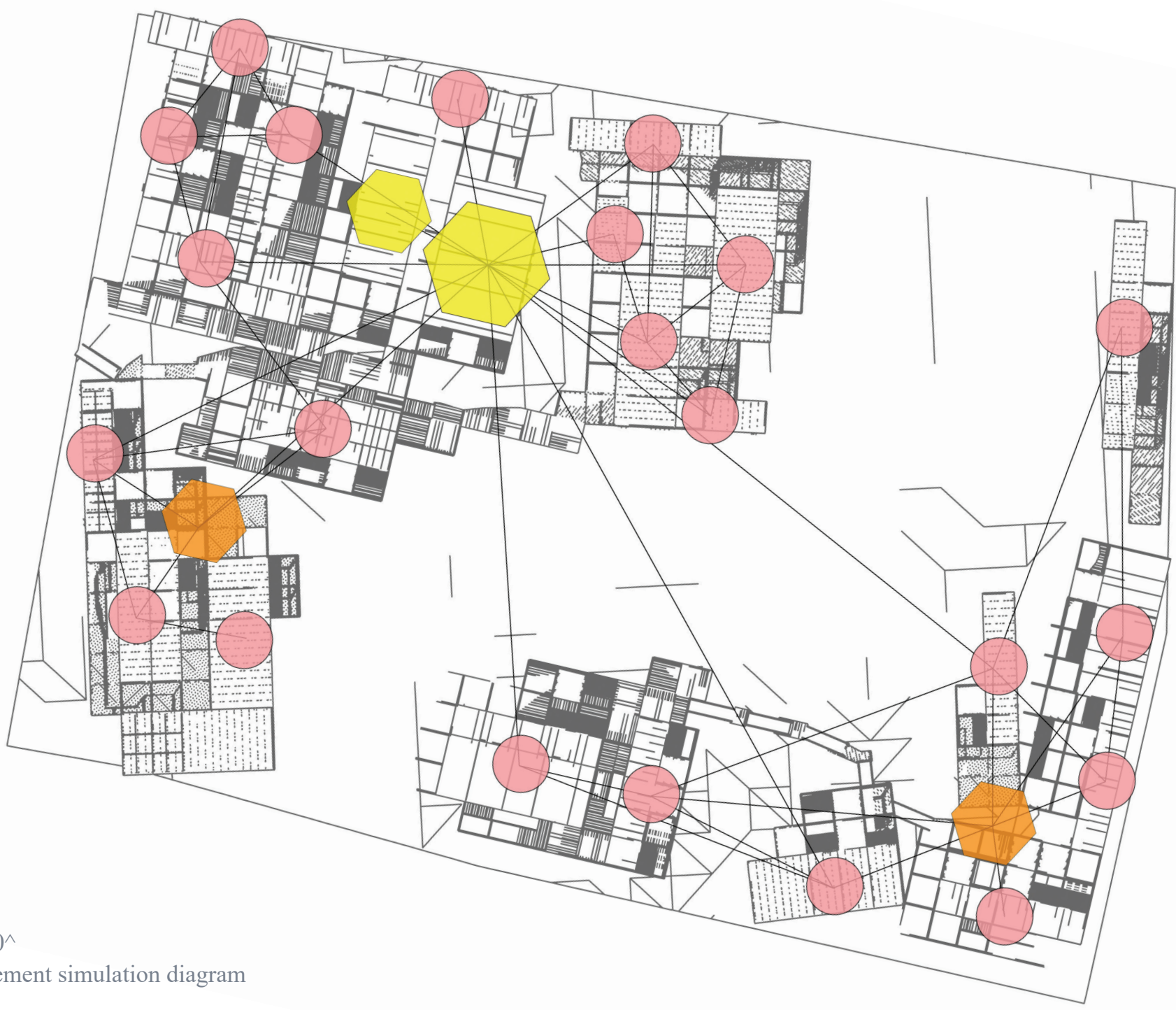

83
Fig $5.10^{\wedge}$
Arrangement simulation diagram 


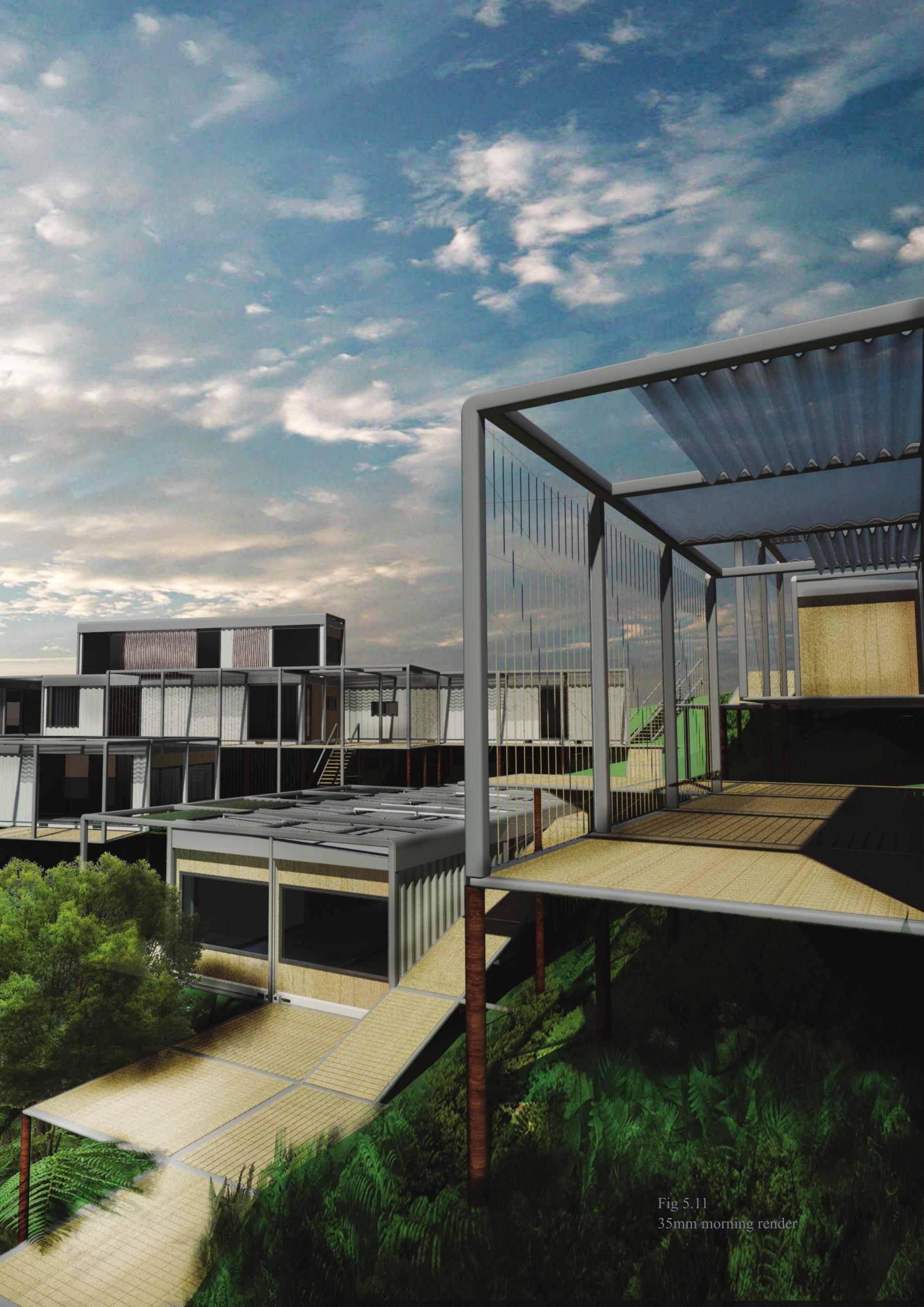

Final Design Simulation

The core function of the system the design is to simulate social values present in traditional papakāinga settlements. These values are represented as social and cultural data that allows the inhabitants to choose the style of living arrangements. This results in a more responsive housing system that reflects the values of those who live in it.

The design of the development does not finish at the arrangement phase. There is a post-arrangement phase that integrates the presence of green living walls and shading systems that further push the creation of shared social spaces. This portion of the design still implements digital design techniques, but through a post rational lens.

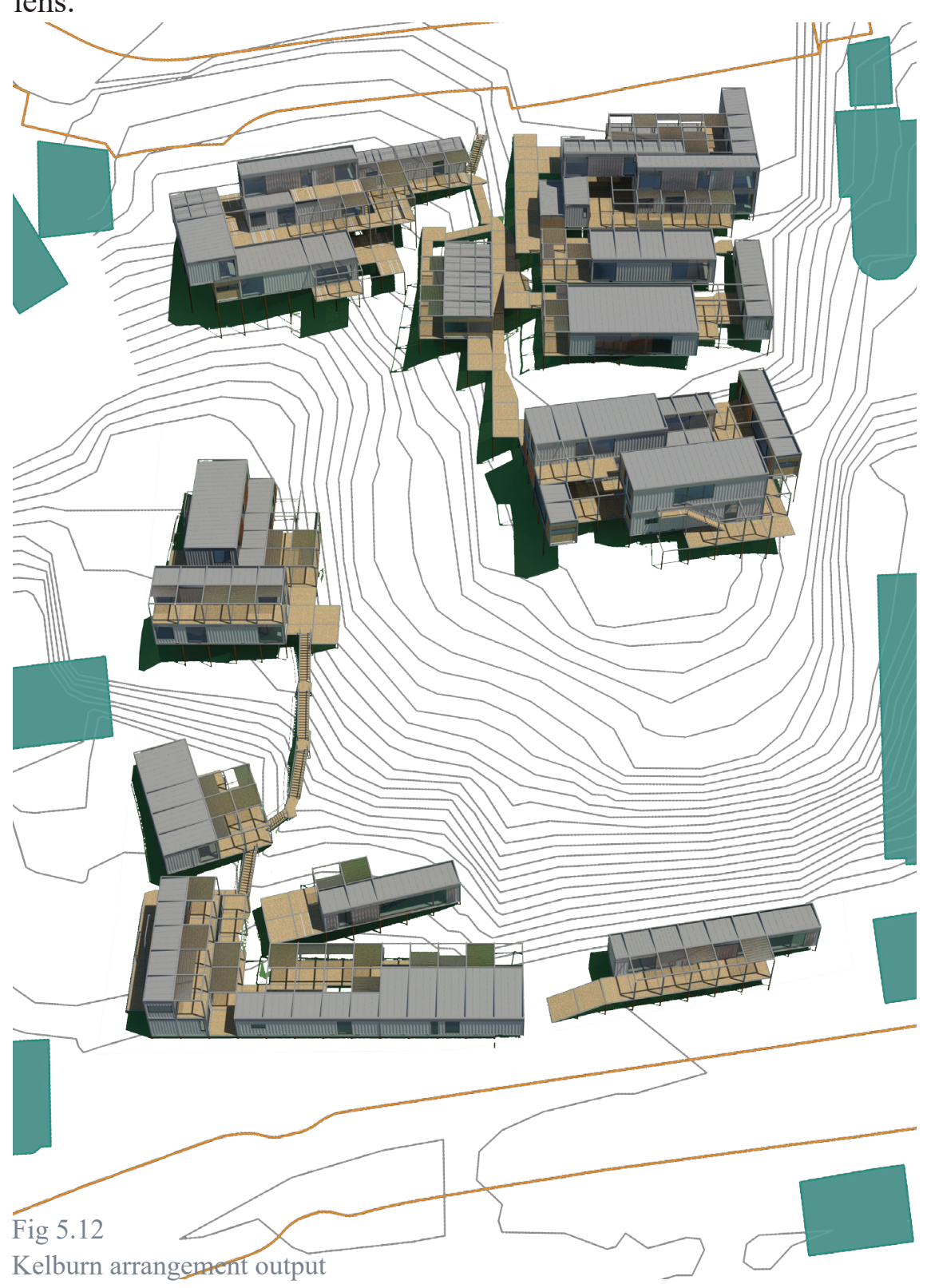




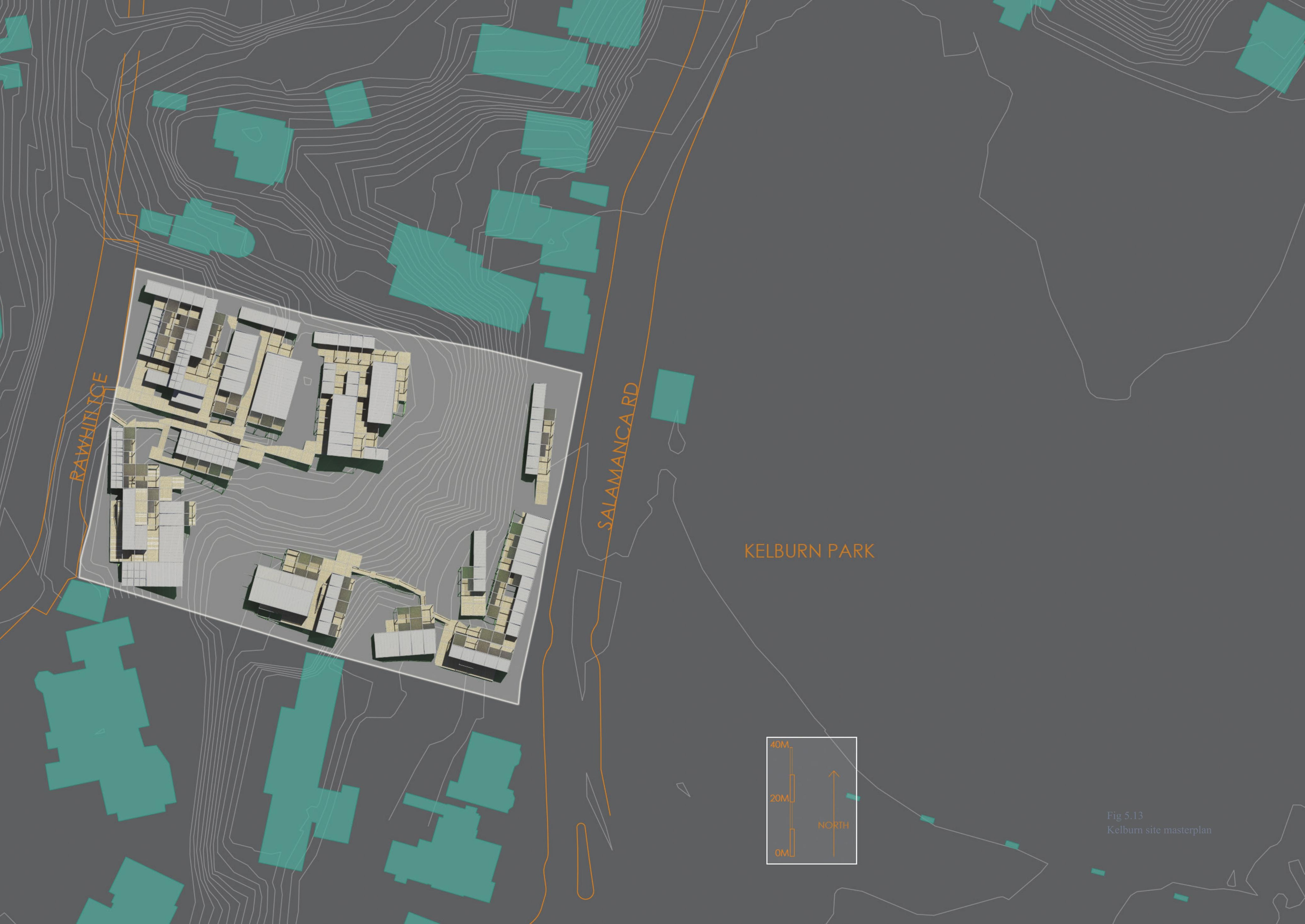



(1) Fig $5.1125 \mathrm{~mm}$ morning
(2) Fig 5.15 Wide angle
(3) Fig $5.1624 \mathrm{~mm}$ Afternoon central space
(4) Fig $5.1735 \mathrm{~mm}$ morning activity
(5) Fig 5.18 Midday spring
6 Fig $5.1935 \mathrm{~mm}$ under the canopy
7 Fig 5.20 Low angle stairs
(8) Fig $5.2135 \mathrm{~mm}$
9 Fig 5.22 Salamanca rd zone
(10) Fig 5.23 Salamanca rd activities
11 Fig $5.2445 \mathrm{~mm}$ pathway
12 Fig 5.25 Removed roof interior
13 Fig 5.26 Interior lounge
14 Fig 5.27 Interior kitchen
15 Fig 5.28 Section
(16) Fig 5.29 Final

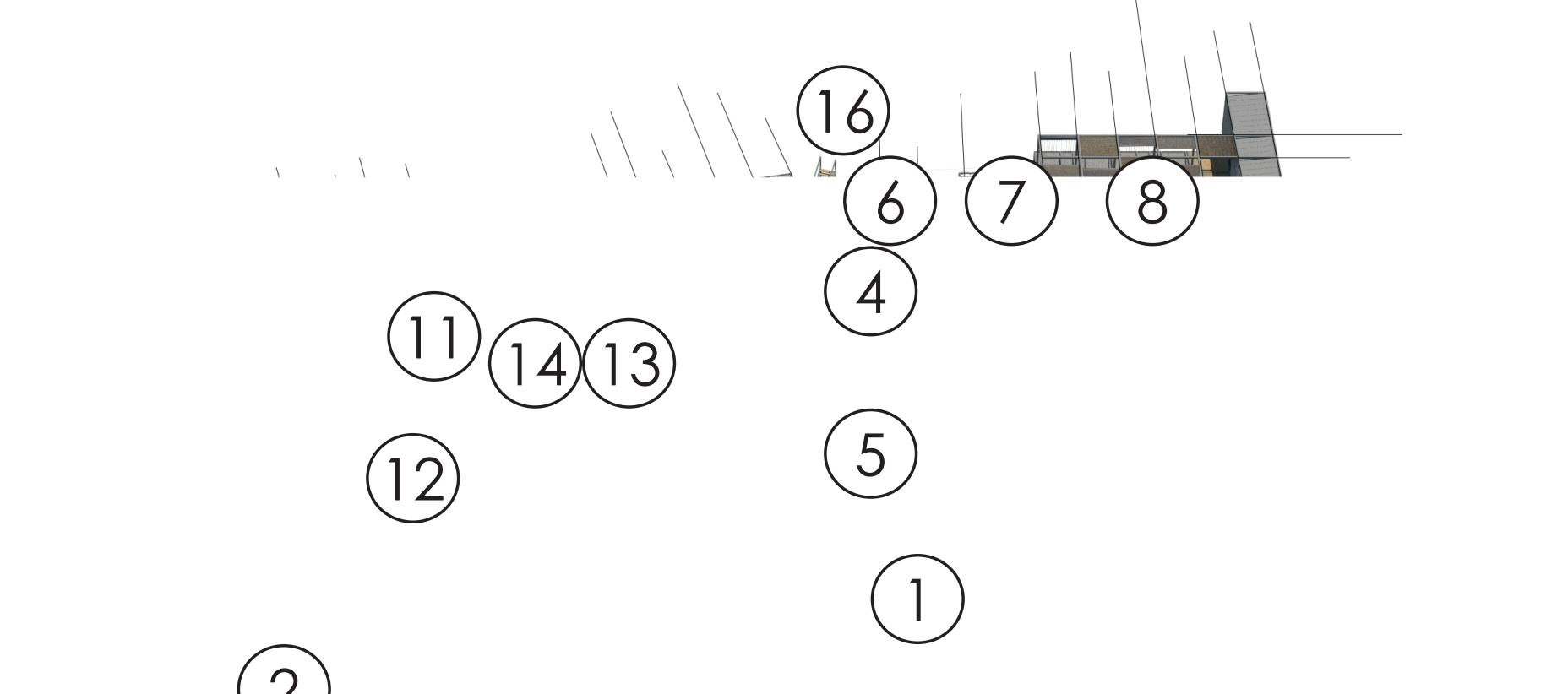

(15) 2

3 


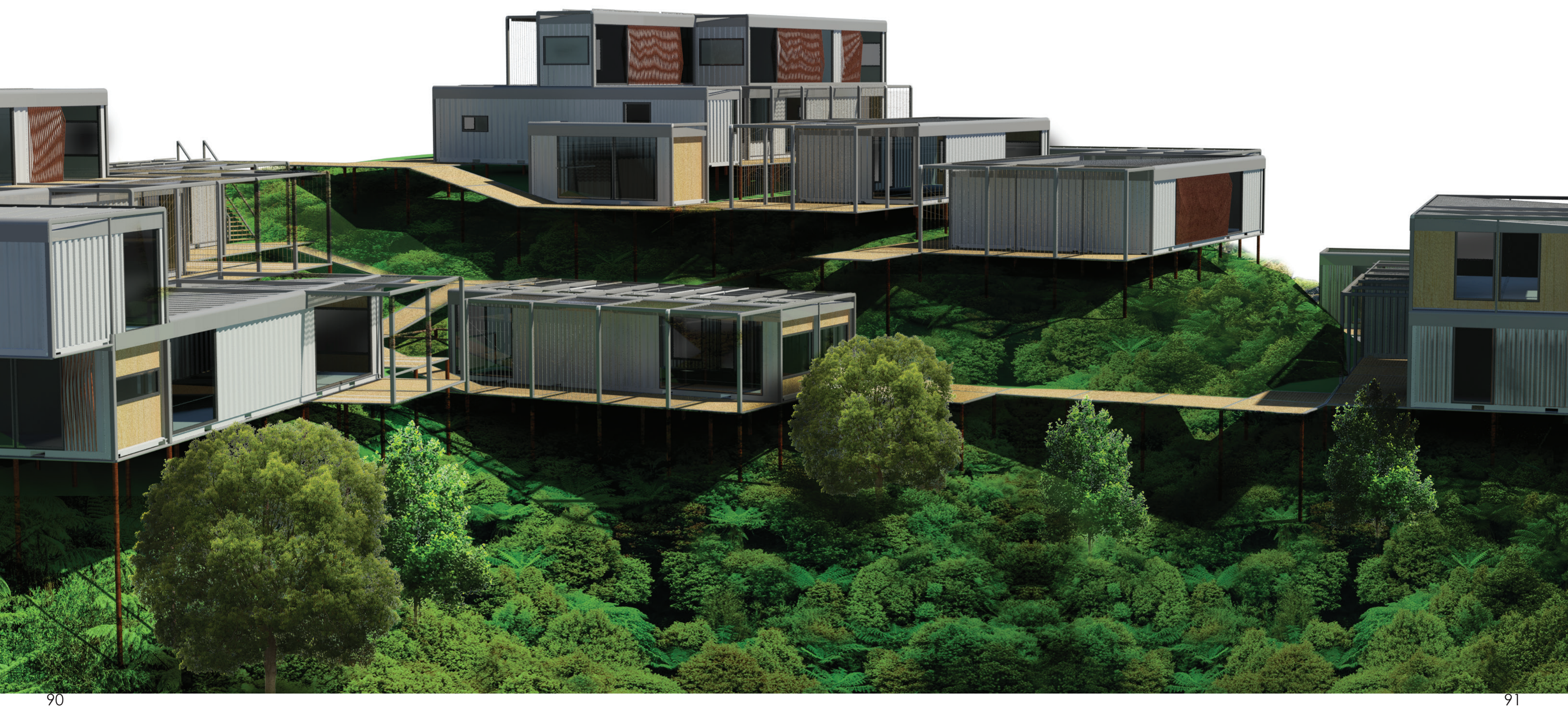




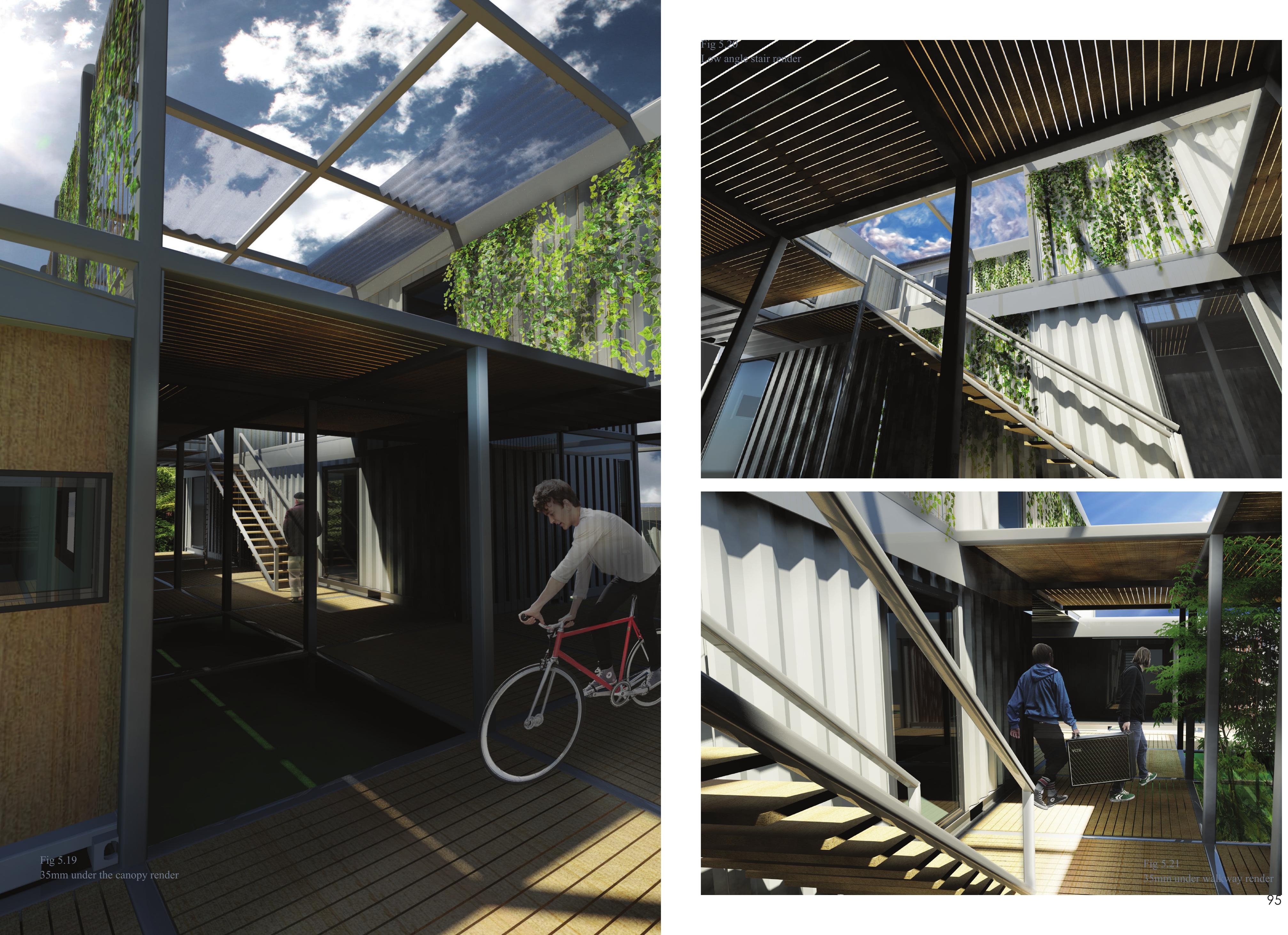


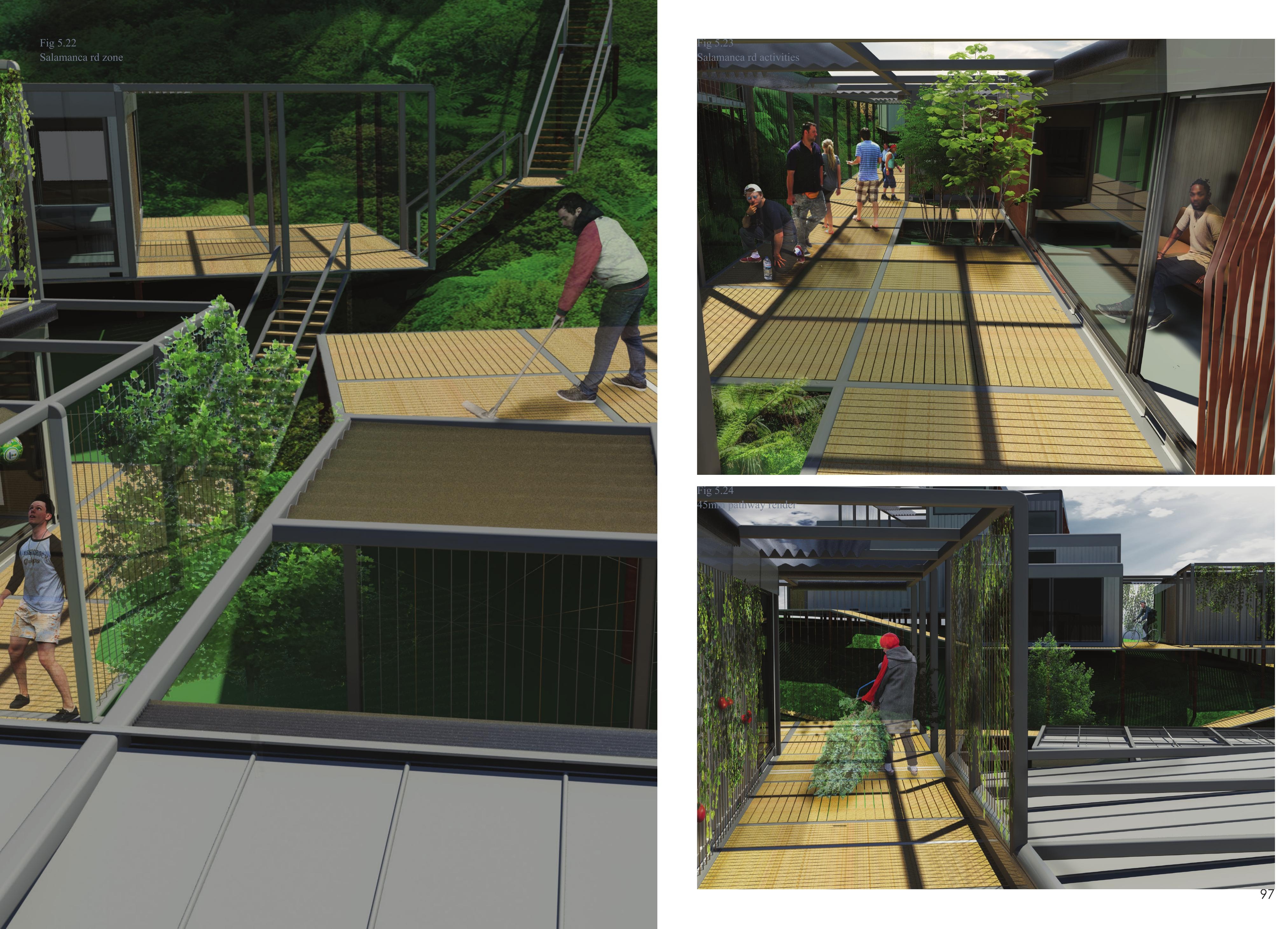



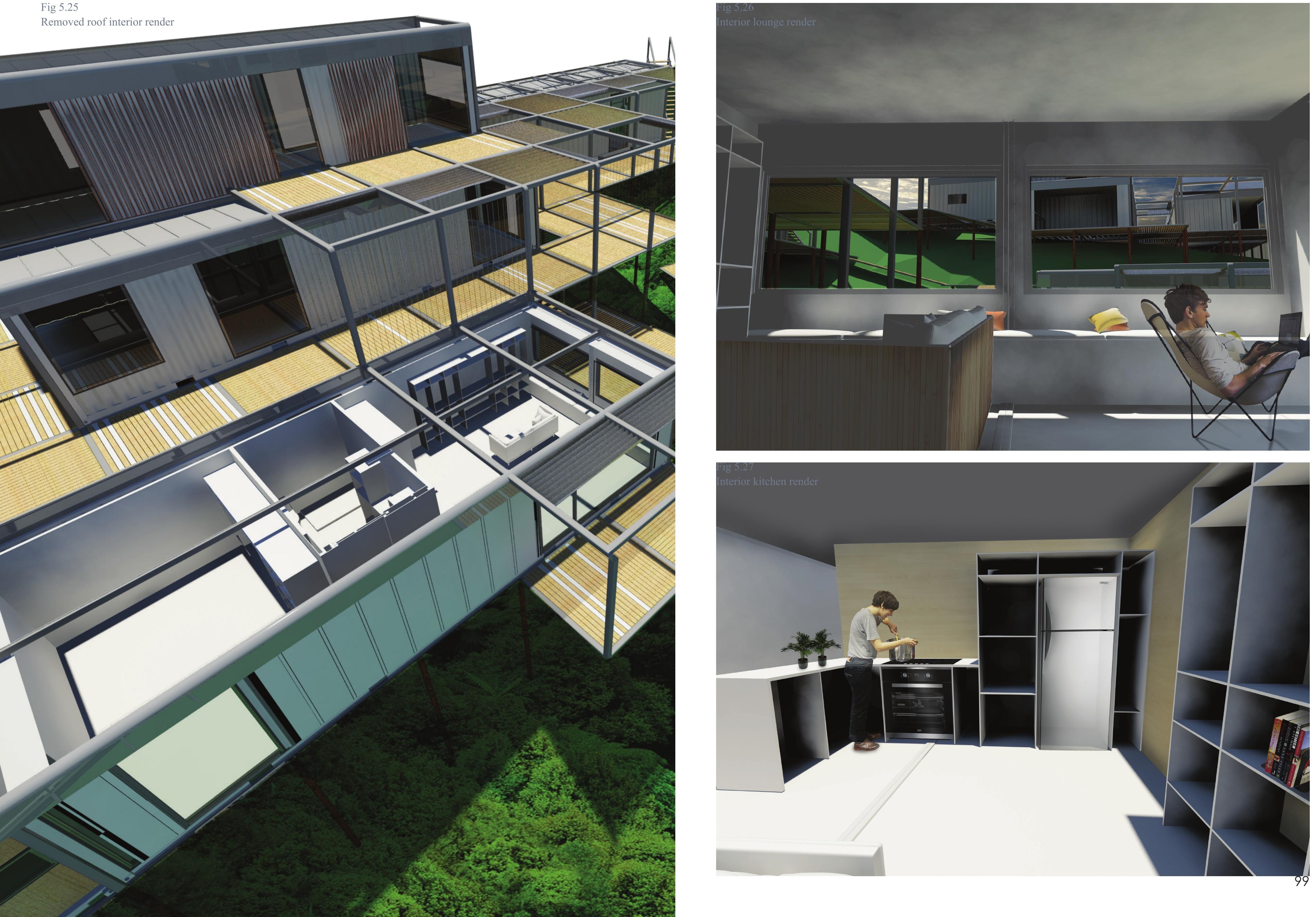


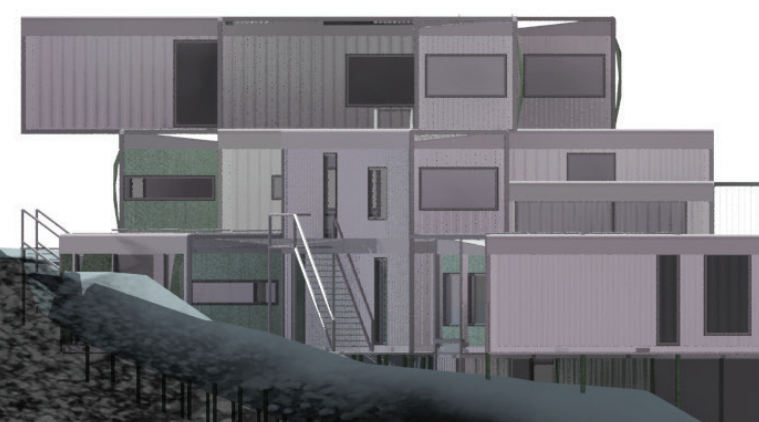

"IIIIII

|

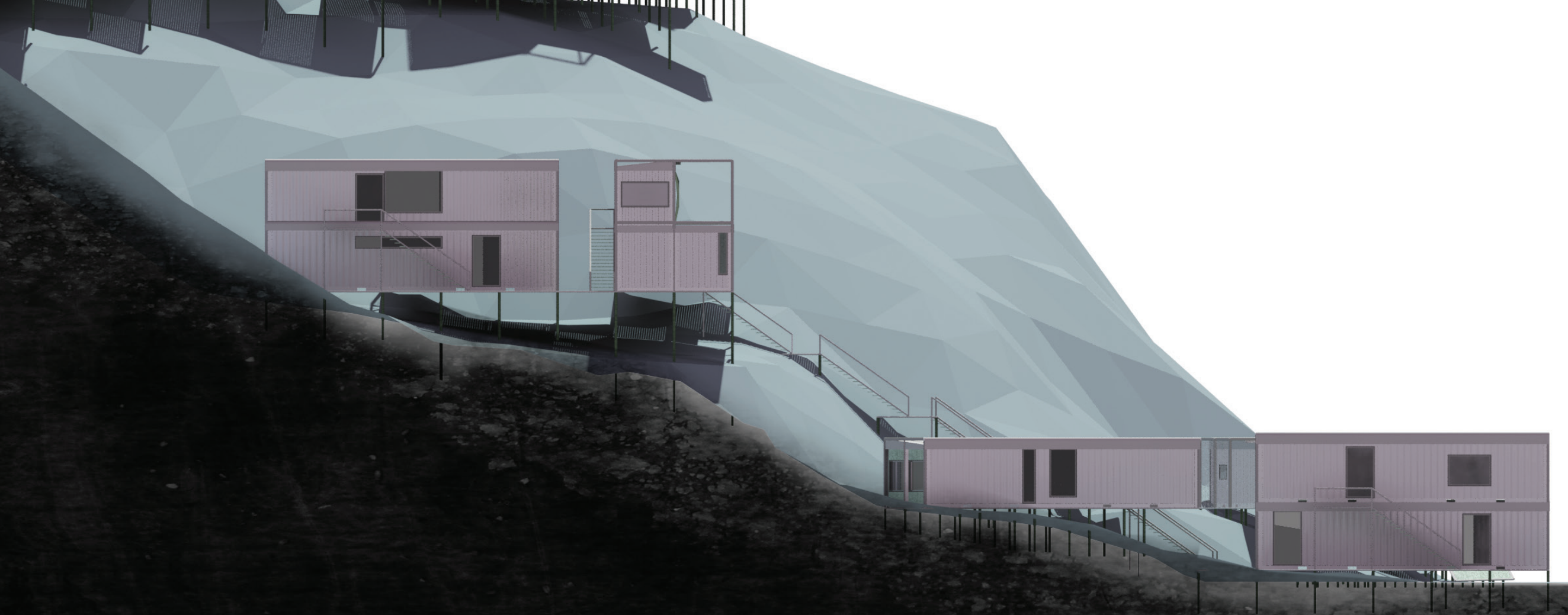




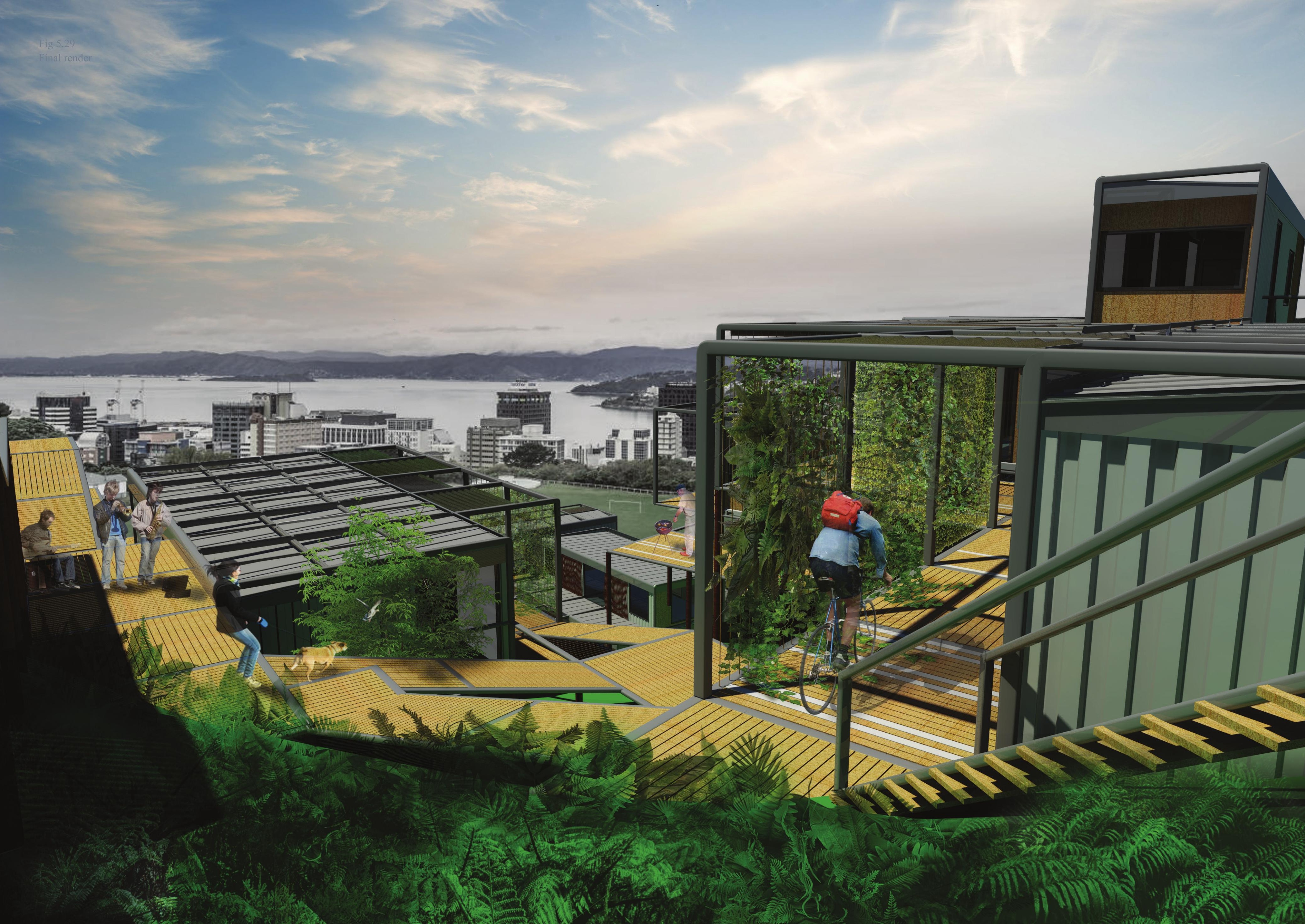



The current architectural discourse concerning 'affordable' housing uses an out-dated system of implementation, planning and construction. This misalignment has resulted in many families being disconnected to the larger community through privatization and antisocial arrangements. This research tests the implications of parametric design tools in the development of adaptable housing systems.

The aim of this research was to discover a new system for New Zealand's affordable housing issue. A system based methodology is adopted as a way of consolidating a number of difficulties in designing socially diverse housing that challenges the current style of unresponsive housing. This thesis explores an arrangement system consistent with encouraging social interactions in a communal setting inspired by traditional Māori housing (papakāinga). This is explored through section 2, whereby the crossover of digital technologies, the Metabolist movement and papakāinga developments results in a more responsive housing system.

The Strategic objectives in this research are to test the outcomes of this system on a challenging theoretical site, whereby a diverse mix of housing typology is explored within a housing complex. The creation of this development resulted in an ecologically responsive form of hybrid housing that deals with the complexities of multigenerational living and differing social dynamics. The main difficulties in developing the arrangement matrix was in the building of the visual programming tool. To combat the issues of arrangement simulation a series of compartmentalized programs were established. These partitions result in a workflow that allows for post rational adaptations before progressing to the following stage.

The key deliverables present in this thesis are the exploration of a hybrid arrangement system, the development of a buildable modular construction and the surface treatment that represents a socially diverse family typology. These outputs are part of a sincere attempt to rationalize the key concepts of diversity and adaptation. Affordable housing is an extremely complex architectural issue and this is presented as an alternative to the current housing typology currently used.
Throughout this research the key was to find alternative modes of housing that relied on a more resilient form of architectural arrangement. By utilizing actual social, climactic and cultural data the system responds to a number of challenging housing issues not currently implemented into affordable housing developments.

Section 3.0 discusses the development of the system and the testing methods discovered through the iteration process. The process explored several methods for simulating differing social typologies and the programming requirements for the complexities of social arrangements. These tests successfully experiment with differing typologies but further simulation methods could have been explored. Primarily the response to security, shared space and sun shadowing could have been built into the system more effectively through the 'ladybug' plugin and climactic simulations.

Structure assembly is explored through section 4.0 and looks to rationalize the arrangement system into a buildable construction method. In this section a building method is described that successfully maintains the core system values presented in previous sections while grounding the research in reality. This portion of the research was investigated thoroughly to find a building system that would assimilate the parametric process into an affordable housing development with flexibility and diversity built in. Perhaps what could have pushed this system even further is the implementation of a differing building style or module that would experiment with the flexibility present more efficiently.

Overall this thesis successfully tests the implementation of parametric design tools in the development of a hybrid housing system for New Zealand's affordable housing market. By exploring a deeper understanding of parametric workflows and flexible housing systems this thesis contributes to the body of knowledge around culturally and socially responsive housing to suit a diverse mix of family typologies. 


\section{Works Cited}

Architectural Design. (2013). The Digital Turn in Institute of civil engineers ICE. (2017, April 4). Architecture 1992-2012. (M. Carpo, Ed.) West Nakagin capsule tower. Retrieved from Design Sussex: John Wiley \& Sons Ltd.

BRANZ. (2014). Passive Solar Design. BRANZ.

Brown, D. (1996). Maori Architecture. Oxford: Johnson, A. (2007). Rebuilding the Kiwi Dream: A Oxford University Press.

Canterbury, U. o. (n.d.). Living in New Zealand. Retrieved from University of Canterbury: http:// www.canterbury.ac.nz/international/uc-a-worldrecognised-university/living-in-new-zealand/

Eisenman, P. (1992). The Affects of Singularity. In A. Design, Digital Turn in Architecture (pp. 23-27). West Sussex: John Wiley \& sons Ltd.

Emden, T. J. (2014). Cutout People. Retrieved from Skal Gubbar: http://skalgubbar.se/

Fallon, V. (2016, September 4). Hundreds of Empty state houses in Wellington. Retrieved from Stuff:

http://www.stuff.co.nz/national/83769749/hundreds- Labs, A. (2014). ideEGE techno park. Retrieved from of-empty-state-houses-in-wellington-while-523- Atolye Labs: http://atolyelabs.com/ideegetechnopark/ wait-for-new-home

Lambert, R. (2015, August 3). Taranaki region Ganti+Associates. (2015). Container Skyscraper. Maori pakeha conflict. Retrieved from Te Ara - The Retrieved from Ganti + Associates: http://www.ganti- encyclopedia of New Zealand: http://www.teara.govt. associates.com/project/international-competition- nz/en/photograph/25322/parihaka-1880s container-skyscraper/\#prettyPhoto

Haywards, N. w. (2014). Treaty of Waitang Settlements. Dunedin: Bridget Williams Books.

Hoskins, R. (2012). Papakāinga technical report for Auckland Council. Auckland: Design Tribe.

Housing New Zealand. (2015). The Simple Guide to Urban design \& development. Wellington: newzealand.govt.nz.

Lin, Z. (2010). Kenzo Tange and the Metabolist Movement. New York: Routledge.

Lynn, G. (1993). Architectural Curvilinearity: The Folded, the Pliant and the Supple. In A. Design, The Digital Turn in Architecture 1992-2012 (pp. 29-44).

Lynn, G. (1993). Folding in Architecture. In A. Reader, \& M. Carpo (Ed.), The Digital Turn in Architecture 1992-2012 (pp. 28-47). West Sussex: John Wiley \& Sons Ltd.
Lynn, G. (2000). Embryological Houses. In A. Design, Orange, C. (2001). Illustrated History of the Treaty of The Digital Turn in Architecture (pp. 126-130). West Waitangi. Wellington: Bridget Williams Books.

Sussex: John Wiley and Sons Ltd. Retrieved from Mahi Tahi : http://www.collaborate. Retrieved from Popup city: http://popupcity.net/noorg.nz/index.php/portfolio/papakainga-housing-in- end-to-the-trend-shipping-container-hostel-opens-inwestern-bay/

vietnam

Māori Dictionary. (2017). Manaaki. Retrieved from Māori Dictionary: http://maoridictionary.co.nz/ word $/ 3425$

Radio NZ. (2014, November 4). Regional News. Retrieved from Radio NZ: http://www.radionz.co.nz/ news/national/2516/state-house-sell-off-'will-shiftproblem'

Māori Dictionary. (2017). papa kāinga . Retrieved from Māori Dictionary: http://maoridictionary.co.nz/

Radio NZ. (2016, February 19). Regional News. Retrieved from Radio NZ: http://www.radionz. Martin, R. (2016, July 15). Govt has wiped its hands co.nz/news/regional/296910/whangarei-needs-moreof Suburb - Labour. Retrieved from Radio NZ: http:// social-housing-ministry

www.radionz.co.nz/news/political/308740/govt-hassciences, 7. West Sussex: John Wiley \& Sons Ltd. wiped-its-hands-of-suburb-labour

Meredith, P. (2000). Urban Māori as 'new citizens': The quest for recognition and resources. Hamilton: University of Waikato.

Ministry of health. (2015, October 8). Socioeconomic indicators. Retrieved from Ministry of Health http://www.health.govt.nz/our-work/populations/ maori-health/tatau-kahukura-maori-health-statistics/ nga-awe-o-te-hauora-socioeconomic-determinantshealth/socioeconomic-indicators

Najafi, M. K. (2011). The Concept of Place and Sense of Place In. International Journal of Human and social

Raubenweiss, A. (2005, July 24). Week Eighteen. Retrieved from Expo 2005 photo essays: http://www. antonraubenweiss.com/expo/week18.html

Rolleston, S. A. (2009). Ngā hua papakāinga: Habitation design principles. Hamilton: Auckland University

Royal, T. A. (2007, September 24). Kaitiakitanga Guardianship and concervation. Retrieved from Te Ara - The Encyclopedia of New Zealand: http://www. teara.govt.nz/en/kaitiakitanga-guardianship-andconservation

Ryan, I. P. (2010). It takes all types - A typology of New Zealand Housing Stock. BRANZ Ltd.

Schalk, M. (2014). The Architecture of Metabolism.

New Zealand Controller and Auditor-General. (2011). Inventing a culture of resilience. MDPI: Arts 2014 Part 2: Māori housing needs and history, and current 279-297.

government programmes. Retrieved from Controller and Auditor-General: http://www.oag.govt.nz/2011/ housing-on-maori-land/part2.htm

Schumacher, P. (2009). Parametricism: A New Global Style for Architecture and Urban Design. In AD, The Digital Turn in Architecture 1992-2012 (pp. 241NZ History. (2014, july 21). State housing. Retrieved 257). West Sussex: John Wiley and Sons Ltd. from New Zealand History: https://nzhistory.govt.nz/ culture/we-call-it-home/the-state-steps-in-and-out

Orange, C. (1987). The Treaty of Waitangi. Wellington: Bridget Williams Books.

SCI-ARC. (2010, September 29). Flyers for Tokyo final! Retrieved from Sci-Arc Tokyo: https:// sciarctokyo.wordpress.com/tag/nakagin-capsuletower/ 
SFU (Producer), \& Friedman, A. (Director). (2012). Yamazaki, R. (Director). (2010). Nakagin Capsule Avi Friedman: Thinking Outside the Box of Affordable Tower - Japanese Metabolist Landmark on the edge Housing [Motion Picture]. Vancouver. Retrieved from of destruction [Motion Picture].olitical/308740/govthttps://www.youtube.com/watch?v=BlOWpmN6nXI has-wiped-its-hands-of-suburb-labour

Spoon\&Tamago. (2016, January 30). Could Tokyo bay host a floating eco city in 30 years. Retrieved from Spoon and Tamago: http://www.spoon-tamago. com/2016/01/30/could-tokyo-bay-host-a-floatingeco-city-in-30-years/

Te Puni Kōkiri. (2001). Te Māori I Nga Rohe: Māori Regional Diversity. Wellington: Te Puni Kōkiri.

Te Taura Whiri i Te Reo Māori. (2017). Tikanga Māori. Retrieved from Te Taura Whiri i Te Reo Māori: Māori Language Commission: http://www.tetaurawhiri. govt.nz/learn-te-reo-maori/tikanga-maori/

Terzidis, K. (2007). The Etymology of Design: PreSocratic Perspective. Design Issues: Volume 23, 23 , 69-78.

Trust, D. H. (2016, October). October 2016 - Blitz study results published. Retrieved from Dwell housing trust: http://dwell.org.nz/index.php/newspublications-3/news-blog?start $=6$

University, V. (n.d.). University Council. Retrieved from Victoria University of Wellington: http://www. victoria.ac.nz/about/governance/council

WDC. (2015). Whangarei District Council . Retrieved from Papakāinga Housing Brochure: http://wdc. govt.nz/CommunitySafetyandSupport/Housing/ Documents/Papakainga-housing-brochure.pdf

Wellington, G. (2014, May 27). Discover Whitireia park. Retrieved from Youtube: https://www.youtube. com/watch?v=uW9ucIcUFNA

Wilson, J. (2005, February 8). History - Māori arrival and settlement. Retrieved from Te Ara - The encyclopedia of New Zealand: http://www.teara.govt. nz/en/history/page-1 
All render cutout people sourced from,

Emden, T. J. (2014). Cutout People. Retrieved from Skal Gubbar: http://skalgubbar.se/

Figure 1.01

Input Entities

Figure 1.02

System Diagram

Figure 2.01

Early state housing design

NZ History. (2014, july 21). State housing.

Retrieved from New Zealand History: https:// nzhistory.govt.nz/culture/we-call-it-home/the-

state-steps-in-and-out

\section{Figure 2.02}

Previous state housing in Christchurch Radio NZ. (2014, November 4). Regional News. Retrieved from Radio NZ: http://www. radionz.co.nz/news/national/2516/state-housesell-off-'will-shift-problem'

\section{Figure 2.03}

Previous state housing in Whangarei

Radio NZ. (2016, February 19). Regiona News. Retrieved from Radio NZ: http:// www.radionz.co.nz/news/regional/296910/ whangarei-needs-more-social-housingministry

\section{Figure 2.04}

State housing in Porirua, unoccupied

Fallon, V. (2016, September 4). Hundreds of Empty state houses in Wellington. Retrieved from Stuff: http://www.stuff.co.nz/ national/83769749/hundreds-of-empty-statehouses-in-wellington-while-523-wait-for-new-
Figure 2.05

North Island, Land Ownership of Maori Since 1860

Orange, C. (2001). Illustrated History of

2 the Treaty of Waitangi. Wellington: Bridget Williams Books.

\section{Figure 2.06}

Traditional Māori settlement from 1880's Lambert, R. (2015, August 3). Taranaki

11 region - Maori pakeha conflict. Retrieved from Te Ara - The encyclopedia of New

Zealand: http://www.teara.govt.nz/en/ photograph/25322/parihaka-1880s

\section{Figure 2.07}

Papakāinga settlement in Western Bay of

12 Plenty

MahiTahi. (2015). Papakainga housing in

Western bay. Retrieved from Mahi Tahi :

http://www.collaborate.org.nz/index.php/

portfolio/papakainga-housing-in-western-bay/

Figure 2.08

12 Te Aro Pa in Evans Bay, Wellington

Trust, D. H. (2016, October). October 2016 Blitz study results published. Retrieved from Dwell housing trust: http://dwell.org.nz/index php/news-publications-3/news-blog?start $=6$

Figure 2.09

Papakāinga design principles

12 Rolleston, S. A. (2009). Ngā hua papakāinga: Habitation design principles. Hamilton:

Auckland University.
Figure 2.10

Kenzo Tange, Tokyo Bay plan

Spoon\&Tamago. (2016, January 30). Could Tokyo bay host a floating eco city in 30 years. Retrieved from Spoon and Tamago: http:// www.spoon-tamago.com/2016/01/30/couldtokyo-bay-host-a-floating-eco-city-in-30years/ Architecture 1992-2012 (pp. 241-257). West

Figure 2.11

Takara Beautilion

Kisho Kurokawa. (1970). Expo' 70 Takara beautilion. Retrieved from Kisho Kurokaw Architects \& Associates: http://www.kisho. co.jp/page/211.html

\section{Figure 2.12}

Takara Beautilion

Raubenweiss, A. (2005, July 24). Week Eighteen. Retrieved from Expo 2005 photo essays: http://www. antonraubenweiss.com/ expo/week18.htm

Figure 2.13

Takara Beautilion

Kisho Kurokawa. (1970). Expo' 70 Takara beautilion. Retrieved from Kisho Kurokawa Architects \& Associates: http://www.kisho. co.jp/page/211.html

Figure 2.14

Capsule tower exploded diagram

SCI-ARC. (2010, September 29). Flyers for Tokyo final! Retrieved from Sci-Arc Tokyo ........https://sciarctokyo.wordpress.com/tag/ nakagin-capsule-tower

\section{Figure 2.15}

Nakagin Capsule tower

Institute of civil engineers ICE. (2017, April 4). Nakagin capsule tower. Retrieved from Design buildings wiki: https://www. designingbuildings.co.uk/wiki/Nakagin Capsule_Tower
18 Figure 2.16

Singapore Masterplan design

Schumacher, P. (2009). Parametricism: A New Global Style for Architecture and

Urban Design. In AD, The Digital Turn in Sussex: John Wiley and Sons Ltd.

Figure 2.7

Lynn, G. (2000). Embryological Houses. In A. Design, The Digital Turn in Architecture (pp. 126-130). West Sussex: John Wiley and Sons Ltd.

Figure 2.18

20 Container Skyscraper

Ganti+Associates. (2015). Container

Skyscraper. Retrieved from Ganti +

Associates: http://www.ganti-associates.com/ project/international-competition-containerskyscraper/\#prettyPhoto

20 Figure 2.19

Skyscraper diagram

Ganti+Associates. (2015). Container

Skyscraper. Retrieved from Ganti +

Associates: http://www.ganti-associates.com/ project/international-competition-container-

skyscraper/\#prettyPhoto

Figure 2.20

CCasa Hostel, Vietnam

Popup City. (2016, December 16). No End to the Trend: Shipping Container Hostel Opens in Vietnam. Retrieved from Popup city: http:// popupcity.net/no-end-to-the-trend-shipping-

21 container-hostel-opens-in-vietnam/

Figure 2.2

CCasa Hostel, Vietnam

Popup City. (2016, December 16). No End to the Trend: Shipping Container Hostel Opens in Vietnam. Retrieved from Popup city: http:// popupcity.net/no-end-to-the-trend-shippingcontainer-hostel-opens-in-vietnam/
20 Embryological House models 
Figure 2.22

CCasa Hostel, Vietnam

Popup City. (2016, December 16). No End to the Trend: Shipping Container Hostel Opens

in Vietnam. Retrieved from Popup city: http:// popupcity.net/no-end-to-the-trend-shipping-

container-hostel-opens-in-vietnam/

Figure 2.23

ideEGE Campus

Labs, A. (2014). ideEGE techno park.

Retrieved from Atolye Labs: http://atolyelabs. com/ideegetechnopark/

Figure 2.24

ideEGE Campus

Labs, A. (2014). ideEGE techno park.

Retrieved from Atolye Labs: http://atolyelabs. com/ideegetechnopark/

Figure 2.25

ideEGE Campus

Labs, A. (2014). ideEGE techno park.

Retrieved from Atolye Labs: http://atolyelabs. com/ideegetechnopark/

Figure 3.01

Input system Diagram

Figure 3.02

Process diagram

Figure 3.03

Family randomize

Figure 3.04

Family typologies

Figure 3.05

Family typology A

Figure 3.06

Family typology B

Figure 3.07

Resident questionnaire
Figure 3.09

Arrangement sheet example

Figure 3.10

Geography simulations

Figure 3.11

Geography script diagram

Figure 3.12

Figure 3.13

Angle mapping

Figure 3.14

Geography mapping script diagram

Figure 3.15

Arrangement simulation

Figure 3.16

Grasshopper spring simulation

Figure 3.17

As

Figure 3.18

Figure 3.19

Repulsion simulation script diagram

Figure 3.20

Attraction simulation script diagram

Figure 3.21

Arrangement simulation repulsion

Figure 3.22

Arrangement simulation Attraction

Figure 4.01

Close-up filters
Figure 4.02

Framing on site

Figure 4.03

Undergrowth diagram

Figure 4.04

Undergrowth render 2

Figure 4.05

Framing render

Figure 4.06

Framing script diagram

Figure 4.07

Social agency diagram

Figure 4.08

Social agency render
54 Figure 4.18 SSS

55 Figure 4.19

SSM

55 Figure 4.20

SSL

55 Figure 4.21

Figure 4.10

Module collection

Figure 4.11

Container dimensions

Figure 4.12

1BXS

Figure 4.13

1BS

Figure 4.14

2BM

Figure 4.15

3BL

Figure 4.16

SBS

Figure 4.17

SBM
56 Figure 4.22

SPM

56 Figure 4.23

SPL

56 Figure 4.24

Exploded component assembly

57 Figure 4.25

Module perforation exploration

60 Figure 4.29

Filter Script diagram

60 Figure 4.30

Aoraki silhouette

Canterbury, U. o. (n.d.). Living in New

60 Zealand. Retrieved from University of Canterbury: http://www.canterbury.ac.nz/ international/uc-a-world-recognised-

61 university/living-in-new-zealand/ 
Figure 4.31

Whitereia silhouette

Greater Wellington. (2014, May 27).

Discover Whitireia park. Retrieved from

Youtube: https://www.youtube.com

watch? $\mathrm{v}=\mathrm{uW}$ 9ucIcUFNA

Figure 4.32

Geo-timber filter

Figure 4.33

Two parametric timber wall iterations

\section{Figure 4.34}

Timber filter perforation

\section{Figure 4.35}

Green living wall veges

\section{Figure 4.36}

Surface treatment render

\section{Figure 5.01}

Final render

\section{Figure 5.02}

Macro mapping trimmed

\section{Figure 5.03}

Wellington aerial image

University, V. (n.d.). University Council.

Retrieved from Victoria University of

Wellington: http://www.victoria.ac.nz/about/ governance/council

\section{Figure 5.04}

Macro mapping

\section{Figure 5.05}

Medium mapping

\section{Figure 5.06}

Glazing diversity

\section{Figure 5.07}

Input geography data
67 Figure 5.08

Framing boundary simulation

Figure 5.09

Social arrangement data

Figure 5.10

67 Arrangement simulation diagram

Figure 5.11

$6835 \mathrm{~mm}$ morning render

Figure 5.12

68 Kelburn arrangement output

Figure 5.13

68 Kelburn site masterplan

Figure 5.14

69 Render key diagram

Figure 5.15

72 Wide angle render

Figure 5.16

$74 \quad 24 \mathrm{~mm}$ afternoon central space render

Figure 5.17

$7535 \mathrm{~mm}$ morning activity render

Figure 5.18

Midday spring render

Figure 5.19

$35 \mathrm{~mm}$ under the canopy render

Figure 5.20

Low angle stair render

Figure 5.2

$35 \mathrm{~mm}$ under walkway render

Figure 5.22

Salamanca rd zone

Figure 5.23

Salamanca rd activities
Figure 5.24

$45 \mathrm{~mm}$ pathway render

Figure 5.25

Removed roof interior render

Figure 5.26

Interior lounge render

Figure 5.27

Interior kitchen render

Figure 5.28

Section render

Figure 5.29

Final render 
